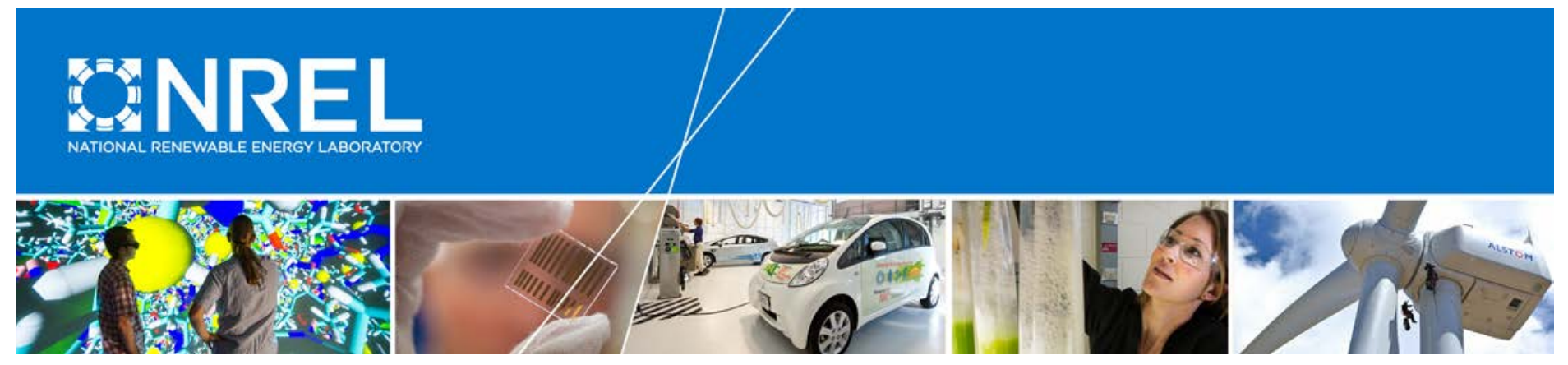

\title{
Power Generation for River and Tidal Generators
}

Eduard Muljadi, Alan Wright, and Vahan Gevorgian

National Renewable Energy Laboratory

James Donegan, Cian Marnagh, and Jarlath McEntee

Ocean Renewable Power Company

NREL is a national laboratory of the U.S. Department of Energy Office of Energy Efficiency \& Renewable Energy Operated by the Alliance for Sustainable Energy, LLC

This report is available at no cost from the National Renewable Energy Laboratory (NREL) at www.nrel.gov/publications.

Technical Report

NREL/TP-5D00-66097

June 2016

Contract No. DE-AC36-08G028308 


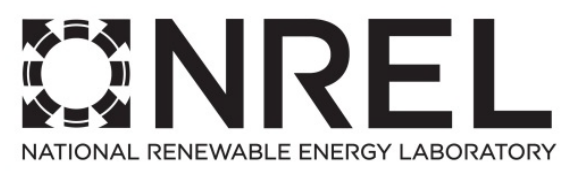

\section{Power Generation for River and Tidal Generators}

Eduard Muljadi, Alan Wright, and Vahan Gevorgian National Renewable Energy Laboratory

James Donegan, Cian Marnagh, and Jarlath McEntee Ocean Renewable Power Company

Prepared under Task Nos. FOWA.0101 and FOWA.0201

NREL is a national laboratory of the U.S. Department of Energy Office of Energy Efficiency \& Renewable Energy Operated by the Alliance for Sustainable Energy, LLC

This report is available at no cost from the National Renewable Energy Laboratory (NREL) at www.nrel.gov/publications.

National Renewable Energy Laboratory 15013 Denver West Parkway Golden, CO 80401 303-275-3000 • www.nrel.gov

\section{Technical Report}

NREL/TP-5D00-66097

June 2016

Contract No. DE-AC36-08G028308 


\section{NOTICE}

This report was prepared as an account of work sponsored by an agency of the United States government. Neither the United States government nor any agency thereof, nor any of their employees, makes any warranty, express or implied, or assumes any legal liability or responsibility for the accuracy, completeness, or usefulness of any information, apparatus, product, or process disclosed, or represents that its use would not infringe privately owned rights. Reference herein to any specific commercial product, process, or service by trade name, trademark, manufacturer, or otherwise does not necessarily constitute or imply its endorsement, recommendation, or favoring by the United States government or any agency thereof. The views and opinions of authors expressed herein do not necessarily state or reflect those of the United States government or any agency thereof.

This report is available at no cost from the National Renewable Energy Laboratory (NREL) at www.nrel.gov/publications.

Available electronically at SciTech Connect http:/www.osti.gov/scitech

Available for a processing fee to U.S. Department of Energy and its contractors, in paper, from:

U.S. Department of Energy

Office of Scientific and Technical Information

P.O. Box 62

Oak Ridge, TN 37831-0062

OSTI http://www.osti.gov

Phone: 865.576.8401

Fax: 865.576.5728

Email: reports@osti.gov

Available for sale to the public, in paper, from:

U.S. Department of Commerce

National Technical Information Service

5301 Shawnee Road

Alexandria, VA 22312

NTIS http://www.ntis.gov

Phone: 800.553 .6847 or 703.605 .6000

Fax: 703.605.6900

Email: orders@ntis.gov 


\section{Acknowledgements}

This work was performed for the Ocean Renewable Power Company by the National Renewable Energy Laboratory (NREL). This work was supported by the U.S. Department of Energy under Contract No. DE-AC36-08-GO28308 with NREL. 


\section{List of Acronyms}

$\mathrm{AC}$

DC

IEEE

IGBT

NREL

PMSG

PV

TSR alternating current

direct current

Institute of Electrical and Electronics Engineers

insulated-gate bipolar transistor

National Renewable Energy Laboratory

permanent magnet synchronous generator

photovoltaic

tip speed ratio 


\section{Table of Contents}

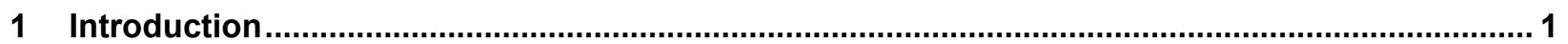

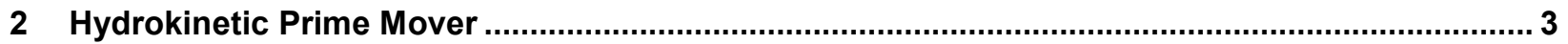

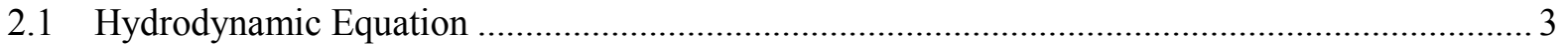

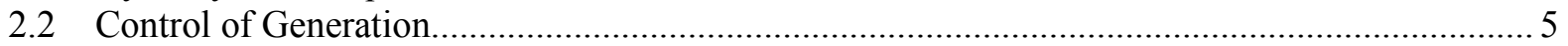

2.3 Maximum Power Point Tracking Using Power Control ........................................................ 5

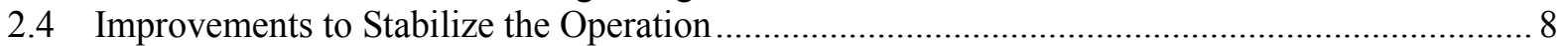

2.4.1 Modified Power-Speed Command to Improve Stability ................................................. 8

2.4.2 Modified Power Control in High Water Flow for High $\mathrm{C}_{\mathrm{p}}$ and to Allow Stalled Operation in High Water Flow Conditions .............................................................. 11

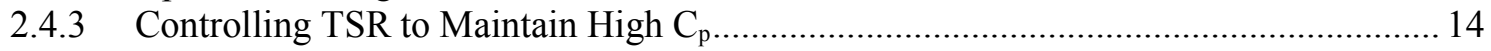

2.4.4 Controlling TSR to Stall the Turbine in High Water Flow ...................................... 17

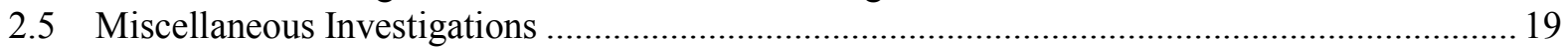

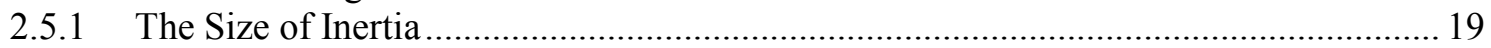

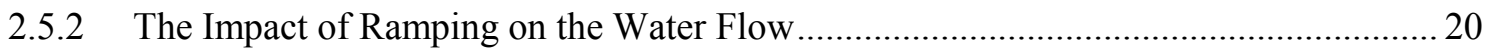

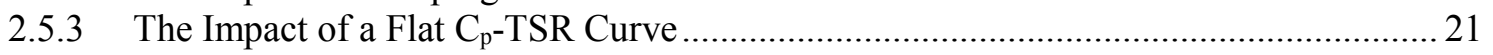

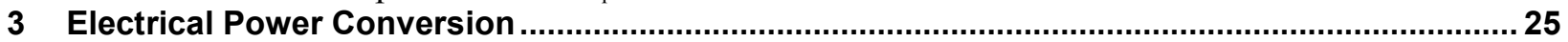

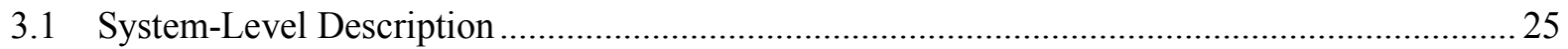

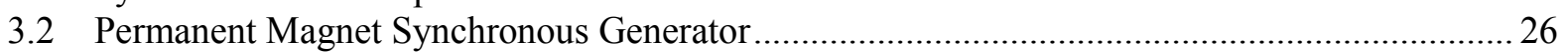

3.3 PMSG Connected to a Constant DC Bus via a Rectifier......................................................... 26

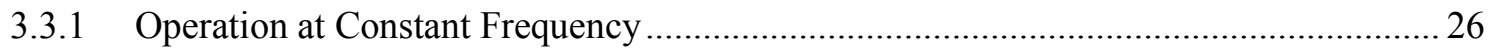

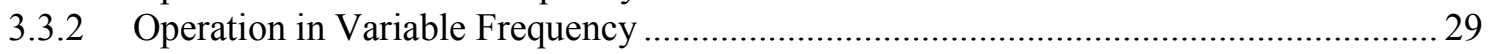

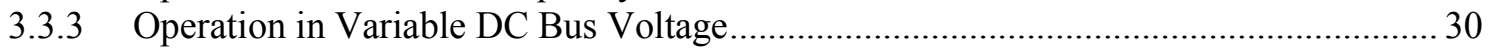

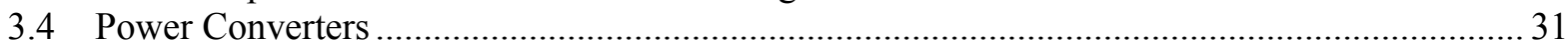

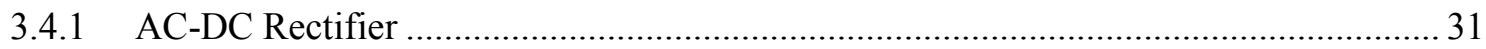

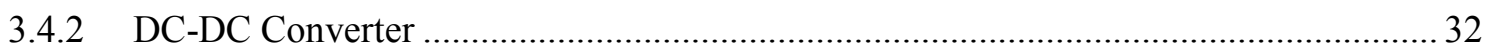

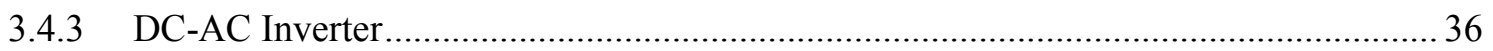

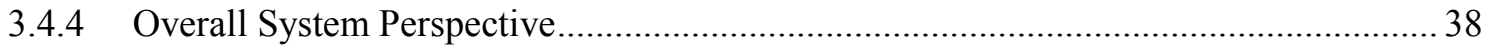

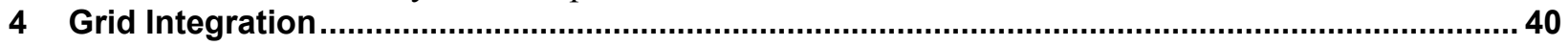

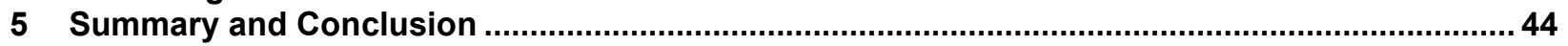

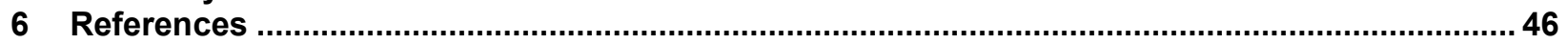




\section{List of Figures}

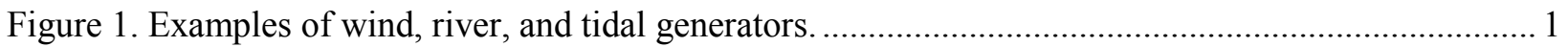

Figure 2. Example tidal generator consisting of series-connected Gorlov turbines..................................... 3

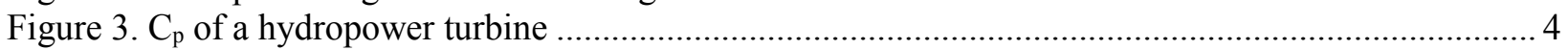

Figure 4. Output power compared to rotational speed at different water flow speeds ............................. 4

Figure 5. Output power control as a function of the rotational speeds ................................................. 5

Figure 6. Hydrokinetic power and the generator power operated at $\mathrm{C}_{\mathrm{pmax}}$ (green) as a function of the

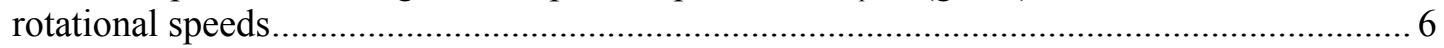

Figure 7. Dynamic simulation to illustrate unstable operation when the turbine is operated at $C_{\text {pmax }}$ and the

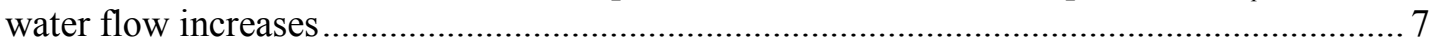

Figure 8. Operating $\mathrm{C}_{\mathrm{p}}$ and TSR as the water flow changes in unstable operation.................................... 8

Figure 9. Output power control as a function of the rotational speeds with modified gain to stabilize the

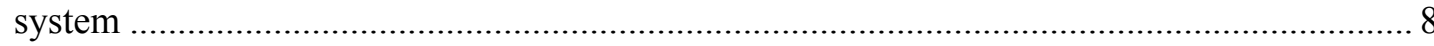

Figure 10. Hydrokinetic power and the generator power operated at $\mathrm{C}_{\mathrm{p}}$ lower than $\mathrm{C}_{\mathrm{pmax}}\left(\mathrm{C}_{\mathrm{p}_{\_} \text {adjusted }}\right)$ as a function of the rotational speed .................................................................................. 9

Figure 11. Dynamic simulation to illustrate stable operation when the turbine is operated at $80 \% \mathrm{C}_{\mathrm{pmax}}$ as

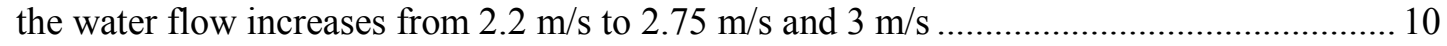

Figure 12. Operating $\mathrm{C}_{\mathrm{p}}$ and TSR as the water flow changes in stable operation................................ 11

Figure 13. Hydrokinetic power and the generator power operated at $\mathrm{C}_{\mathrm{p}_{-} \text {adjusted }}$ in low water flow $(0-2.5$ $\mathrm{m} / \mathrm{s}$ ) and changed to $\mathrm{C}_{\mathrm{p}_{-} \text {max }}$ in higher water flow $(>2.5 \mathrm{~m} / \mathrm{s})$ as a function of the rotational

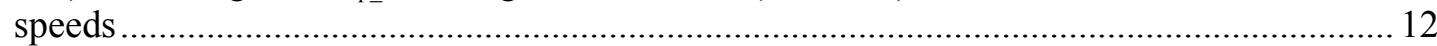

Figure 14. Illustration of the operating point for different modes of operation ...................................... 12

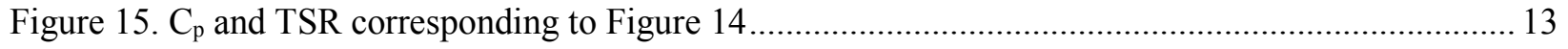

Figure 16. Water flow, rotational speed, output power, and torque as the turbine control is modified to allow for higher $\mathrm{C}_{\mathrm{p}}$ operation in higher water flow........................................................... 13

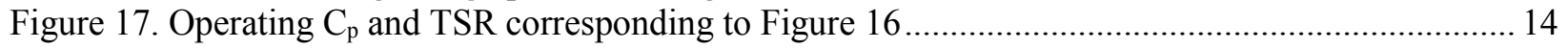

Figure 18. Modified control utilizing the water flow input to control the rotational speed corresponding to $\mathrm{TSR}_{\mathrm{tgt}}$ to stabilize the system .....

Figure 19. Water flow, rotational speed, output power, and torque as the turbine control is modified to

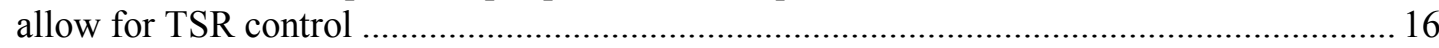

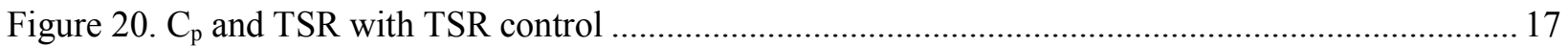

Figure 21. Overspeed control is included to force the turbine to stall above rotational rated speed by

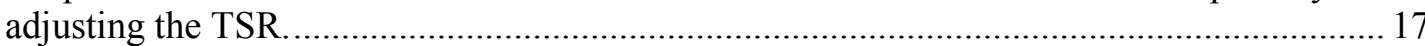

Figure 22. Stall control is included to force the turbine to stall in higher water flows by adjusting the TSR

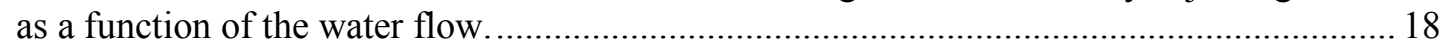

Figure 23. Illustration of $\mathrm{C}_{\mathrm{p}}$ and TSR during stalled operation in high water flows............................... 19

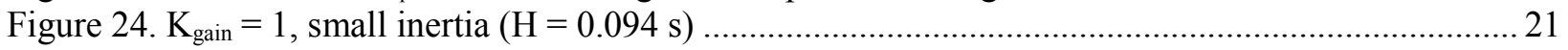

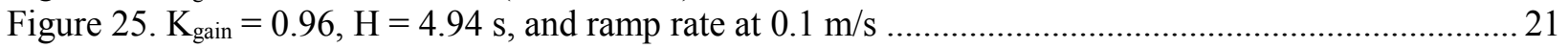

Figure 26. Comparison between the sharp $\mathrm{C}_{\mathrm{p}}$-TSR and flat $\mathrm{C}_{\mathrm{p}}$-TSR ............................................. 22

Figure 27. Comparison of power curves between the sharp $\mathrm{C}_{\mathrm{p}}$-TSR and the flat $\mathrm{C}_{\mathrm{p}}$-TSR .................... 22

Figure 28. The turbine characteristics simulated with the flat $\mathrm{C}_{\mathrm{p}}$-TSR characteristic, with $\mathrm{K}_{\text {gain }}=1.0, \mathrm{H}=$

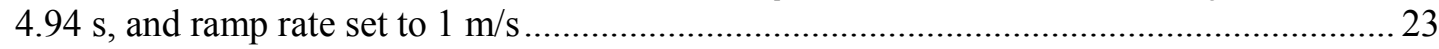

Figure 29. The corresponding performance coefficient, $C_{p}$, and TSR for the case of the flat $C_{p}-T S R$ characteristic, with $\mathrm{K}_{\text {gain }}=1.0, \mathrm{H}=4.94 \mathrm{~s}$, and ramp rate set to $1 \mathrm{~m} / \mathrm{s}$............................. 24

Figure 30. Typical electrical power transmission system from generator to substation transformer of a

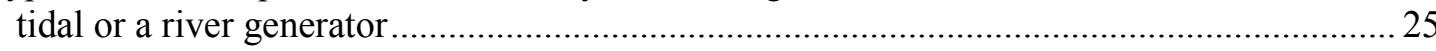

Figure 31. Single-line diagram of interconnected converters ....................................................... 26

Figure 32. Per-phase equivalent circuit of a PMSG and corresponding phasor diagram for a fixed-

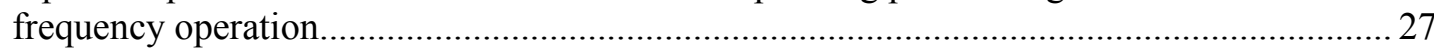

Figure 33. Output power of a PMSG connected to a rectifier operated at a constant frequency ............... 28 


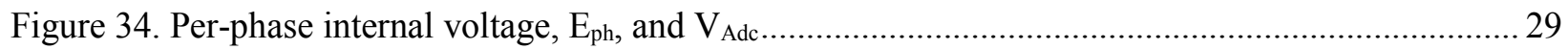

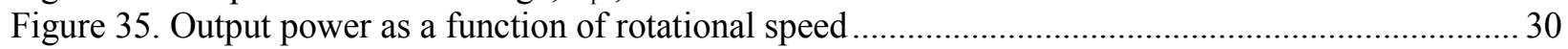

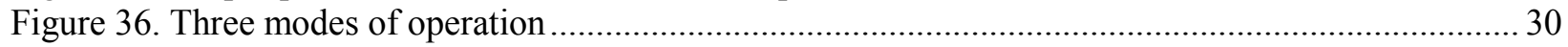

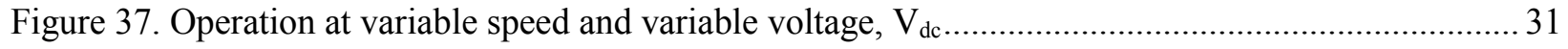

Figure 38. Equivalent circuit of a variable-speed PMSG connected to a passive diode bridge.................. 32

Figure 39. DC-DC boost converter used to match the variable $\mathrm{V}_{\mathrm{DC} \text {-in }}$ to the constant $\mathrm{V}_{\mathrm{DC}-\mathrm{Bus}}$ and the input

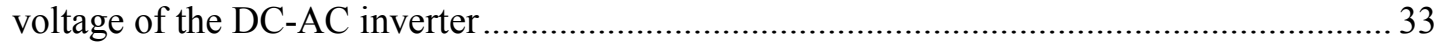

Figure 40. Currents, power, and voltage within a DC-DC boost converter ............................................ 34

Figure 41. Output power of the DC-DC boost converter as a function of the duty ratio .......................... 35

Figure 42. DC-AC inverter controlled to maximize the output power of the turbine and to interface the

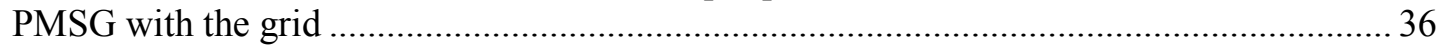

Figure 43. Real and reactive power errors drive the q-axis and d-axis current controllers, respectively ... 37

Figure 44. Current limiter to limit the current that can be passed through the power switches................. 37

Figure 45. Entire system and corresponding outputs in three frequencies: variable AC, DC, and $60 \mathrm{~Hz}$

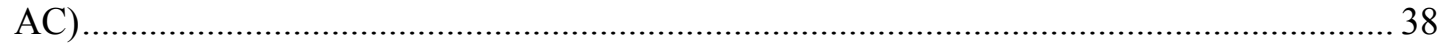

Figure 46. Representation of voltage compared to maximum clearing time as described in IEEE 1547 (L-

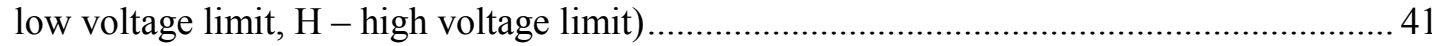

Figure 47. Representation of frequency compared to maximum clearing time as described in IEEE 1547 (L-low frequency limit, H-high frequency limit) ................................................................ 41

\section{List of Tables}

Table 1. Voltage Range and Maximum Clearing Time 42

Table 2. Frequency Range and Maximum Clearing Time 


\section{Introduction}

Renewable energy sources are the second largest contributor to global electricity production, after fossil fuel. The integration of renewable energy continued to grow in 2014 against a backdrop of increasing global energy consumption and a dramatic decline in oil prices during the second half of the year. As renewable generation has become less expensive during recent decades, and it becomes more accepted by the global population, the focus on studying and integrating renewable generation has expanded from primarily wind and solar to include new types with promising future applications, such as hydropower generation, including river and tidal generation. Today, hydropower is considered one of the most important renewable energy sources. In river and tidal generation, the input resource flow is slower but also steadier than it is in wind or solar generation, yet the level of water turbulent flow may vary from one place to another.

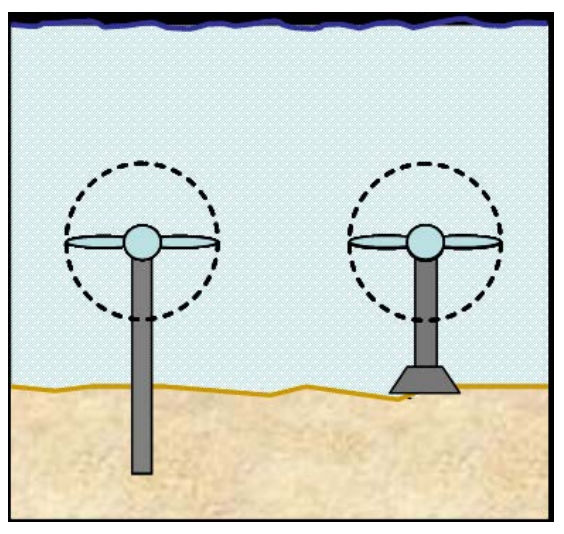

(a)

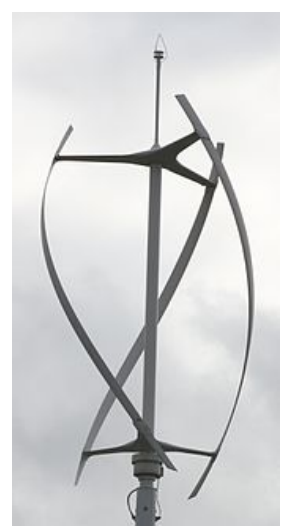

(b)

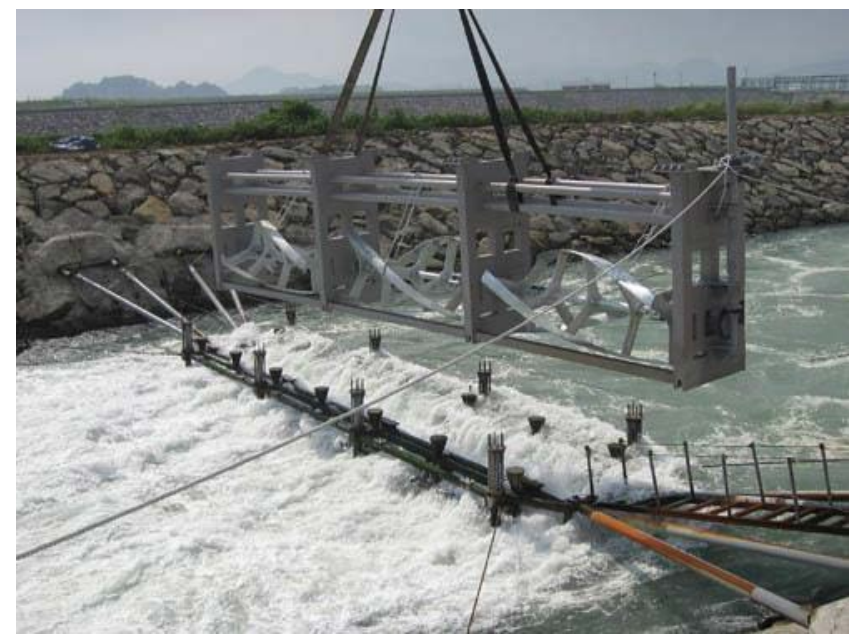

(c)

Figure 1. Examples of wind, river, and tidal generators.

(a) Bottom-mounted horizontal axis generator, (b) Gorlov turbine as a vertical-axis wind turbine, and (c) Gorlov turbine as a horizontal-axis river turbine 
This report focuses on hydrokinetic power conversion. We use a simplified electrical system to clarify the hydrokinetic system and its associated controls. River and tidal generators can be mounted on the bottom of an estuary (see Figure 1 (a)), and they are very similar in shape to wind turbine generators. Other types of tidal or river generators have a structure similar to that of Savonius or Darrieus wind turbines, and they may be placed vertically or horizontally, depending on the resource and the site (see Figure 1 (b) and (c)). Of particular interest, the Gorlov helical turbine water turbine is a design that evolved from altering the Darrieus turbine design to have helical blades/foils. The Gorlov helical turbine was invented by Professor Alexander M. Gorlov of Northeastern University [1].

There are two types of tidal energy conversion wherein the water flow is used to drive the turbine generator: one is based on utilizing the difference between the high and low tides utilizing tidal barrage, and the other is based on utilizing the water flow during the flood and ebb of the water. Tidal generation is more predictable than wind or solar generation; however, the level of turbulence and the impacts on the conversion devices are no less severe than they are with wind turbulence [2].

Prospecting tidal energy is no trivial matter. Monitoring, measuring, and performing numerical simulations are used to compute the potential energy that can be harvested in a regional area. Various numerical methods are used to forecast the annual energy production at different sites to ensure successful tidal deployment [3-4]. Marine hydrokinetic energy resources have very promising futures. Various types of marine hydrokinetic generators have been explored, and some have been commercialized [5-6].

Tidal generation is dependent of the resource availability; thus, the resource must be identified by preliminary assessments and surveys [7]. One difference between tidal generation and river generation is the water flow that drives the turbine. In river generation, the water flows in one direction and is more or less constant. In tidal generation, the water flows in two directions: during the flood, the water flows from the ocean toward the land or river; and during the ebb, the water flows back toward the ocean. There are various ways to harness tidal generation, either from a single turbine [8-9], as a power plant with multiple turbines [10], or in a multiple turbine or tidal power plant environment [11]. Each site has its own characteristics; thus, control and optimization may be unique for different installations [12-13]. 


\section{Hydrokinetic Prime Mover}

The hydrokinetic prime mover in river and tidal power generation, for this report, is a series of Gorlov hydropower turbines connected together as shown in Figure 2. The two sets of turbines drive the generator in the middle. This system uses a direct-drive permanent magnet generator.

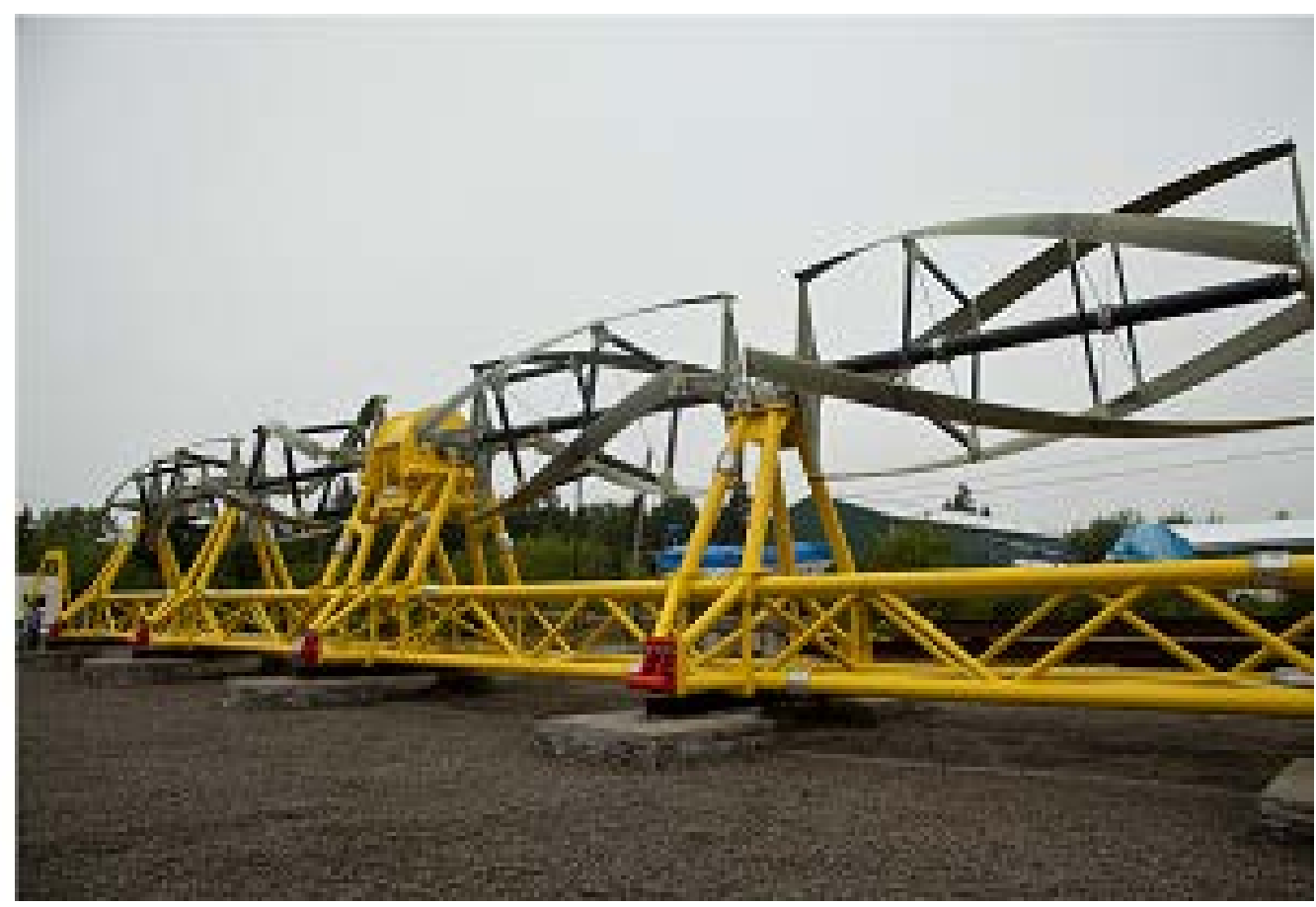

Figure 2. Example tidal generator consisting of series-connected Gorlov turbines

\subsection{Hydrodynamic Equation}

The available hydrokinetic power of a water turbine can be computed from the water flow and the turbine dimension as:

$$
P_{\text {turbine }}=0.5 \rho A C_{p} V^{3}
$$

where $\mathrm{A}$ is the effective cross-sectional area of the turbine, $\rho$ is the water density, $\mathrm{V}$ is the water flow, and $C_{p}$ is the power coefficient of the turbine. The tentative performance coefficient of the turbine as a function of its tip speed ratio (TSR, equation (2)) is shown in Figure 3. The peak performance coefficient of a hydropower turbine is sharper than the performance coefficient of a wind turbine, and the TSR of the $\mathrm{C}_{\mathrm{pmax}}$ occurs at a lower value (around 2, compared to 8 in a wind turbine generator).

This type of $\mathrm{C}_{\mathrm{p}}$ characteristic has a major advantage in that the turbine can be hydro-dynamically stalled (operation at the low $\mathrm{C}_{\mathrm{p}}$ region to the left of the $\mathrm{C}_{\mathrm{pmax}}$ ) to control the rotational speed, thereby preventing a runaway condition without the need for pitch control as in a wind turbine. The corresponding power-versus-speed characteristic for different flow speeds is given in Figure 4. 


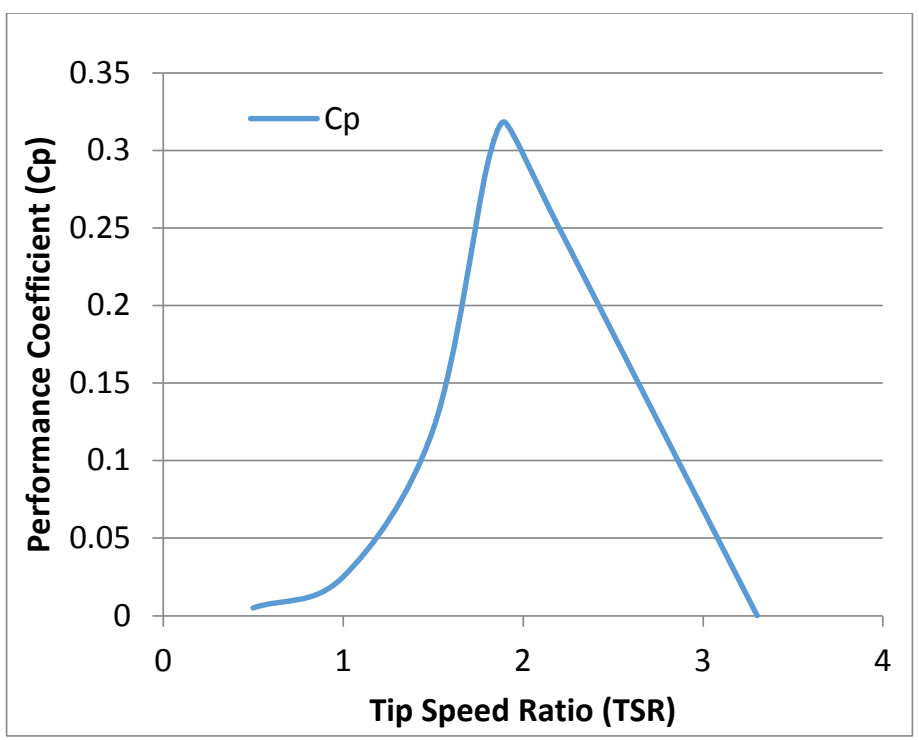

Figure 3. $\mathrm{C}_{\mathrm{p}}$ of a hydropower turbine

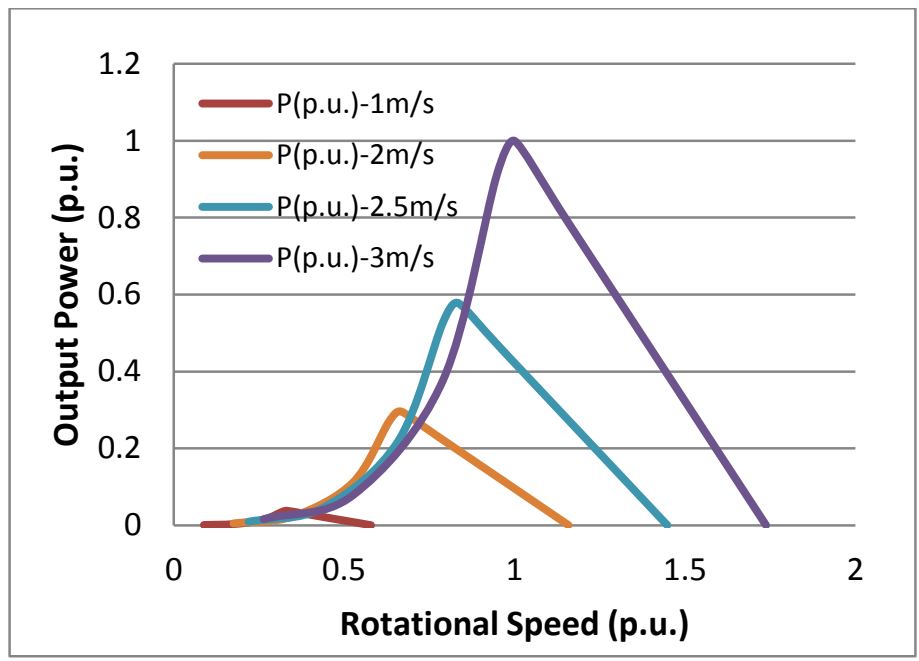

Figure 4. Output power compared to rotational speed at different water flow speeds

The next few sections discuss various control algorithms, beginning with an analogy to wind turbine generation. The controller is then modified to stabilize the system, and another modification is needed to prevent a runaway condition by stalling the turbine. All of the quantities are given by per unit to make it easier to understand and to scale up or down, depending on the need.

The TSR is defined as the ratio of the linear speed of the tip of the blade to the water flow speed:

$$
T S R=\frac{\omega R}{V}
$$

where the rotational speed, $\omega$, is the rotational speed of the blade. As shown in Figure 3, there is a specific TSR that has a maximum operating $\mathrm{C}_{\mathrm{p}}$. This $\mathrm{TSR}$ corresponds to $\mathrm{TSR}_{\mathrm{tgt}}=1.9$, 
corresponding to $\mathrm{C}_{\mathrm{pmax}}=0.32$. The output power as a function of rotational speed is given in Figure 4.

\subsection{Control of Generation}

The water flow, $\mathrm{V}$, in equation (1) can be substituted by the rotational speed, $\omega$, in equation (2). The new equation can be written as:

$$
P_{\text {turbine }}=0.5 \rho A C_{p}\left(\frac{\omega R}{T S R}\right)^{3}
$$

\subsection{Maximum Power Point Tracking Using Power Control}

Using equation (3), we can then replace $C_{p}$ with $C_{p m a x}$ and the TSR with TSR $_{\text {tgt }}$ The resulting equation can be used to control the generator and power converter:

$$
P_{g e n}=0.5 \rho A C_{p \max }\left(\frac{\omega R}{T_{S R} R_{\text {tgt }}}\right)^{3}
$$

The equation used to control the generation can be further simplified:

$$
P_{\text {genCpmax }}=K_{\text {Cpmax }} \omega^{3}
$$

where

$$
K_{C p \max }=0.5 \rho A C_{p \max }\left(\frac{R}{T S R_{\text {tgt }}}\right)^{3}
$$

Figure 5 shows the implementation of the output power control by controlling the generator output as a cube function of the rotational speed. This type of control is often used in variablespeed wind turbine generation and has been proven successful. The control algorithm can be implemented by using a prescribed power-speed lookup table, as shown by equations (4-5).

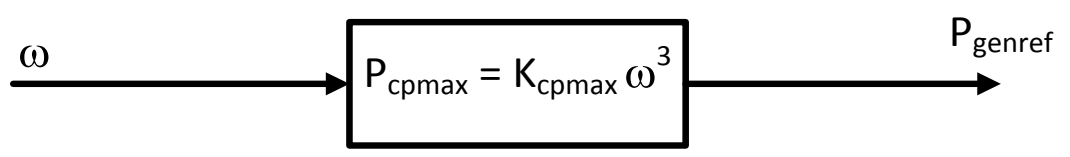

Figure 5. Output power control as a function of the rotational speeds

Figure 6 shows the hydrokinetic power of the turbine by the lines with symbols in different colors that represent different water flow speeds. The electrical output power is commanded (by controlling the power converter connected to the generator) to follow the equation, which is the cube function of the rotational speed shown in equation (5), and it is shown as the green line in Figure 6. Unfortunately, this controller does not lead to a stable operating point. To illustrate the unstable operation, assume that the turbine is originally operated at a water flow of $2.5 \mathrm{~m} / \mathrm{s}$ corresponding to Point $\mathrm{A}$. The generator power is commanded to follow the $\mathrm{C}_{\text {pmax }}$ (green line), and the hydrokinetic power corresponds to the blue line. 


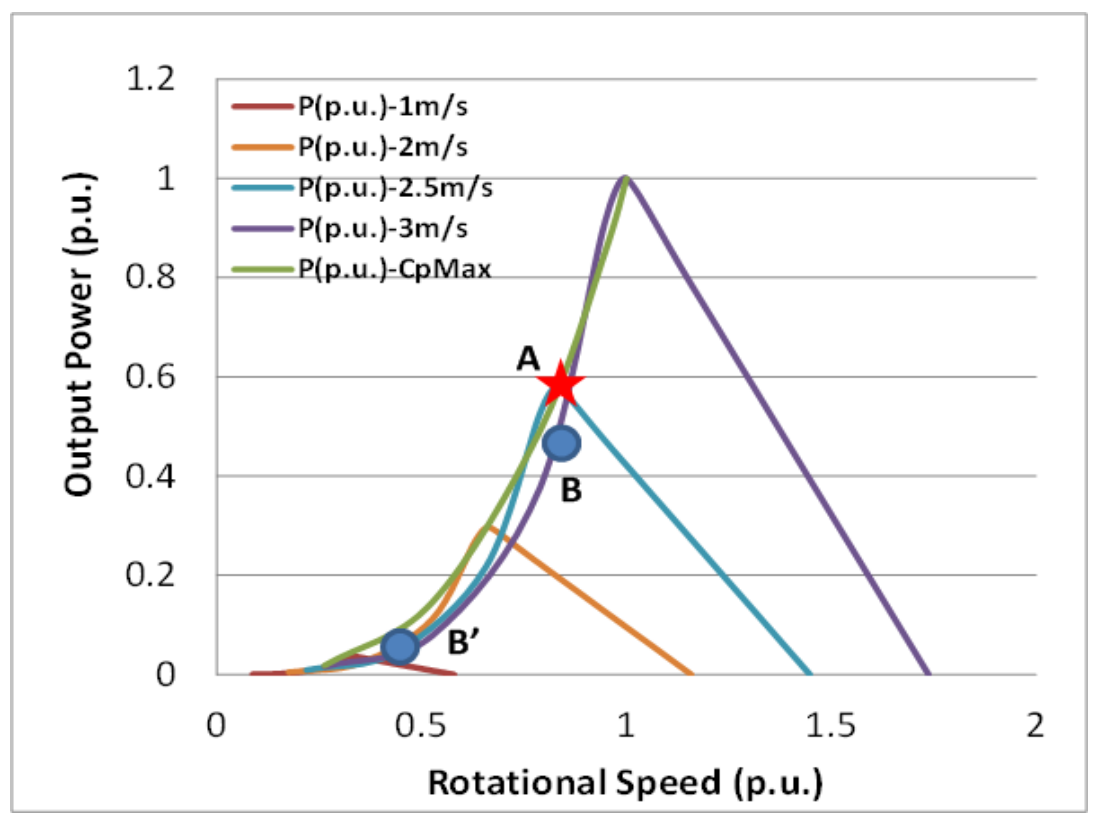

Figure 6. Hydrokinetic power and the generator power operated at $\mathrm{C}_{\mathrm{pmax}}$ (green) as a function of the rotational speeds

A sudden increase of the water flow from $2.5 \mathrm{~m} / \mathrm{s}$ to $3 \mathrm{~m} / \mathrm{s}$ will not bring the hydrokinetic power up; instead, it will bring the hydrokinetic power down. As shown in Figure 6, the hydrokinetic power originally coincides with the generator output power at Point A (star). As the water flow increases to $3 \mathrm{~m} / \mathrm{s}$, the hydrokinetic power suddenly drops from Point A to Point B. As a result, the output of the generator is higher than the hydrokinetic power; thus, the rotational speed will slow down. The operating point of the hydrokinetic power will follow the purple curve (for a water flow of $3 \mathrm{~m} / \mathrm{s}$ ) from Point B to Point B', the generator power will follow the green curve from Point A to Point B', and the generator power will meet the hydrokinetic power at Point B', the new stable operating point.

Figure 7 shows the unstable operation of the turbine operated at $\mathrm{C}_{\mathrm{pmax}}$ based on equation (5). The water flow was originally at $2.2 \mathrm{~m} / \mathrm{s}$, and it increases to $2.75 \mathrm{~m} / \mathrm{s}$. Instantaneously, the operating

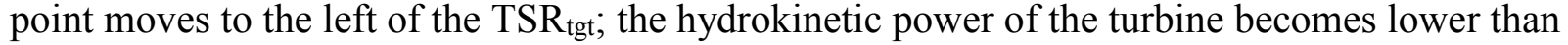
the electrical output power, slowing the rotational speed of the turbine; and the TSR becomes even smaller. An additional increase of the water flow to $3 \mathrm{~m} / \mathrm{s}$ does not improve the $\mathrm{C}_{\mathrm{pmax}}$. 


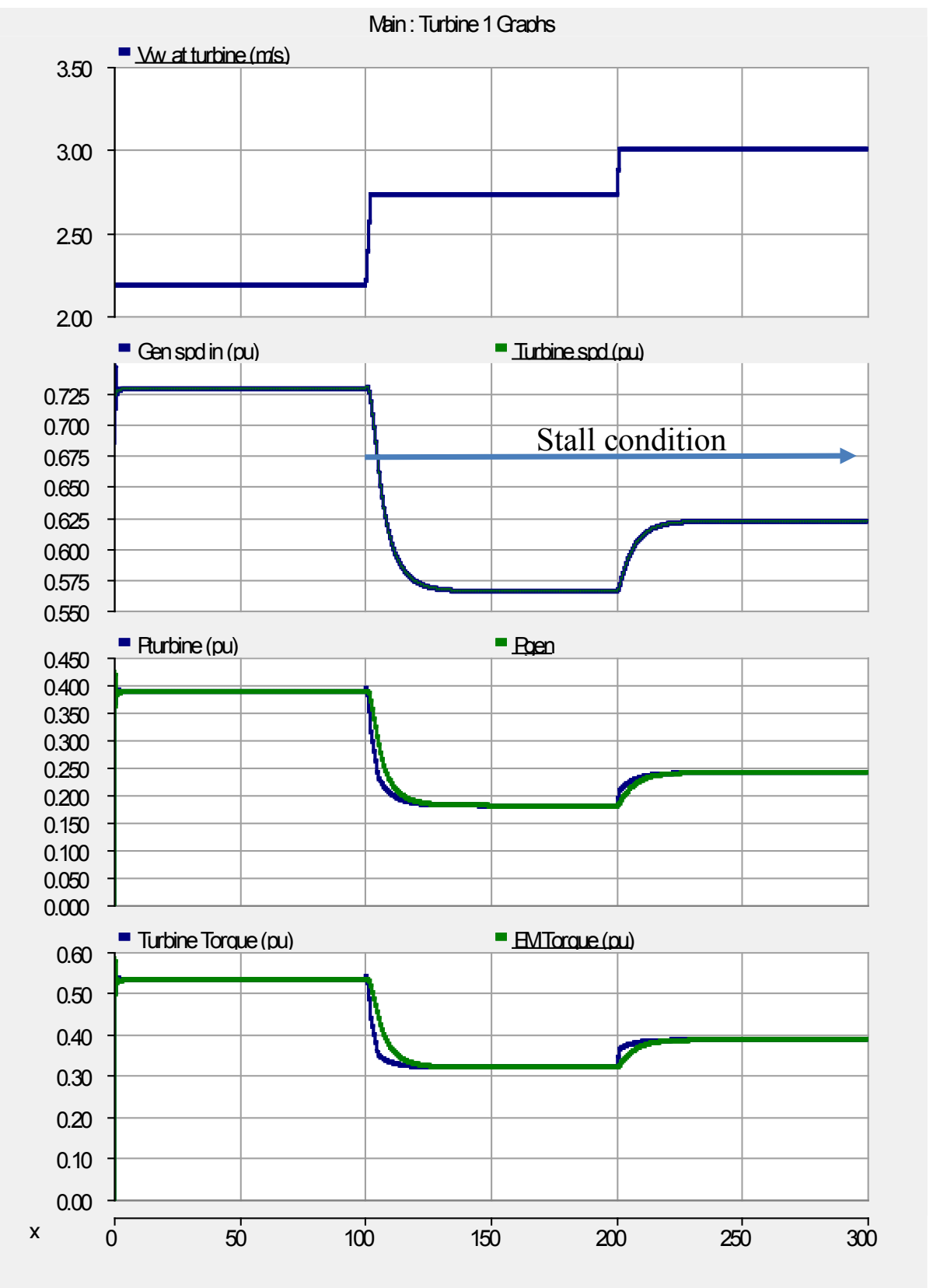

Figure 7. Dynamic simulation to illustrate unstable operation when the turbine is operated at $\mathrm{C}_{\mathrm{pmax}}$ and the water flow increases

The corresponding TSR and the operating $\mathrm{C}_{\mathrm{p}}$ are illustrated in Figure 8. This operation becomes unstable when the turbine enters, and the performance coefficient $\mathrm{C}_{\mathrm{p}}$ collapses as the TSR drops significantly. 


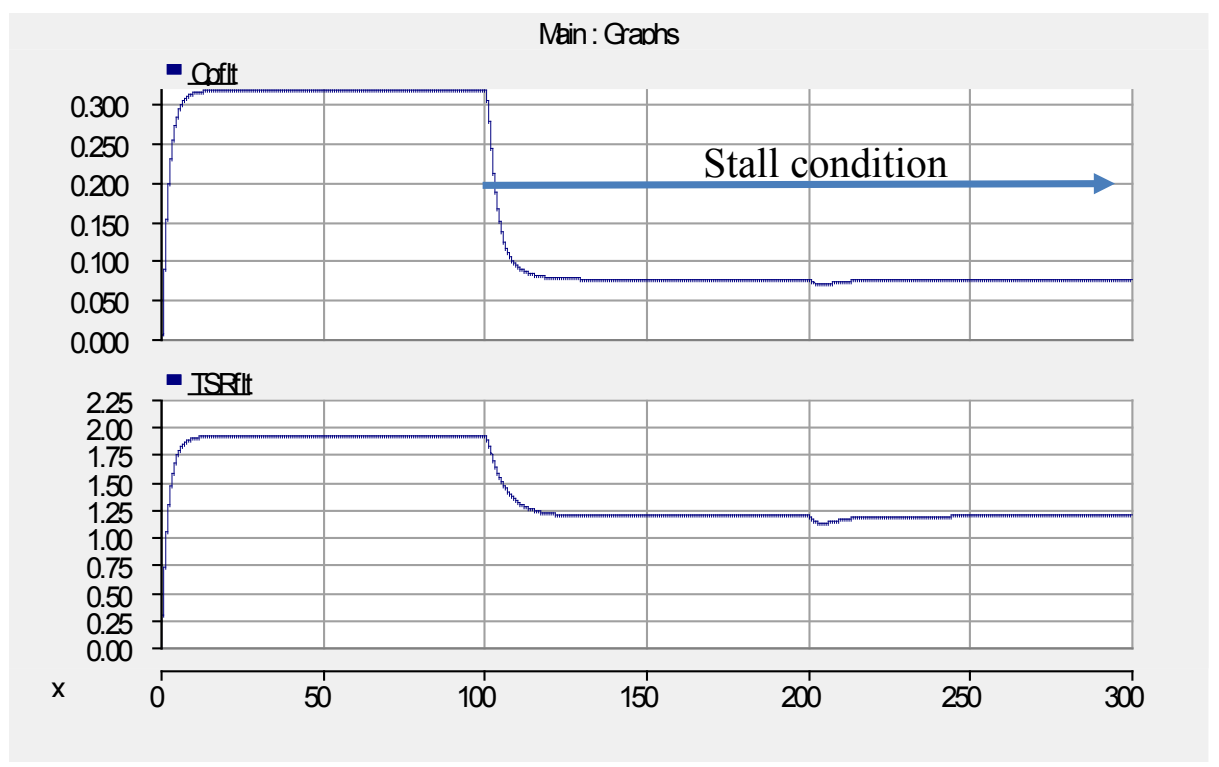

Figure 8. Operating $C_{p}$ and TSR as the water flow changes in unstable operation

\subsection{Improvements to Stabilize the Operation}

As shown in Figure 6 through Figure 8, the controller used to control the turbine to follow the maximum power point tracking is not very stable. However, this controller can be slightly modified to stabilize the system.

\subsubsection{Modified Power-Speed Command to Improve Stability}

The controller can be slightly modified to make the system more stable. Figure 9 shows the modified block diagram by scaling down the maximum power point tracking power compared to the rotational speed by a factor of $20 \%$ (e.g., $\mathrm{K}_{\text {gain }}=0.8$ ); thus, the generator output power is commanded to follow a reduced output as a function of the rotational speed (see Figure 10).

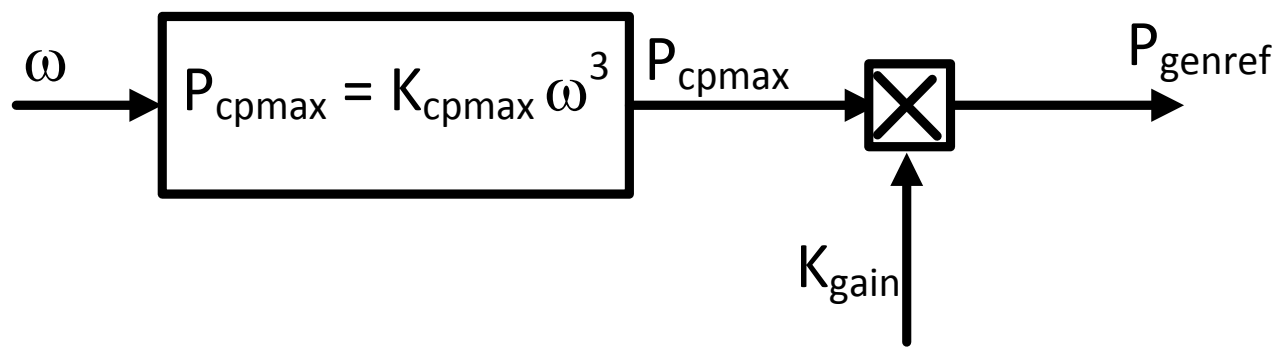

Figure 9. Output power control as a function of the rotational speeds with modified gain to stabilize the system 


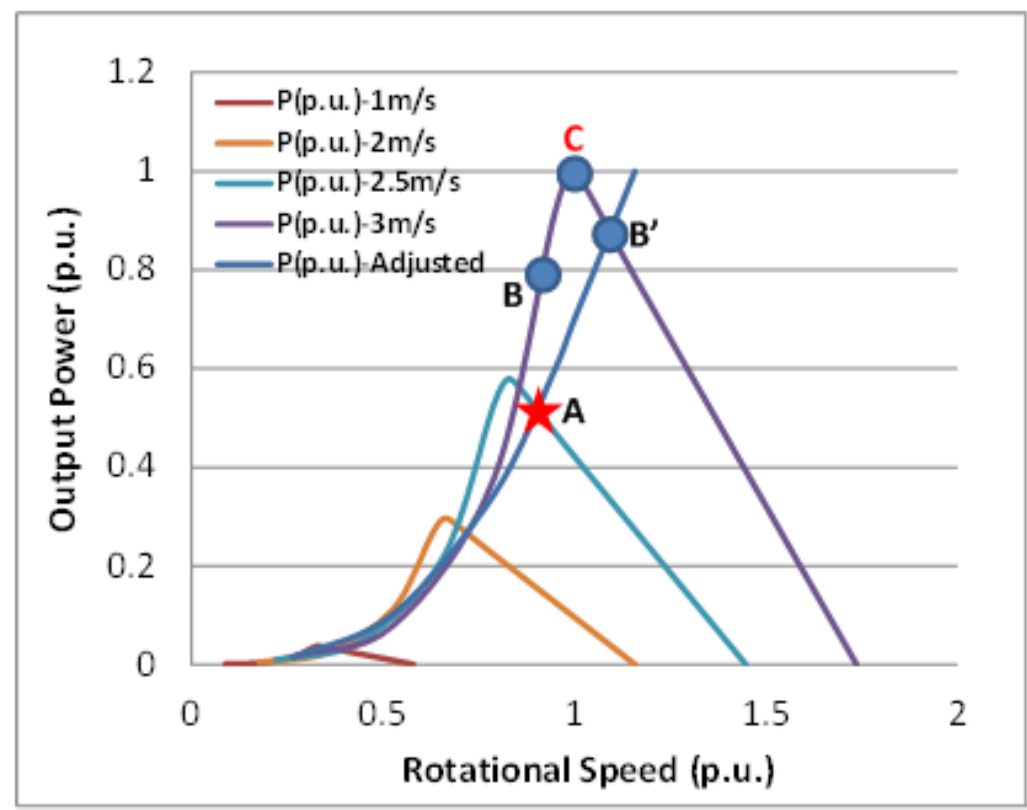

Figure 10. Hydrokinetic power and the generator power operated at $C_{p}$ lower than $C_{p m a x}\left(C_{p_{-} \text {adjusted }}\right)$ as a function of the rotational speed

Reducing $\mathrm{K}_{\text {gain }}$ has the same effect as moving the steady-state operating point from $\mathrm{C}_{\text {pmax }}$, $\mathrm{TSR}_{\text {tgt }}$ to the right of the $\mathrm{TSR}_{\text {tgt }}$ but at a lower $\mathrm{C}_{\mathrm{p}}\left(\mathrm{C}_{\mathrm{p}_{-} \text {adjusted }}\right)$ than $\mathrm{C}_{\mathrm{pmax}}$. This strategy will work because the inertia of the rotating mass will resist a sudden change in rotational speed, which will help the operation of the turbine. As shown by equation (2), a sudden increase of water flow at a constant rotational speed will reduce the TSR and move the operating point from $\mathrm{C}_{\mathrm{p}}$ to a higher value that is closer to $C_{\text {pmax }}$. This operation is best illustrated in Figure 14 below. In addition, because the generator output power is tied to the rotational speed, as in equation (5), the increase of the hydrodynamic torque will drive the rotational speed higher, which will compensate for the changes in the rotational speed and return the TSR and $\mathrm{C}_{\mathrm{p}}$ to their original values.

Figure 10 shows the modified characteristic of the generator output power as a function of the rotational speed at reduced gain $\left(\mathrm{K}_{\text {gain }}=0.8\right)$; thus, the prescribed power-speed lookup table should be changed accordingly. As an illustration, consider the same operation when the water flow is at $2.5 \mathrm{~m} / \mathrm{s}$ with the operating point crossing between the hydrokinetic curve and the generator at Point A (red star). When the water flow suddenly increases to $3 \mathrm{~m} / \mathrm{s}$, the hydrokinetic operating Point A moves to Point B; thus, the turbine will drive the generator to a higher rotational speed while moving the generator operating point along the path $A B$ '. At the same time, the hydrokinetic turbine operating point moves from Point B to Point B' along the path BCB'. Note that this operation at Point B' is slightly less than the maximum operating point at Point $\mathrm{C}$; however, this operating point is stable.

Figure 11 shows the operation of the turbine at $\mathrm{C}_{\mathrm{p} \_ \text {adjusted }}$ (below $\mathrm{C}_{\mathrm{pmax}}$ ) to improve the stability of the turbine based on the control block diagram shown in Figure 9. The water flow is originally at $2.2 \mathrm{~m} / \mathrm{s}$. It increases to $2.75 \mathrm{~m} / \mathrm{s}$, and instantaneously the operating point moves to the left of the original TSR and the TSR tgt, but the $\mathrm{C}_{\mathrm{p}}$ can be maintained close to $\mathrm{C}_{\mathrm{pmax}}$ and a stable operation can be maintained. An additional increase of the water flow to $3 \mathrm{~m} / \mathrm{s}$ does not make the operation 
unstable. Note that the extreme ramp rates illustrated below show the worst-case scenario; in practice the ramp rate of the water flow is not as severe as that shown in Figure 11, as discussed in Section 2.5. The temporary difference between the hydrodynamic torque (blue line) and electrical torque (green line) will accelerate or decelerate the rotational speed. The corresponding TSR and the operating $\mathrm{C}_{\mathrm{p}}$ are illustrated in Figure 12.

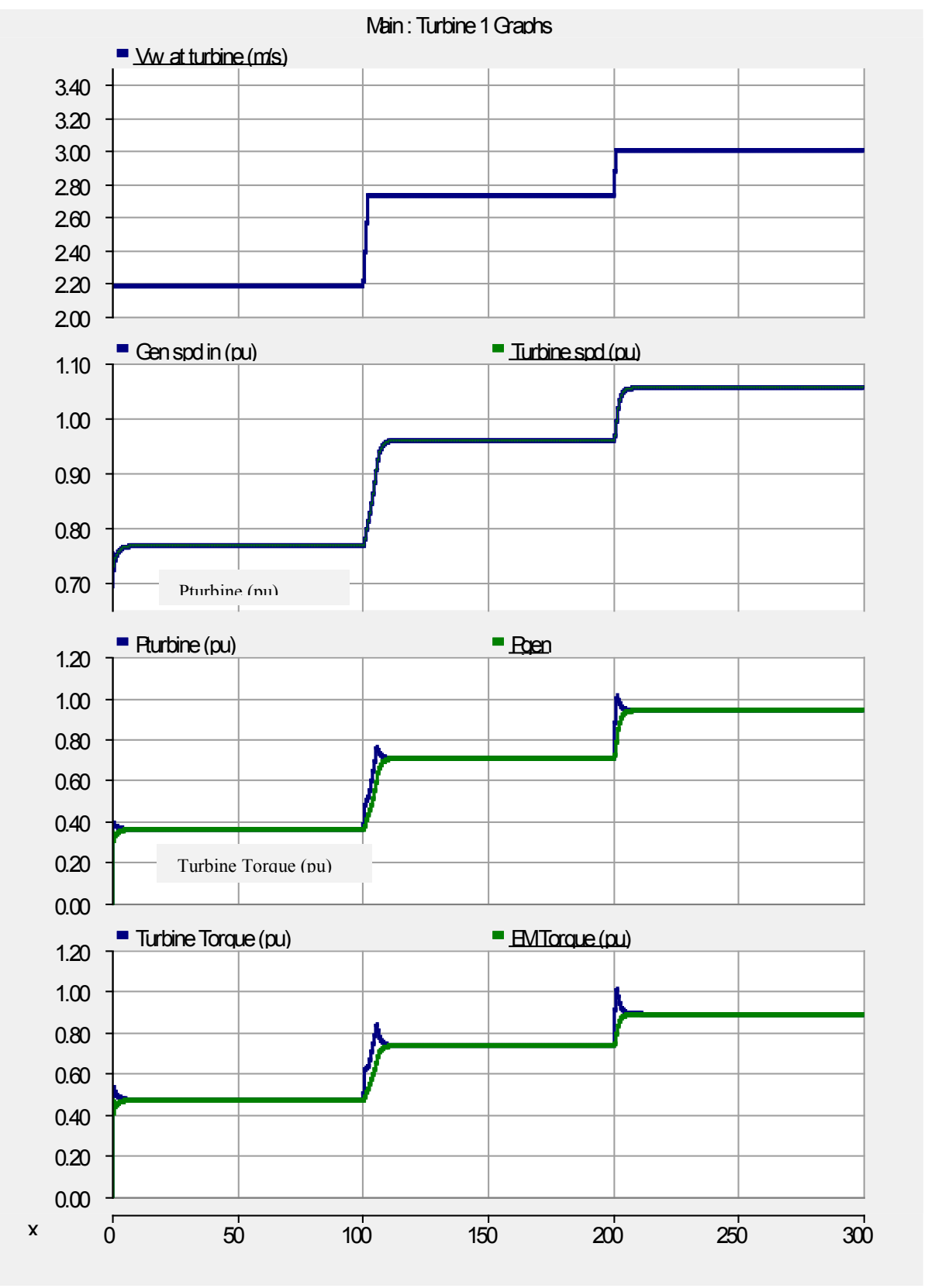

Figure 11. Dynamic simulation to illustrate stable operation when the turbine is operated at $80 \%$ $\mathrm{C}_{\mathrm{pmax}}$ as the water flow increases from $2.2 \mathrm{~m} / \mathrm{s}$ to $2.75 \mathrm{~m} / \mathrm{s}$ and $3 \mathrm{~m} / \mathrm{s}$ 


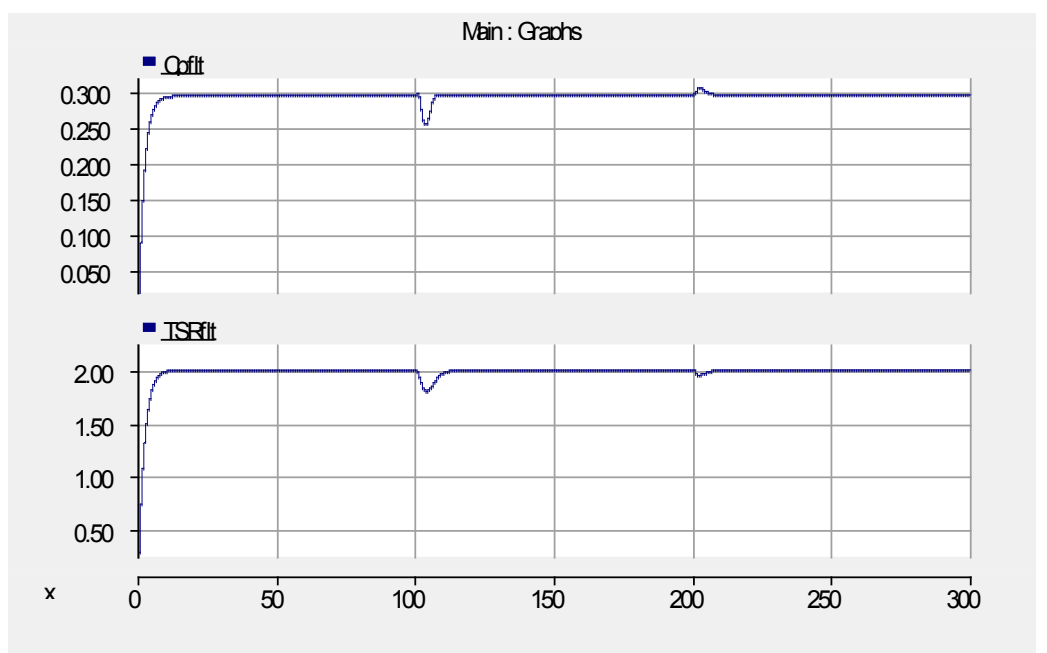

Figure 12. Operating $C_{p}$ and TSR as the water flow changes in stable operation

Note that there is no mechanism for this particular turbine to adjust the hydrokinetic power with a pitch control as in a modern wind turbine. As shown in Figure 11, the turbine speed, power, and torque keep increasing as the TSR and the performance coefficient (shown in Figure 12) stay the same and the water flow changes. This is quite different in unstable operation, as shown in Figure 7 and Figure 8, wherein the speed, power, TSR, and $C_{p}$ become very low and the turbine enters stalled operation.

\subsubsection{Modified Power Control in High Water Flow for High $C_{p}$ and to Allow Stalled Operation in High Water Flow Conditions}

The controller modified in the previous section can be further improved by changing the power controller when the water flow is in the medium to high range (between $2.5 \mathrm{~m} / \mathrm{s} \mathrm{and} 3 \mathrm{~m} / \mathrm{s}$ ) to improve the energy yield while improving system stability (i.e., the system is more stable in the range from low to medium water flow). The reason for this control strategy is that in higher water flow, the system should stall to ensure that a runaway situation will not occur.

Figure 13 shows the modified power-speed path between Point B and Point C. As shown, the slope from Point B to Point C increases. This change can be expressed in equations (6-9). Note that this change can be made more aggressive to force the turbine to stall in the higher water flow regions by changing the value of $\mathrm{K}_{\text {slope }}$ expressed in equation (7). Stalling the turbine in higher water flow will ensure that the turbine will not experience a runaway condition when a sudden change in water flow increases above the rated speed; thus, without a pitching mechanism, this control strategy can be adopted.

The operation can be illustrated by referring to the power performance characteristics shown in Figure 14, wherein the operating point $\mathrm{C}_{\mathrm{p} \_ \text {adjusted }}$ from low to medium water flow is slightly less than the peak $\mathrm{C}_{\mathrm{p}}\left(\mathrm{C}_{\mathrm{p}_{-} \text {max }}\right)$. Thus, from low to medium water flow the generator will be operated to stay at $\mathrm{C}_{\mathrm{p}_{-} \text {adjusted }}$ to maintain stability; from medium to high water flow, the turbine will be transitioned from $\mathrm{C}_{\mathrm{p}_{-} \text {adjusted }}$ to $\mathrm{C}_{\mathrm{p}_{-} \text {max }}$ operation. A simple modification to the power equation is as follows:

$$
\omega_{\text {change }}=0.8 \text { p.u. }
$$




$$
\mathrm{K}_{\text {slope }}=1.0
$$

If $\left(\omega<\omega_{\text {change }}\right)$, then

$$
\mathrm{K}_{\text {gain }}=0.8
$$

else

$$
\mathrm{K}_{\text {gain }}=\mathrm{K}_{\text {slope }}\left(\omega-\omega_{\text {change }}\right)+0.8
$$

where $\omega_{\text {change }}$ is the rotational speed when the slope is changed, and $\mathrm{K}_{\text {slope }}$ is the steepness of the slope applied.

$$
P_{\text {gen }}=K_{\text {gain }} K_{\text {Cpmax }} \omega^{3}
$$

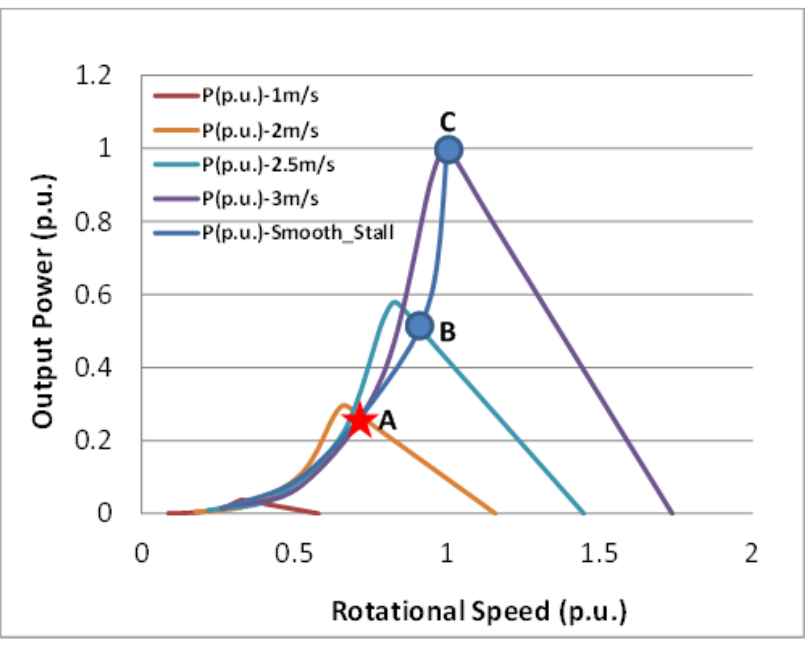

Figure 13. Hydrokinetic power and the generator power operated at $\mathrm{C}_{p_{-} \text {adjusted }}$ in low water flow ( 0 $2.5 \mathrm{~m} / \mathrm{s}$ ) and changed to $C_{p_{-} \max }$ in higher water flow $(>2.5 \mathrm{~m} / \mathrm{s})$ as a function of the rotational speeds

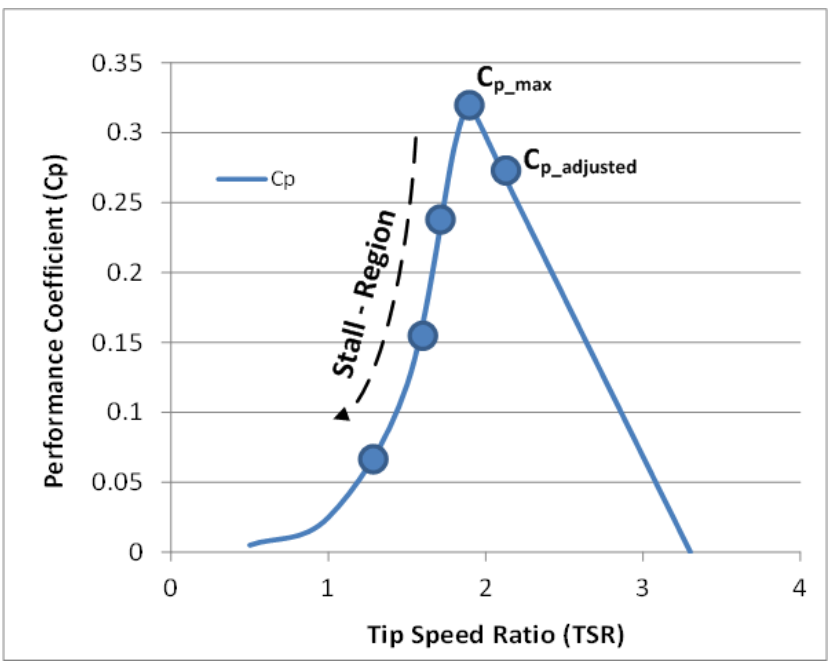

Figure 14. Illustration of the operating point for different modes of operation

The control block diagram shown in Figure 9 can be used. This accomplishes higher $C_{p}$ operation, and the possibility of a runaway condition is removed because the generator will force the turbine to operate in unstable stalling mode when the rotational speed reaches the rated speed.

Figure 15 shows that the performance coefficient, $\mathrm{C}_{\mathrm{p}}$, improves and the TSR gets closer to the TSR target, TSR tgt $_{\text {t }}$ TSR $=1.9$ ), as the water flow increases from $2.2 \mathrm{~m} / \mathrm{s}$ to $2.75 \mathrm{~m} / \mathrm{s}$ and $3 \mathrm{~m} / \mathrm{s}$. Notice the improvements in both the TSR (closer to 1.9) and $C_{p}$ (closer to 0.318 ) values as the water flow increases from $2.2 \mathrm{~m} / \mathrm{s}$ to $3 \mathrm{~m} / \mathrm{s}$. 


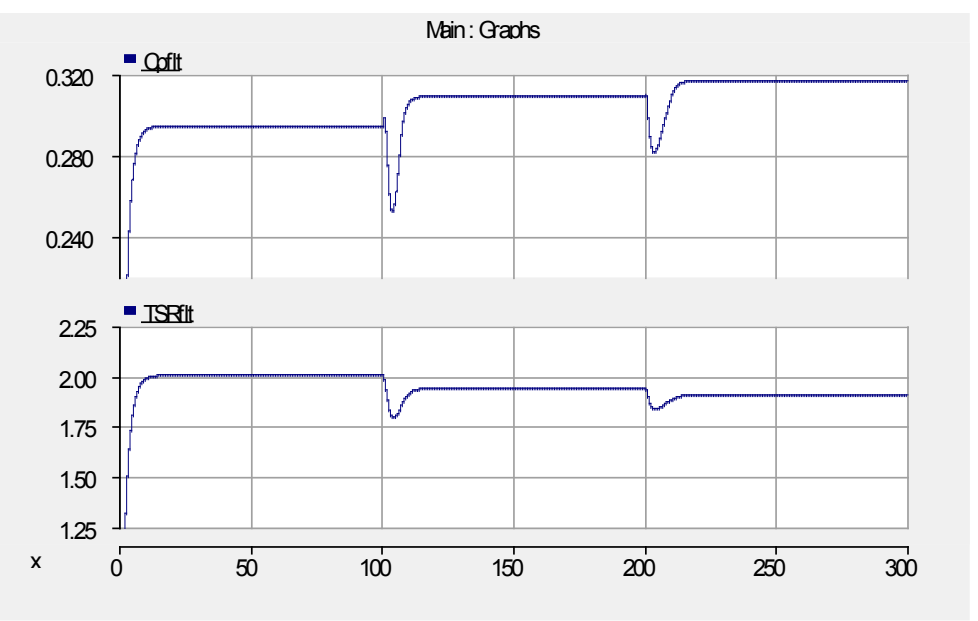

Figure 15. $C_{p}$ and TSR corresponding to Figure 14

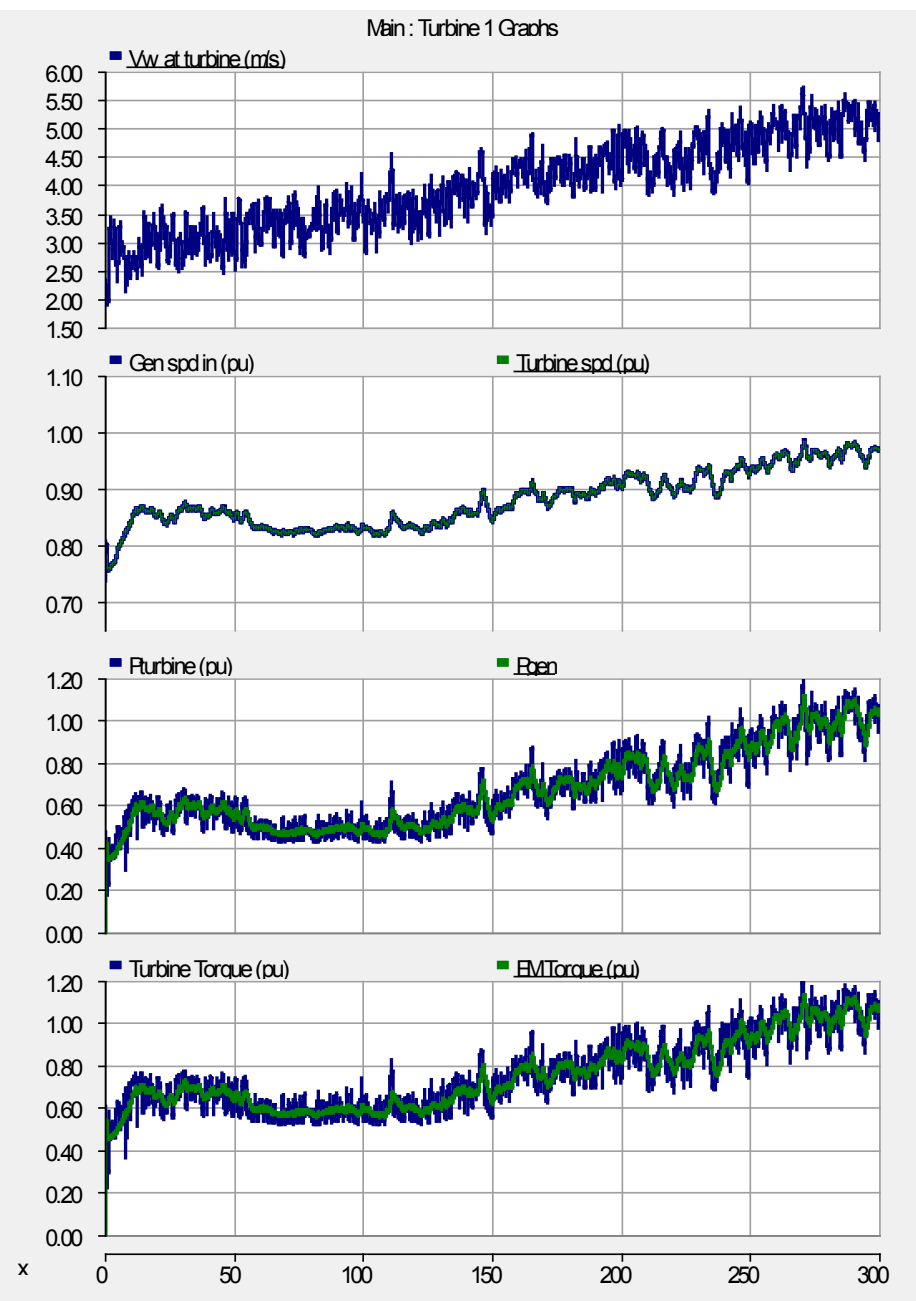

Figure 16. Water flow, rotational speed, output power, and torque as the turbine control is modified to allow for higher $C_{p}$ operation in higher water flow 
To illustrate the stall operation, a time series of water flow is used with the average water flow range from $2.5 \mathrm{~m} / \mathrm{s}$ to $5 \mathrm{~m} / \mathrm{s}$. The rotational speed increases as the water flow increases; however, the rotational speed settles below rated speed (1.0 p.u.) in the higher water flow region. The level of stall operation can be adjusted by changing the value of $K_{\text {slope. }}$. At $K_{\text {slope }}=1$, the turbine reaches TSR tgt and $\mathrm{C}_{\mathrm{pmax}}$ at the water flow rate of $3 \mathrm{~m} / \mathrm{s}$. However, at a more aggressive setting of $\mathrm{K}_{\text {slope }}>1$, the stall operation can be achieved at a water flow rate lower than $3 \mathrm{~m} / \mathrm{s}$, and, similarly, at $\mathrm{K}_{\text {slope }}<1$, the $\mathrm{TSR}_{\text {tgt }}$ and $\mathrm{C}_{\text {pmax }}$ can achieved at the water flow rate of higher than 3 $\mathrm{m} / \mathrm{s}$.

Figure 16 shows that the rotational speed does not exceed the rated speed, and Figure 11 shows that the rotational speed exceeds the rated speed by approximately $6 \%$. Similarly, as shown in Figure 16, the rotational speed, output power, and torque are all limited at 1.0 p.u. The level of stalling can be adjusted by adjusting $K_{\text {slope }}$ as presented in equation (7). From the traces of the $C_{p}$ and TSR, Figure 17 indicates that the turbine enters the stall operation in the high water flow region. Increasing $\mathrm{K}_{\text {slope }}$ will limit the rotational speed, output power, and output torque of the turbine around 1.0 p.u. as the water flows exceeds $5 \mathrm{~m} / \mathrm{s}$. In this case, the $\mathrm{K}_{\text {slope }}$ is set to 2.0 .

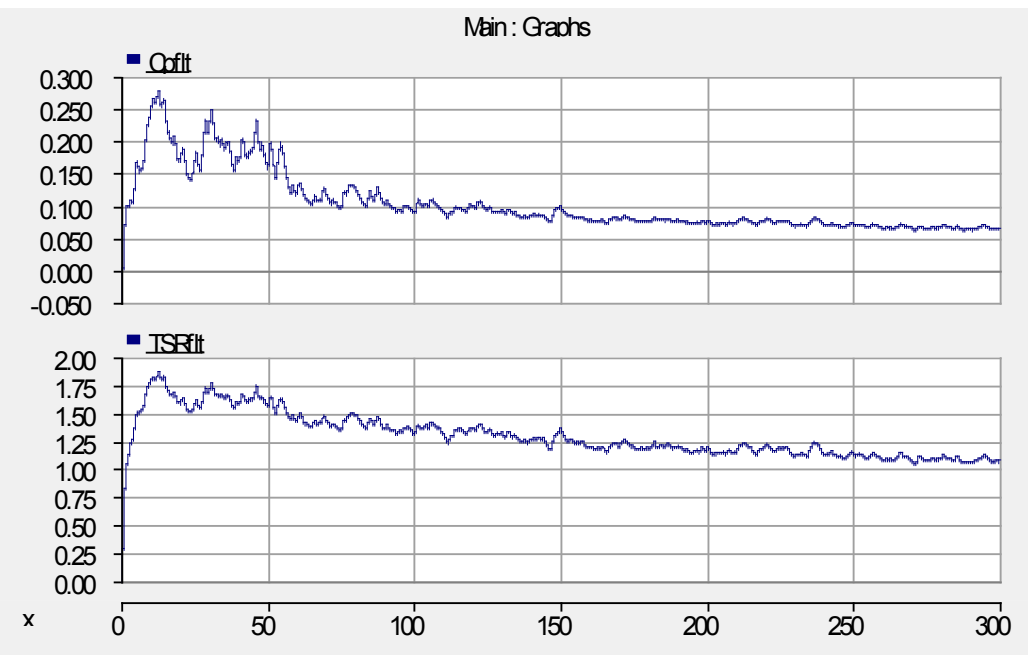

Figure 17. Operating $C_{p}$ and TSR corresponding to Figure 16

\subsubsection{Controlling TSR to Maintain High $C_{p}$}

Another method that can be used is to modify the power equation and improve the operation by using the water flow as part of the feedback. This method was not used in traditional wind turbine control because there is a strong perception that wind speed over the large blade-swept area varies, and thus measurements taken from an anemometer are not a good indication of average wind speeds.

Wind turbine controllers are now being developed that use measurements of wind speeds ahead of the rotor. These measurements are obtained by nacelle-mounted Lidar that look upwind of the machine and obtain wind speed measurements in a vertical plane [14-15]. These measurements represent the disc-averaged wind speeds that affect overall power regulation. This advanced wind speed knowledge allows the blade pitch actuators to start adjusting before the wind actually hits the rotor and thus improves overall performance. This methodology may be applicable to 
river and tidal generation technology if appropriate water flow measurement sensors can be employed.

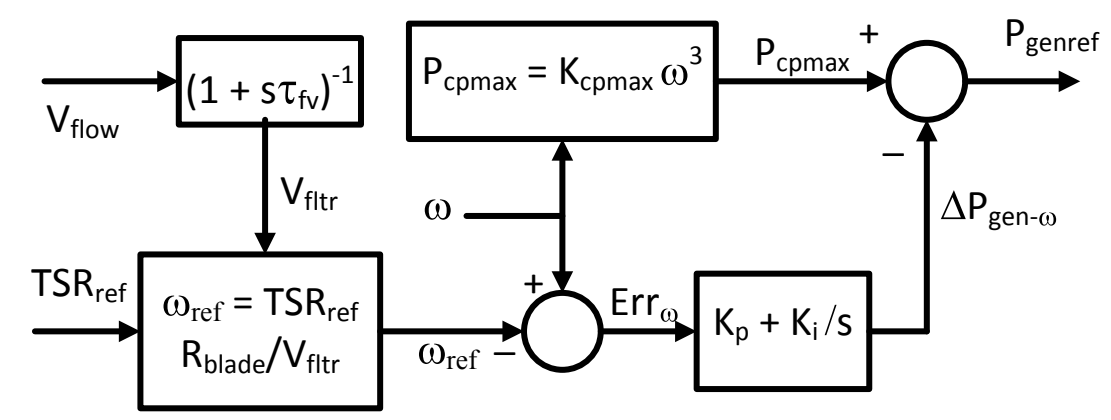

Figure 18. Modified control utilizing the water flow input to control the rotational speed corresponding to $\mathrm{TSR}_{\text {tgt }}$ to stabilize the system

On the other hand, water density is 1,000 times that of air density; thus, for the same power rating, the swept area of a water turbine is much smaller than the swept area of a wind turbine. In reference to Figure 8 and Figure 15, the reference TSR for a water turbine at $\mathrm{C}_{\mathrm{pmax}}$ is $\mathrm{TSR}_{\text {ref }}=$ $\mathrm{TSR}_{\mathrm{tgt}}=1.9$. Utilizing equation (2), and assuming that we can measure average water flow accurately, we can control the operation of the turbine to stay at TSR $=1.9$ by controlling the output of the generator to maintain the operating TSR. This control algorithm is presented in Figure 18. Note that the operation of the generation is kept at the prescribed power-speed

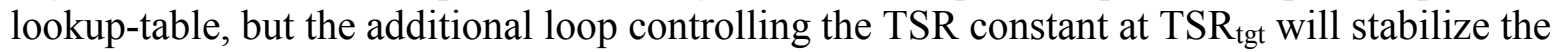
system.

The low-pass filter shown in Figure 18 is intended to remove the noise and turbulence from the water flow measurement; thus, it is expected to obtain the average water flow from the output of the low-pass filter. Because of the inertia of the rotating blades, the generator, and all other rotating masses associated with the turbine, the noise and small turbulence do not contribute to the main driving torque of the turbine that is driving the electrical generator; thus, the average value or filtered value is more appropriate for the control variable. The input to the blockcomputing reference rotational speed is based on the known $\mathrm{C}_{\mathrm{p}}$-TSR characteristics where the $\mathrm{C}_{\text {pmax }}$ and $\mathrm{TSR}_{\text {tgt }}$ are known quantities.

Figure 19 shows that the system is stable, and relying on the water flow to guide the rotational speed allows us to maintain the $\mathrm{TSR}_{\text {tgt }}$ by controlling the rotor speed. Comparing Figure 19 to Figure 7 shows that the ability to control the TSR $\mathrm{T}_{\text {tgt }}$ enables us to stabilize the system with certainty. Figure 20 shows the corresponding TSR and the $\mathrm{C}_{\mathrm{p}}$ behavior during the transitions at different wind speeds. It can be observed that during the transient there is some overshoot, which takes some time to settle. This is because the filter block is in place to filter out the turbulence flow and noise signal before computing the reference TSR or the reference rotational speed. 


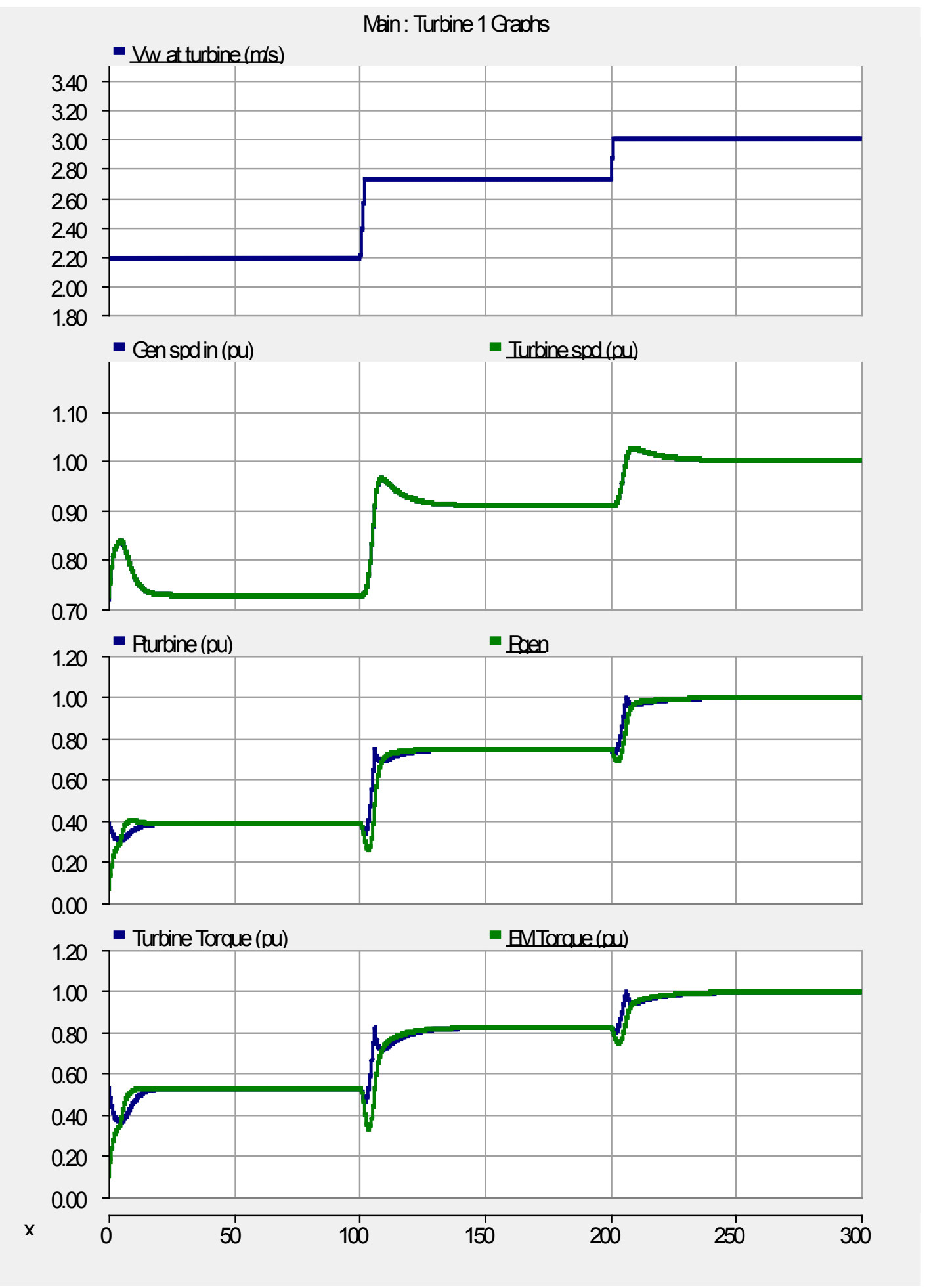

Figure 19. Water flow, rotational speed, output power, and torque as the turbine control is modified to allow for TSR control 


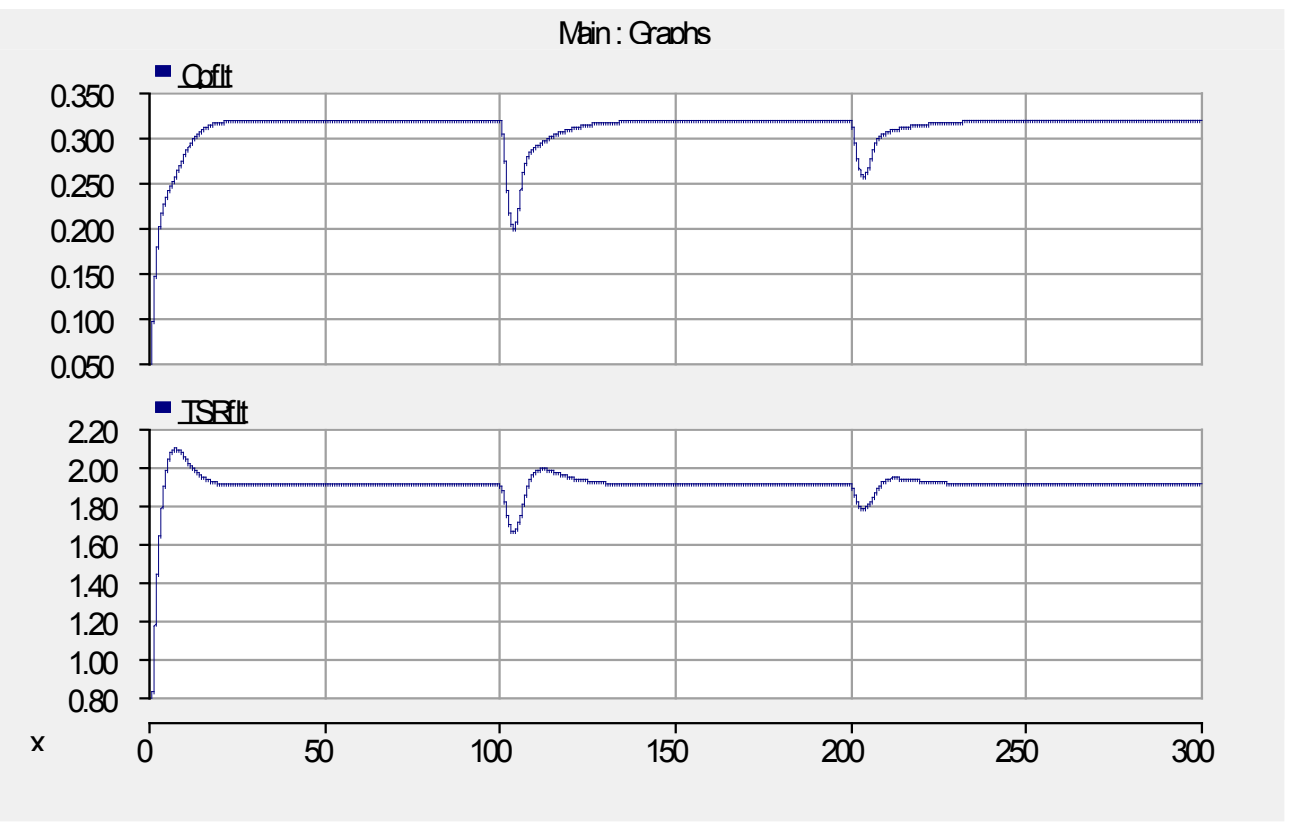

Figure 20. $C_{p}$ and TSR with TSR control

\subsubsection{Controlling TSR to Stall the Turbine in High Water Flow}

The controller discussed in the previous section can be modified to prevent the turbine from running away in case the water flow increases much higher than the rated level. A simple additional block diagram shown in Figure 21 is intended to change the reference TSR from maintaining TSR $_{\text {tgt }}$ to a TSR reference that will force the turbine to slow down the rotational speed at increasing water flow and indirectly force the turbine to enter the stall region (low TSR).

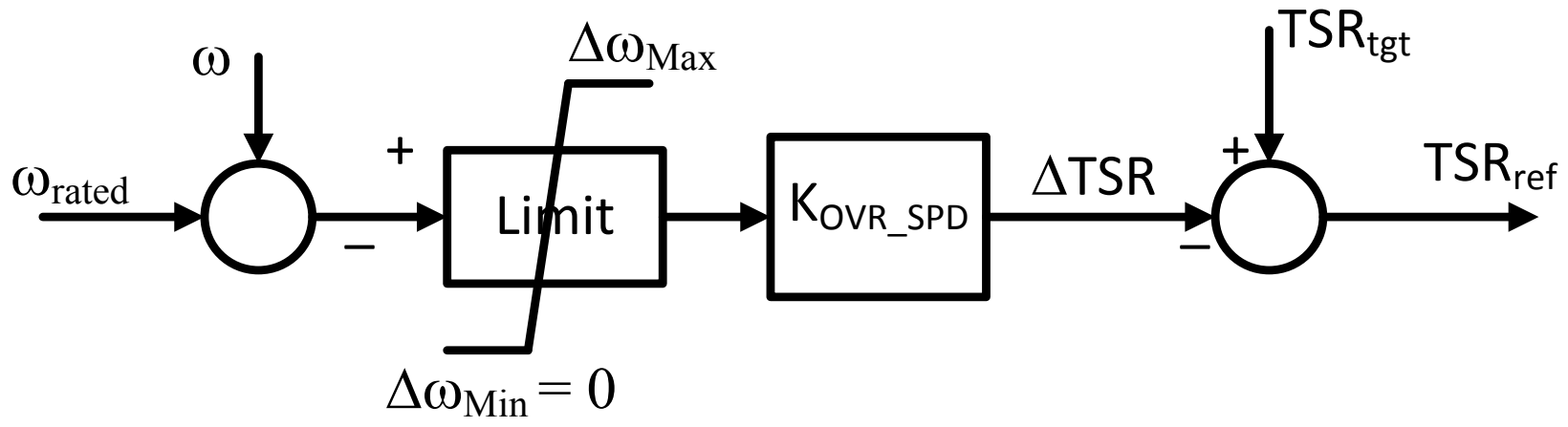

Figure 21. Overspeed control is included to force the turbine to stall above rotational rated speed by adjusting the TSR.

This controller may be more relevant for river turbines, as tidal cross flow turbines' maximum speeds are not as major a concern as they are for wind and axial tidal turbines. Maintaining a TSR of 2 for extreme sites $(3.5 \mathrm{~m} / \mathrm{s})$ would mean an RPM of $\sim 60$, which is well within design 
specifications. Similarly, at a maximum TSR of 3, the rotational speed would be 90 RPM, which is well within design specifications.

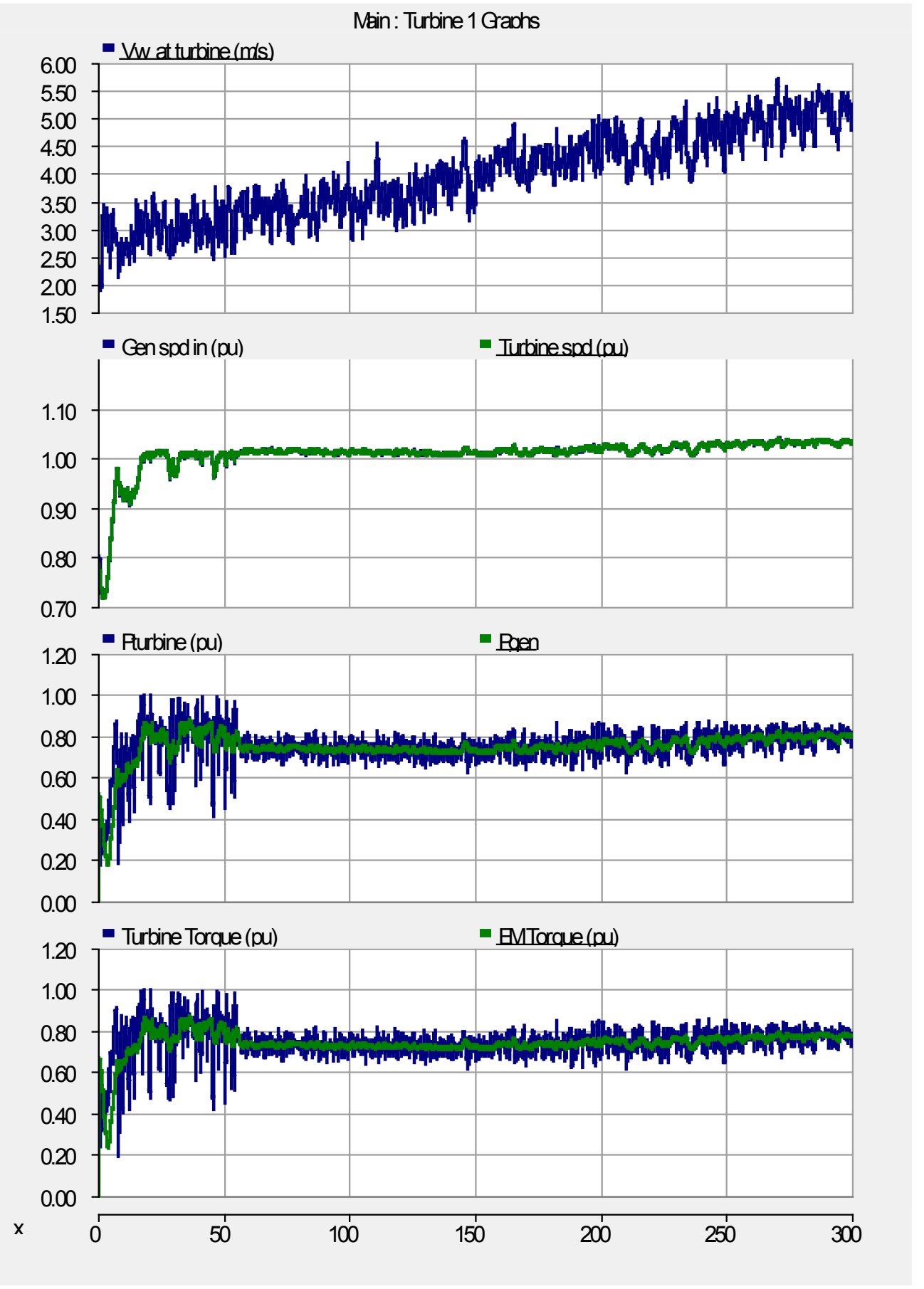

Figure 22. Stall control is included to force the turbine to stall in higher water flows by adjusting the TSR as a function of the water flow.

Figure 22 shows that the water flow increases in the same fashion as that shown in Figure 16. The rotational speed, output power, and output torque are well under control as we stall the 
turbine. In this way, this type of controller is very similar to the governor control in a conventional power plant, including the droop applicable to above-rated speed. The effectiveness of the TSR control to stall the turbine can be adjusted by setting the gain KovR_SPD; thus, to be more aggressive, KOVR_SPD $=10$ is used for the simulation shown in Figure 22 and Figure 23. Figure 23 shows how the $C_{p}$ and TSR vary and the water flow increases to a very high level. The stall algorithm shown in the control block diagram in Figure 21 works very effectively, as shown by the rotational speed behavior in the high water flow region in Figure 22 and the controlled behavior of the $\mathrm{C}_{\mathrm{p}}$ and TSR in Figure 23 .

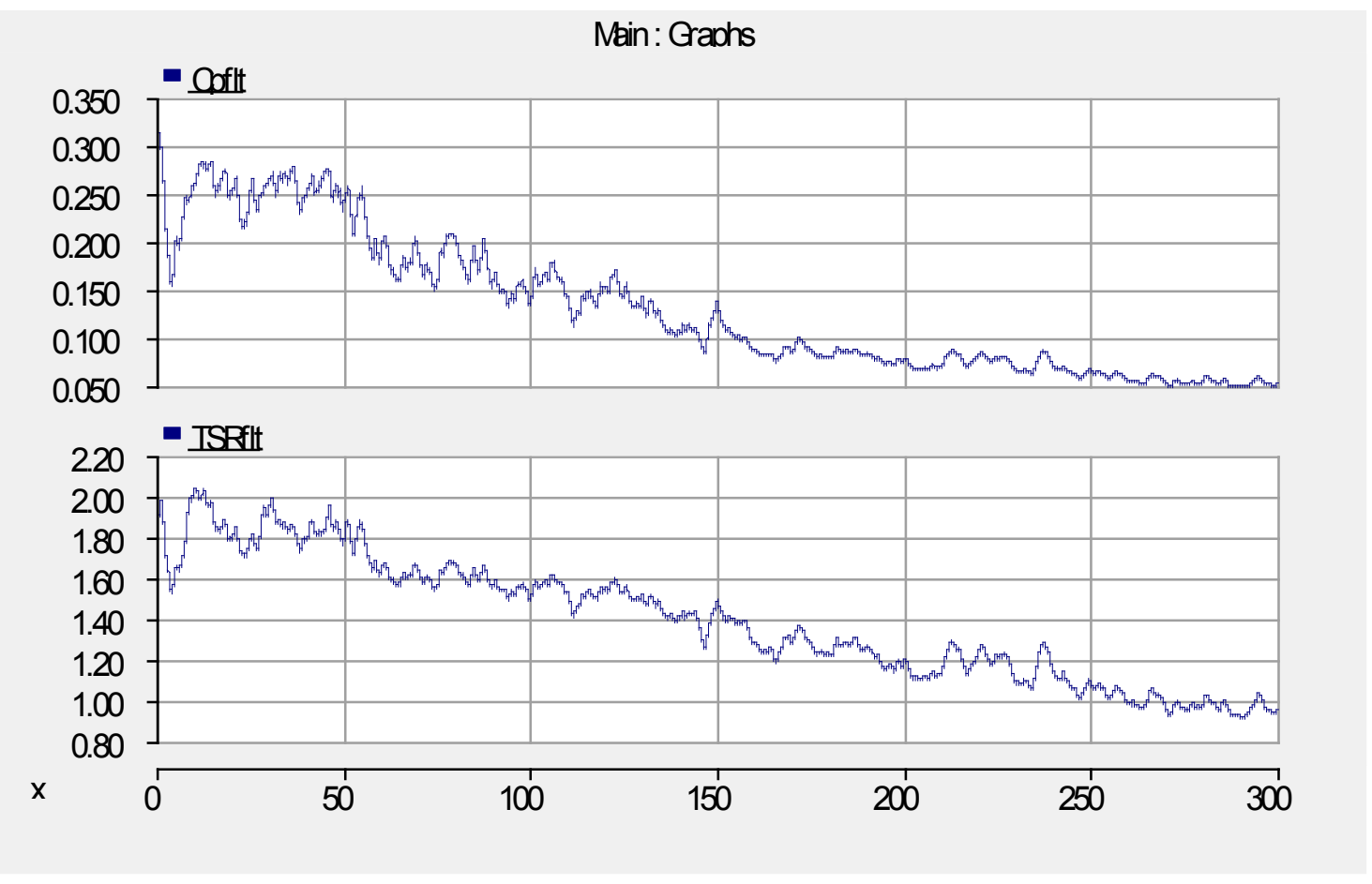

Figure 23. Illustration of $C_{p}$ and TSR during stalled operation in high water flows

\subsection{Miscellaneous Investigations}

\subsubsection{The Size of Inertia}

In this work, the inertia of a typical power plant generator is expressed as the time constant $\mathrm{H}$ with the unit of seconds. $\mathrm{H}$ is expressed as the ratio of the stored kinetic energy and the rated apparent power $(\mathrm{S})$ of the generator.

The stored kinetic energy in the rotating mass can be expressed as

$$
K E_{\text {stored }}=\frac{1}{2} J \omega_{m}^{2}
$$

where $\mathrm{J}$ is the inertia of the rotating mass of the turbine and generator, and

$$
H=\frac{\frac{1}{2} J \omega_{m}^{2}}{S_{g e n}}
$$


The unit of $\mathrm{H}$ can be expressed as

$$
\frac{\text { Joules }}{\text { Volt.Ampere }}=\frac{\text { Watt.sec }}{\text { VA }}=\text { seconds }
$$

For example, the turbine presented in this work is assumed to have $\mathrm{H}=4.94$ seconds.

To exercise the dynamic model, we use the same condition presented in Section 2.3 and Figure 7 through Figure 9. In Section 2.3, the system that has $\mathrm{K}_{\text {gain }}=1$ and $\mathrm{H}=4.94$ seconds is not stable. However, if we reduce the inertia to $\mathrm{H}=0.094$ second, or, practically, if the inertia is almost zero, then the turbine will respond directly to the changes in water flow, and Point A (red star) and Point B (blue circle) as described in Figure 6 will never be separated because the rotational speed will directly follow the water flow changes. Any abrupt changes in water flow will be followed by the instantaneous changes in rotational speed.

As shown in Figure 24, the system with very small inertia is stable. However, zero inertia is an impractical ideal model, although the resulting performance coefficient, $\mathrm{C}_{\mathrm{p}}$, is at $\mathrm{C}_{\mathrm{pmax}}$ operation.

\subsubsection{The Impact of Ramping on the Water Flow}

In the previous sections, we examined an extreme condition where the water flow changes abruptly like steps. This works well to exercise the control systems implemented and to investigate the control algorithms suitable for extreme conditions. However, changes in water flow are generally gradual. Here, we investigate different ramp rates on the water flow and observe the behavior of the turbines under these conditions. With a low ramp rate, the water flow changes at a slower rate; thus, the rotational rotor speed of the turbine is able to follow the changes of the water flow. This condition will make it possible for Point A and Point B shown in Figure 6 to stay together when the rotational speed of the turbine is able to follow the changes of the water flow.

In Figure 11 and Figure 12, the system is implemented with $\mathrm{K}_{\text {gain }}=0.8$, and it is a stable. To show the impact of the ramp rate of the water flow, we examine the same system with normal inertia the water flow changing at 100 seconds and 200 seconds at a ramp rate of $0.1 \mathrm{~m} / \mathrm{s}$. As shown in Figure 25, if the ramp rate of the water flow is reduced, the gain factor can be increased to $\mathrm{K}_{\text {gain }}=0.96$; thus, it is very close to $\mathrm{C}_{\mathrm{pmax}}$ operation. Note that this is an additional $16 \%$ increase in energy conversion efficiency gained from the knowledge that the maximum ramp rate of the water flow is at $0.1 \mathrm{~m} / \mathrm{s}$. The setting of the $\mathrm{K}_{\text {gain }}$ may be adjusted for different sites for installation; this number is different from one place to another, from one time of day to another, or from one season to another depending on the nature (i.e., ramp rate) of the water flow. Perhaps an adaptive gain schedule can be implemented as we gain more experience and more data from the field tests conducted during the coming years. 

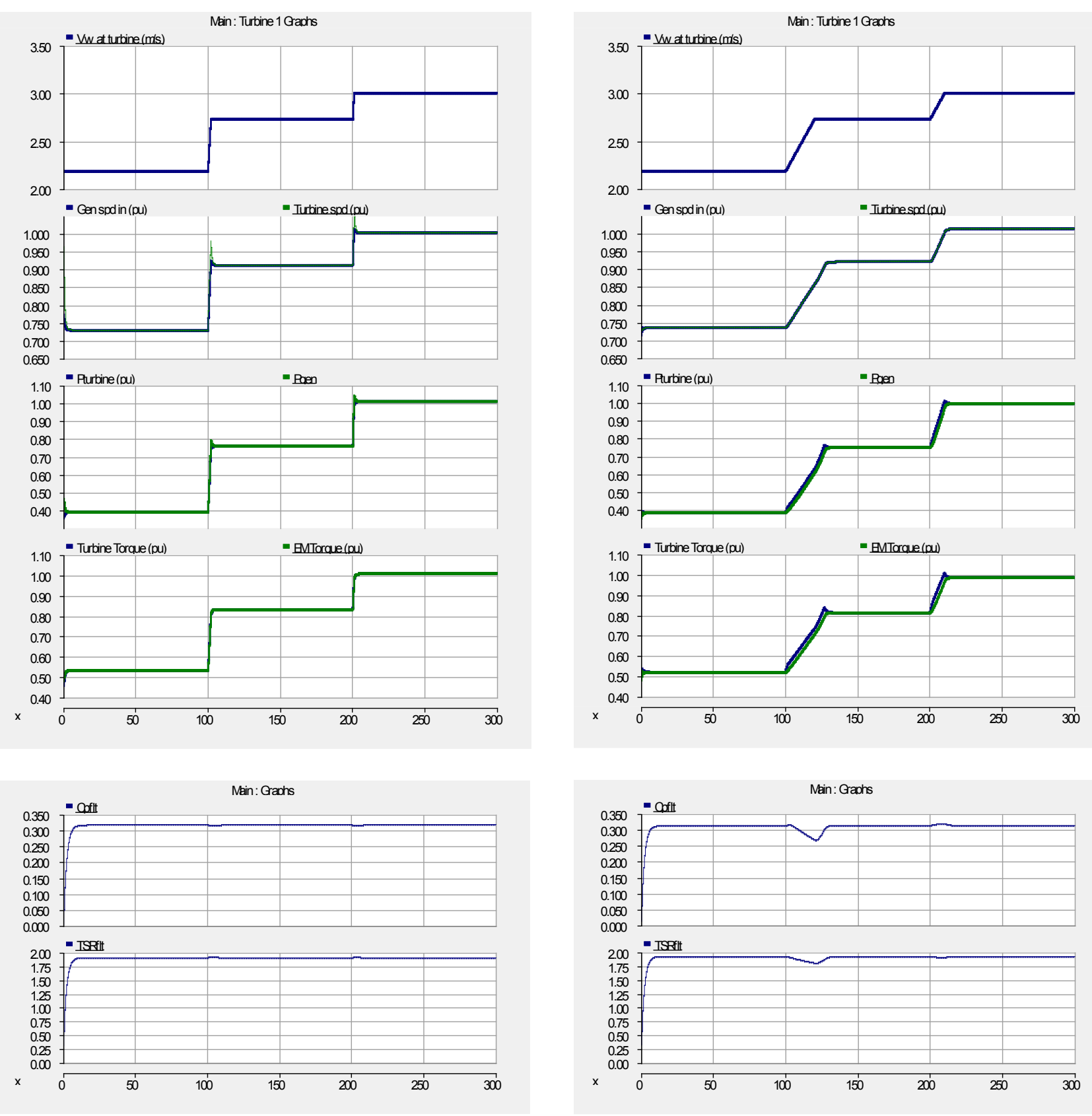

Figure 24. $K_{\text {gain }}=1$, small inertia $(H=0.094 \mathrm{~s})$

Figure 25. $\mathrm{K}_{\text {gain }}=0.96, \mathrm{H}=4.94 \mathrm{~s}$, and ramp rate at $0.1 \mathrm{~m} / \mathrm{s}$

\subsubsection{The Impact of a Flat $C_{p}$-TSR Curve}

To examine the impact of the shape of the $\mathrm{C}_{\mathrm{p}}$-TSR curve on the performance of the turbine, we compare the system we investigated to a turbine system with a flat $\mathrm{C}_{\mathrm{p}}$-TSR characteristic. A tentative $C_{p}$ curve is presented side-by-side with the original $C_{p}$ curve we used in the previous sections. 
As shown in Figure 26, the range of the TSR with high $\mathrm{C}_{\mathrm{p}}$ for the flat $\mathrm{C}_{\mathrm{p}}$-TSR is broad compared to the case of the sharp $C_{p}$-TSR; thus, there is less sensitivity near the point of $C_{\text {pmax }}$. A small change in rotational speed or water flow, or the ratio between the two (TSR) around the $\mathrm{C}_{\mathrm{pmax}}$, does not cause a large change in the performance coefficient. This is in contrast with the sharp $\mathrm{C}_{\mathrm{p}}$-TSR shown on the left in Figure 26.
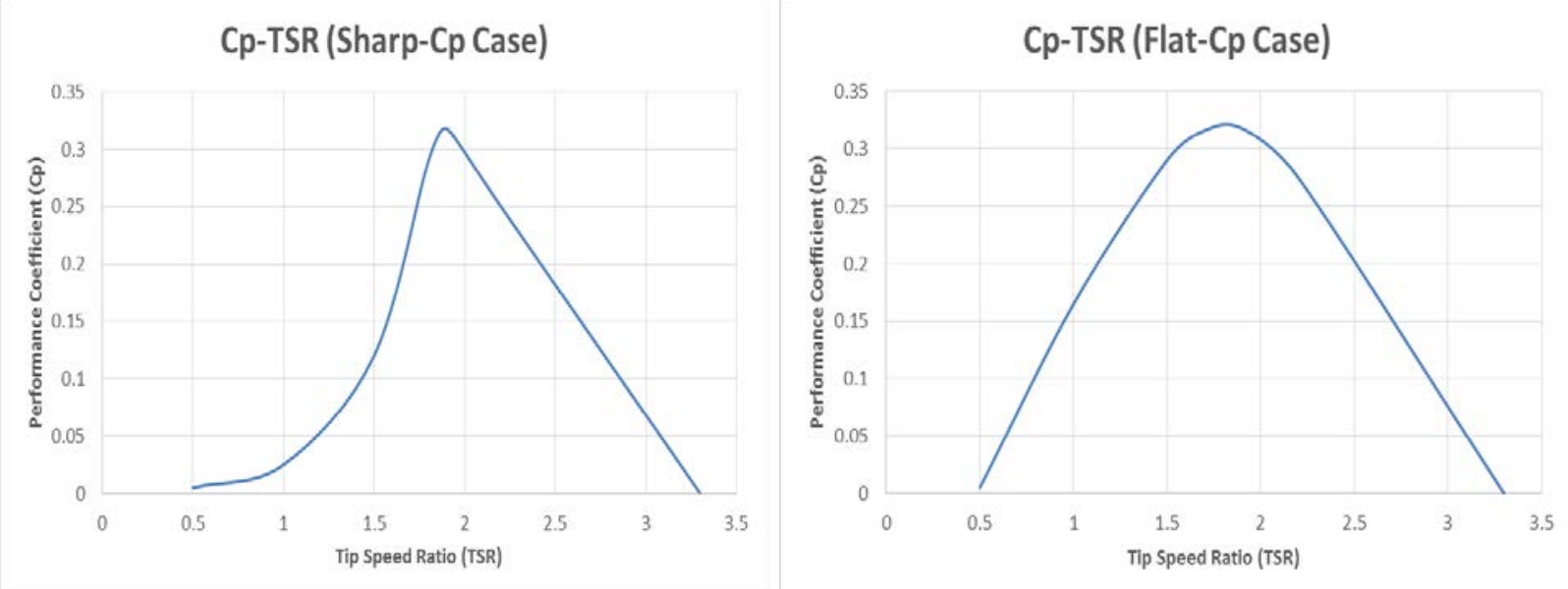

Figure 26. Comparison between the sharp $C_{p}-T S R$ and flat $C_{p}-T S R$
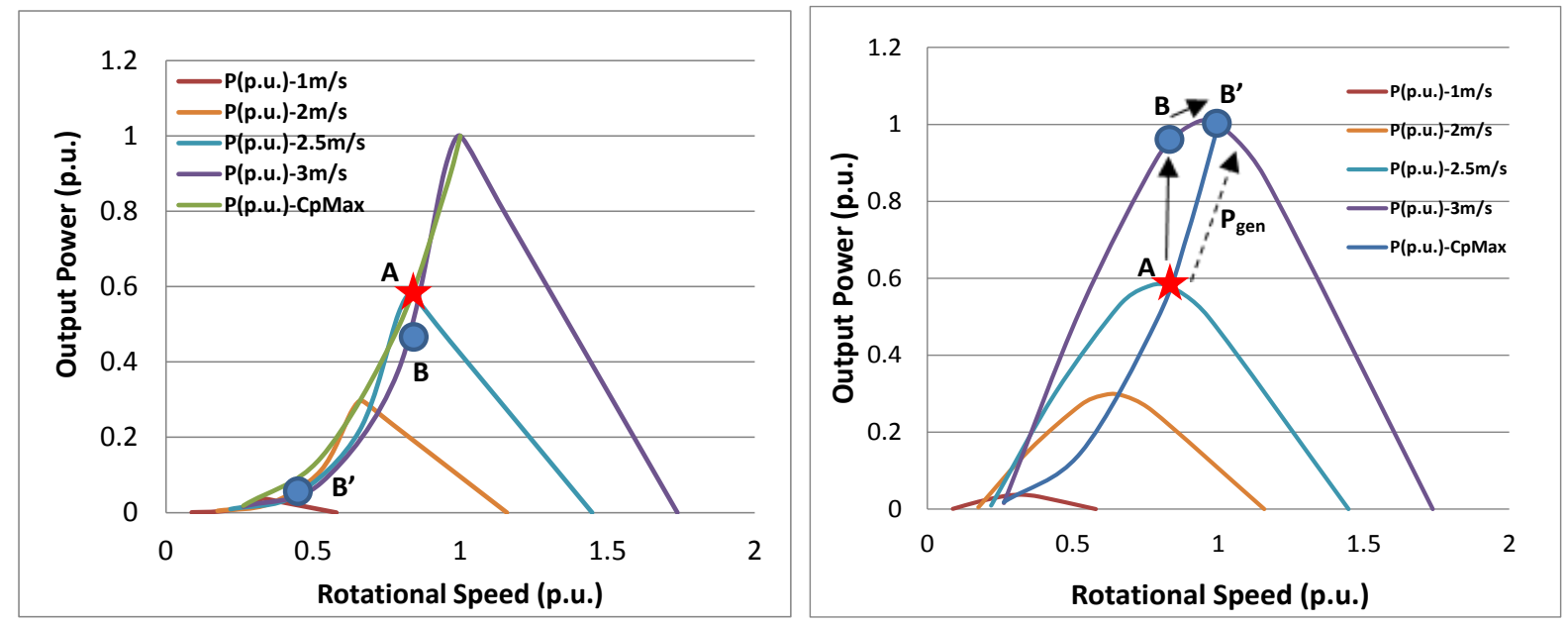

Figure 27. Comparison of power curves between the sharp $C_{p}-T S R$ and the flat $C_{p}-T S R$

Similarly, the power curves are redrawn, and a side-by-side comparison is shown in Figure 27. With a flat $\mathrm{C}_{\mathrm{p}}$-TSR characteristic (as shown by the curves on the right side in Figure 27), the operating point is at Point A when the water flow is at $2.5 \mathrm{~m} / \mathrm{s}$. When the water flow changes from $2.5 \mathrm{~m} / \mathrm{s}$ to $3 \mathrm{~m} / \mathrm{s}$, the turbine hydrodynamic operating point moves from Point A to Point B. Because the turbine power B is higher than the generator output power $\mathrm{A}$, the rotational speed accelerates. The acceleration power, $\mathrm{P}_{\mathrm{AB}}$, drives the rotational speed faster, while at the same time the operating point moves along a separate curve. The turbine operating point moves from Point A to Point B to Point B' (along the hydrodynamic power operating at the water flow of 3 
$\mathrm{m} / \mathrm{s})$, while the generator power moves along the electric power $\left(\mathrm{C}_{\mathrm{pmax}}\right.$ operation $)$ from Point $A$ to Point B', where the turbine power meets the generator power, and the operating point settles at Point B'.

The flat $\mathrm{C}_{\mathrm{p}}$-TSR characteristic is simulated as in Section 2.3, with the same water flow input steps $(\mathrm{ramp}$ rate $=1 \mathrm{~m} / \mathrm{s}), \mathrm{K}_{\text {gain }}=1.0$, and the same inertia $(\mathrm{H}=4.94$ seconds $)$.

Figure 28 shows the result of the dynamic simulation. As can be predicted, the system is very stable, and the operating performance coefficient, $C_{p}$, is shown to be very stable at $C_{p m a x}$ operation.

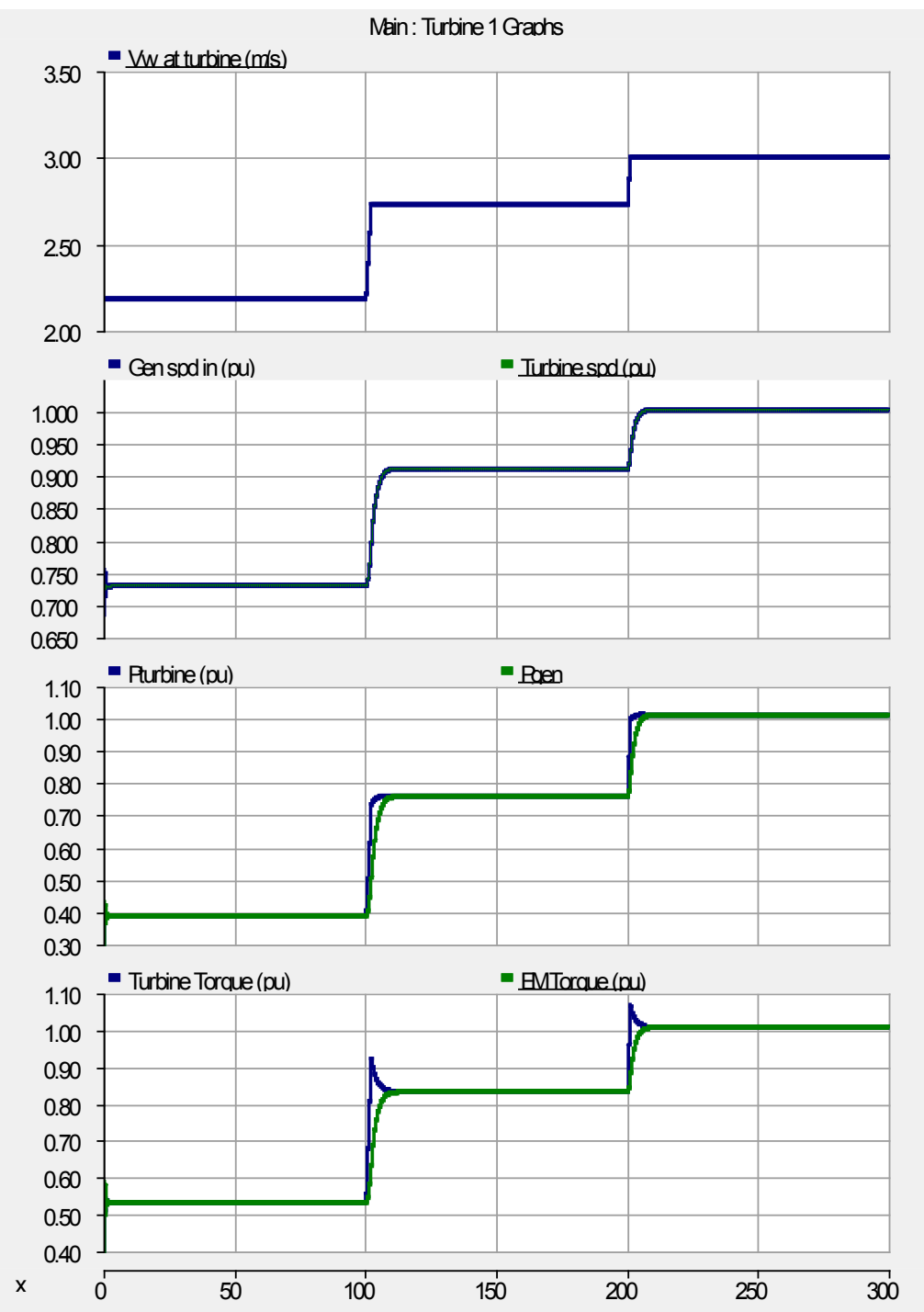

Figure 28. The turbine characteristics simulated with the flat $C_{p}-T S R$ characteristic, with $K_{\text {gain }}=1.0$, $\mathrm{H}=4.94 \mathrm{~s}$, and ramp rate set to $1 \mathrm{~m} / \mathrm{s}$ 


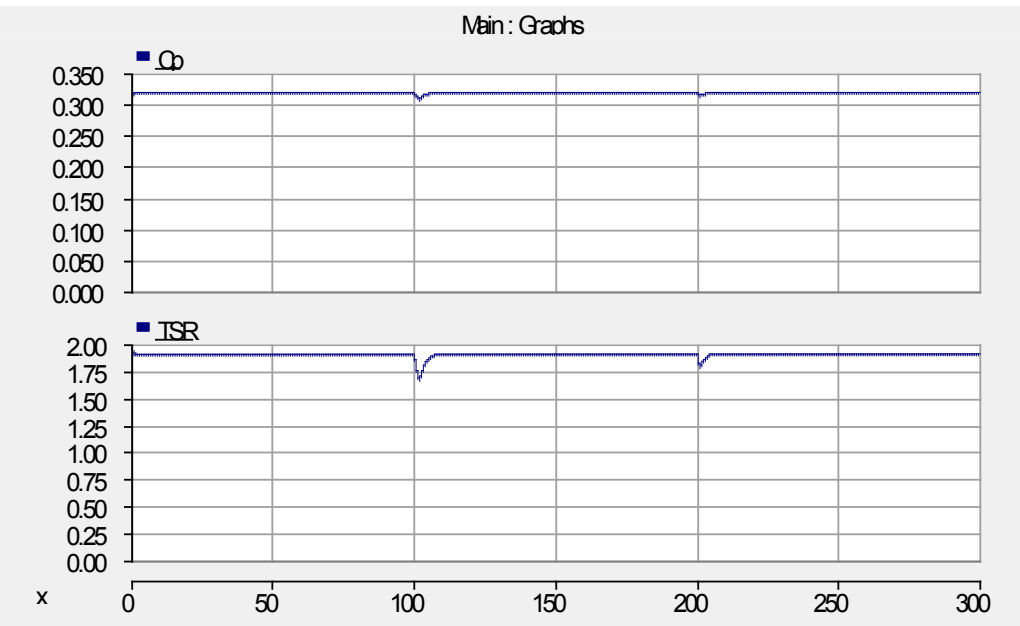

Figure 29. The corresponding performance coefficient, $C_{p}$, and TSR for the case of the flat $C_{p}-T S R$ characteristic, with $K_{\text {gain }}=1.0, H=4.94 \mathrm{~s}$, and ramp rate set to $1 \mathrm{~m} / \mathrm{s}$ 


\section{Electrical Power Conversion}

The electrical power conversion in this type of generation is very similar to the generating system of wind power generation. It consists of major components: a rectifier (variable AC-toDC converter) and an inverter (DC-to-AC 60-Hz converter). Depending on the generator type, the rectifier can be a passive rectifier or an active rectifier. We assume that the system described in this paper is based on a passive rectifier; thus, a DC-DC converter is used to match and maintain the DC bus voltage constant. Note that this DC-DC converter will be able to compensate for the voltage drop (and reduce the copper loss along the feeder line) from the offshore generator to the substation onshore. With an active rectifier, it is possible to control the DC bus voltage by utilizing the active rectifier alone. This section presents the electrical power conversion.

\subsection{System-Level Description}

River generation using a permanent magnet synchronous generator (PMSG) is investigated. A PMSG has the advantage of higher efficiency and reliability. Because of its lack of a field winding and the nature of variable generation, the PMSG is typically controlled by a series of power converters to produce power for the grid. The major conversion processes are as follows:

- Hydrokinetic generation is converted into electrical power (tidal turbine and PMSG).

- The variable AC (three-phase) output of a PMSG is converted into variable DC voltage (three-phase diode bridge).

- The variable DC output voltage of the diode bridge is connected to a DC-DC boost converter. The output of the DC-DC boost converter is a constant DC bus.

- The constant DC bus voltage is converted into three-phase AC at $60 \mathrm{~Hz}$ (the inverter is controlled to optimize tidal generation).

The power transmission system from the generator to the substation transformer of a tidal or river generator is illustrated in Figure 30.

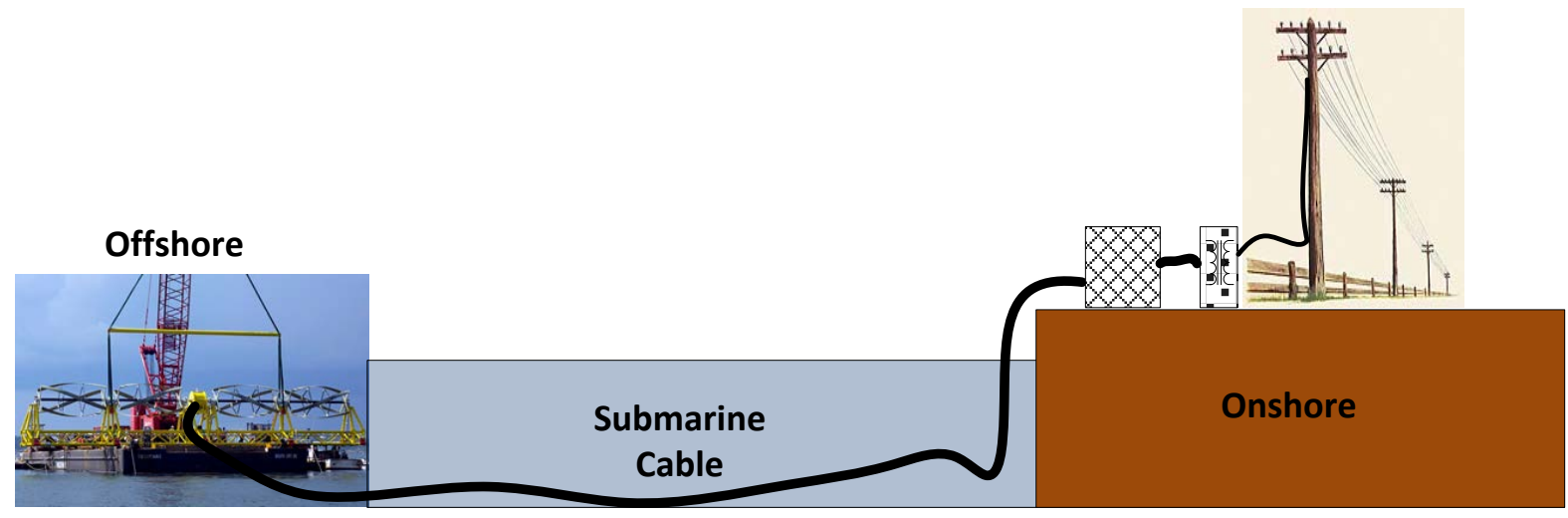

Figure 30. Typical electrical power transmission system from generator to substation transformer of a tidal or a river generator

In the system investigated, the PMSG driven by the tidal turbine is located in the tidal flow (offshore). As shown in Figure 31, it is connected to a rectifier onshore via a submarine cable to 
a three-phase diode rectifier system. A reactive power compensator (a delta-connected AC capacitor set) is connected at the input (three-phase AC) of the rectifier. The rectifier output (DC) is connected to a DC-DC boost converter to optimize the operation of the tidal generator. The output of the DC-DC converter is connected to the input of the DC-AC inverter, and the inverter is controlled to keep the DC bus voltage constant.

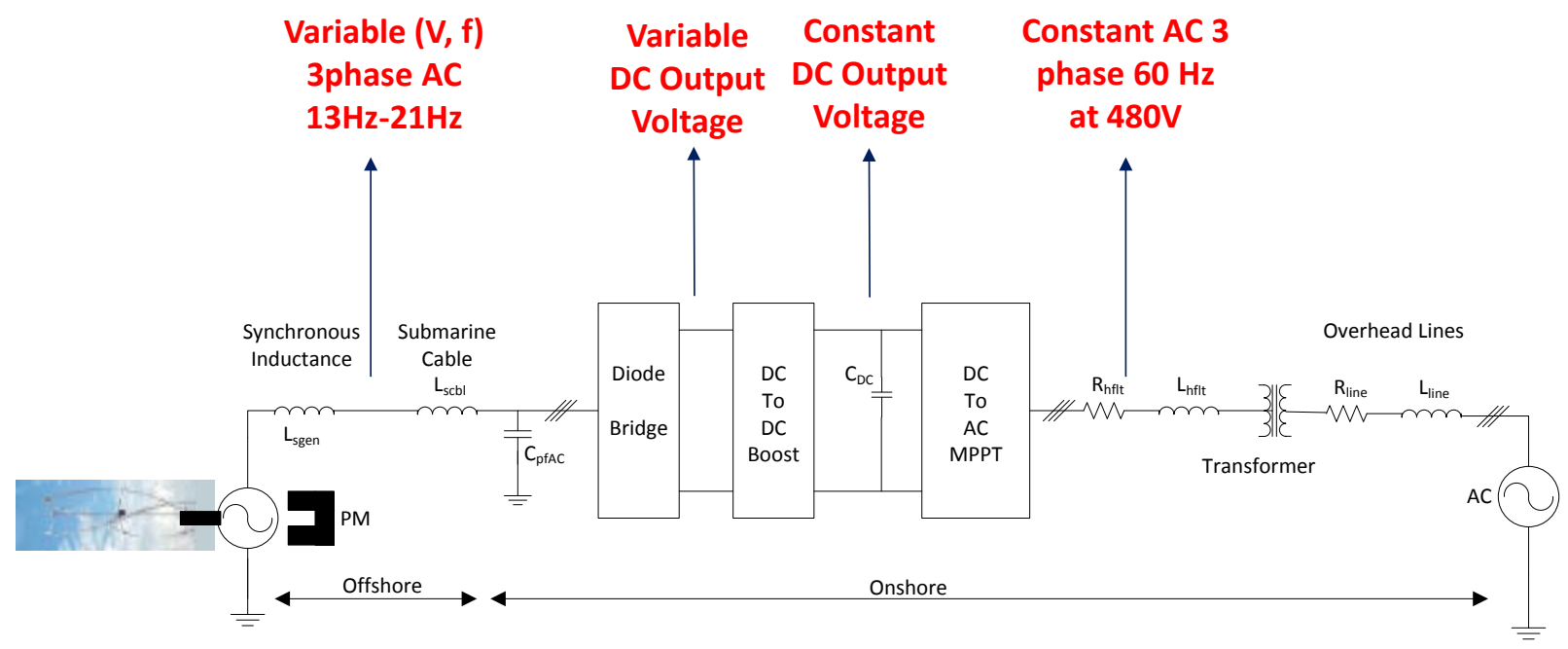

Figure 31. Single-line diagram of interconnected converters

\subsection{Permanent Magnet Synchronous Generator}

PMSGs are very popular in variable generation applications. Many of these applications use direct-drive generators that use rare-earth permanent magnets. The advantage of a rare-earth permanent magnet is that the residual flux density is very high, commonly $\mathrm{B}=1.4$ Tesla or higher. In comparison, the commonly used permanent magnet in the past has been the ferrite magnet, which has a low flux density, at $\mathrm{B}=0.4$ Tesla or lower. High flux density magnets are very important because, for the same power rating and rotational speeds, the higher the flux density, the smaller and the lighter the generator will be. It is assumed that the permanent magnet generator is surface mounted. The equivalent circuit of a permanent magnet generator is shown in Figure 32.

\subsection{PMSG Connected to a Constant DC Bus via a Rectifier}

In this section, the PMSG is connected to a constant DC bus voltage via a three-phase rectifier. A simplified version of a surface-mounted PMSG is used.

\subsubsection{Operation at Constant Frequency}

Consider a constant frequency application wherein the PMSG is operated at constant rotational speed. In this case, the output voltage, $\mathrm{E}$, is constant because both the magnetic flux and the rotational speed are constant. 


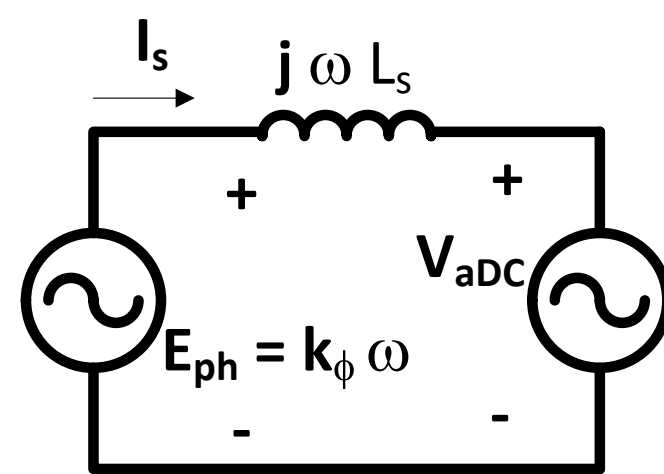

(a) Constant frequency

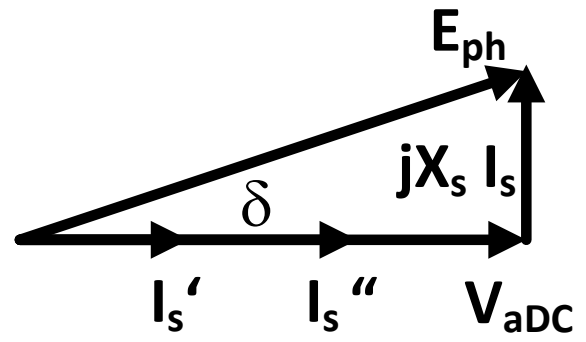

(b) Phasor diagram representation

Figure 32. Per-phase equivalent circuit of a PMSG and corresponding phasor diagram for a fixedfrequency operation

Because the flux and the frequency (rotational speed) are constant, for a given size of synchronous inductance, $\mathrm{L}_{\mathrm{s}}$, only one output current $\left(\mathrm{I}_{\mathrm{s}}{ }^{\prime}\right)$ and one output power $\left(\mathrm{P}_{\mathrm{s}}{ }^{\prime}\right)$ are associated with this operation (single-point operation). However, if the size of the synchronous inductance is $50 \%$ of the original, the resulting current $\left(\mathrm{I}_{\mathrm{s}}\right.$ ") and output power ( $\mathrm{P}_{\mathrm{s}}$ ") will be twice the original. The terminal voltage equation of the PMSG generator connected to a diode rectifier can be expressed as

$$
\begin{gathered}
V_{a D C}=\frac{\pi}{3 \sqrt{6}} V_{D C} \\
E_{p h}=k_{\Phi} \omega
\end{gathered}
$$

The voltage equation can be expressed as

$$
E_{p h}=V_{a D C}+j \omega L_{s} I_{s}
$$

where:

- $\mathrm{V}_{\mathrm{aDC}}$ is the $\mathrm{AC}$ equivalent of the per-phase terminal voltage connected to a rectifier (not drawn).

- $\mathrm{V}_{\mathrm{DC}}$ is DC voltage output of the three-phase rectifier.

- The rectifier is connected to the terminal of the generator.

- $\mathrm{E}_{\mathrm{ph}}$ is the per-phase internal electromagnetic field of the PMSG.

- $\mathrm{I}_{\mathrm{S}}$ is the stator current feeding the rectifier bridge at unity power factor.

- $\mathrm{L}_{\mathrm{s}}$ is the stator inductance.

- $\omega$ is the rotational speed in radian/s.

Because the terminal output of the generator is connected to a three-phase rectifier, the per-phase terminal voltage and the stator current are in phase. At this point, assume that the terminal 
voltage is connected to a rectifier and that the output of the rectifier is a constant DC bus voltage. Thus, the AC equivalent of the terminal voltage is clamped to this $\mathrm{DC}$ bus voltage.

$$
I_{S}=\frac{\sqrt{E_{p h}^{2}-V_{a D C}^{2}}}{\omega L_{S}}
$$

The per-phase output power can be expressed as

$$
P_{g e n}=V_{a D C} I_{s}
$$

Referring to the phasor diagram in Figure 32, the $\mathrm{V}_{\mathrm{aDC}}$ can be replaced by $\mathrm{E}_{\mathrm{ph}} \cos (\delta)$. By substitution, the output power can also be expressed as

$$
P_{g e n}=\frac{E_{p h}^{2} \sin 2 \delta}{2 \omega L_{s}}=\frac{k_{\Phi}^{2} \omega \sin 2 \delta}{2 L_{s}}
$$

The power angle, $\delta$, is the angle between the per-phase internal electromagnetic field voltage, $\mathrm{E}_{\mathrm{ph}}$, and the per-phase terminal voltage, $\mathrm{V}_{\mathrm{aDC}}$. It can be computed as:

$$
\delta=\operatorname{acos}\left(\frac{V_{a D C}}{E_{p h}}\right)
$$

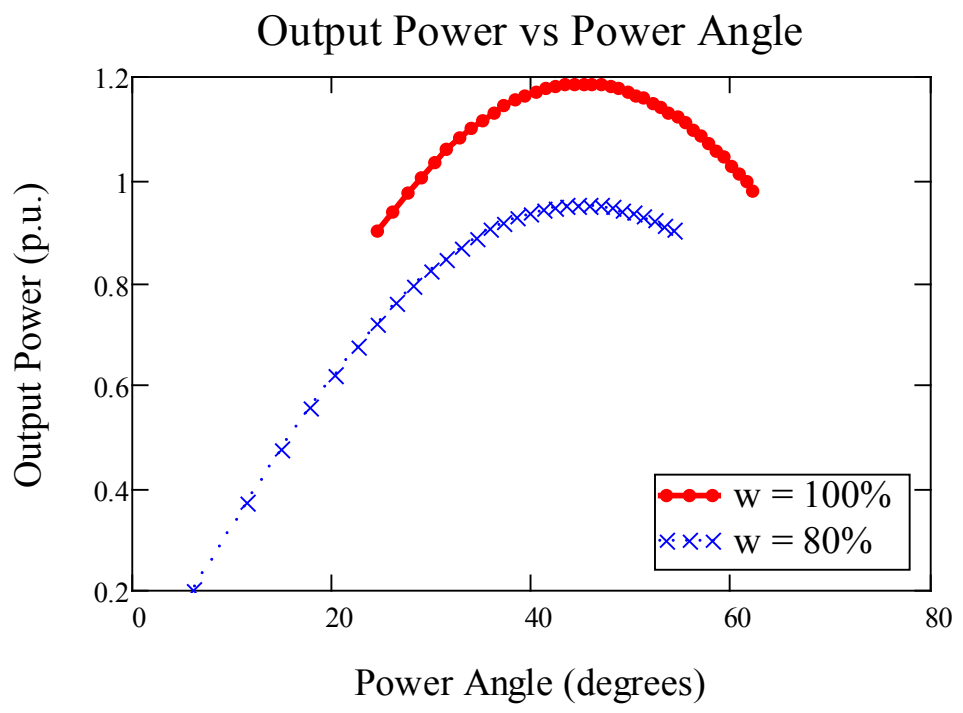

Figure 33. Output power of a PMSG connected to a rectifier operated at a constant frequency

For operation at a constant frequency, a synchronous generator is connected to a fixed-voltage DC bus via a three-phase rectifier; it has a peak value at $\delta=45^{\circ}$. This is different from a conventional synchronous generator, which has a peak value at $\delta=90^{\circ}$. As shown in Figure 33, as predicted by equation (18), the operation at a lower frequency will have a lower peak value proportional to the frequency. Referring to the phasor diagram given in Figure 32, we can say that as we increase the current, $I_{s}$, the voltage drop, $X_{s} I_{s}$, increases, and the voltage $V_{a D C}$ decreases; thus, the power equation will rise at the beginning. However, because the power is 
defined by both the current, $\mathrm{I}_{\mathrm{s}}$, and the voltage $\mathrm{V}_{\mathrm{aDC}}$, eventually the product of the two reaches a peak value where an additional increase of $I_{S}$ no longer brings the output power up because of the decrease of the voltage $\mathrm{V}_{\mathrm{aDC}}$, and past this point, another increase of $\mathrm{I}_{\mathrm{S}}$ will reduce the output power. This point is reached when $\delta=45^{\circ}$ for the configuration analyzed.

\subsubsection{Operation in Variable Frequency}

Consider a variable-frequency application, wherein the PMSG is operated at variable speed. In this case, the internal electromagnetic field voltage, $E_{\text {ph }}$, varies with the rotational speed because the magnetic flux of the permanent magnet is constant and the rotational speed varies. For PMSG operation, the frequency output is proportional to the operating speed by the following equation:

$$
\begin{aligned}
& r p m=\frac{120 f}{\text { poles }} \\
& \omega=\frac{r p m(2 \pi)}{60 \mathrm{sec}}
\end{aligned}
$$

From the voltage equations, it is clear that as the rotational speed, $\omega$, increases, the $\mathrm{E}_{\mathrm{ph}}$ increases, while $\mathrm{V}_{\mathrm{aDC}}$ is constant. As a result, when $\mathrm{E}_{\mathrm{ph}}>\mathrm{V}_{\mathrm{aDC}}$, the generator starts to generate. The output current, $\mathrm{I}_{\mathrm{s}}$; the output power $\mathrm{P}_{\text {gen }}$; and the power angle, $\delta$, also increase.

The calculations in this section are given in per unit to make them easier to analyze. For the generator under consideration, the generator starts to generate output power when $\mathrm{E}_{\mathrm{ph}}$ exceeds the output terminal voltage $\mathrm{V}_{\mathrm{aDC}}$ at $\omega=0.91$ p.u. (see Figure 34). Note that the blue dasheddotted line illustrates a condition when the generator used can generate only $80 \%$ of the internal voltage. In this situation, the generator can never generate power, even at rated rotational speed.

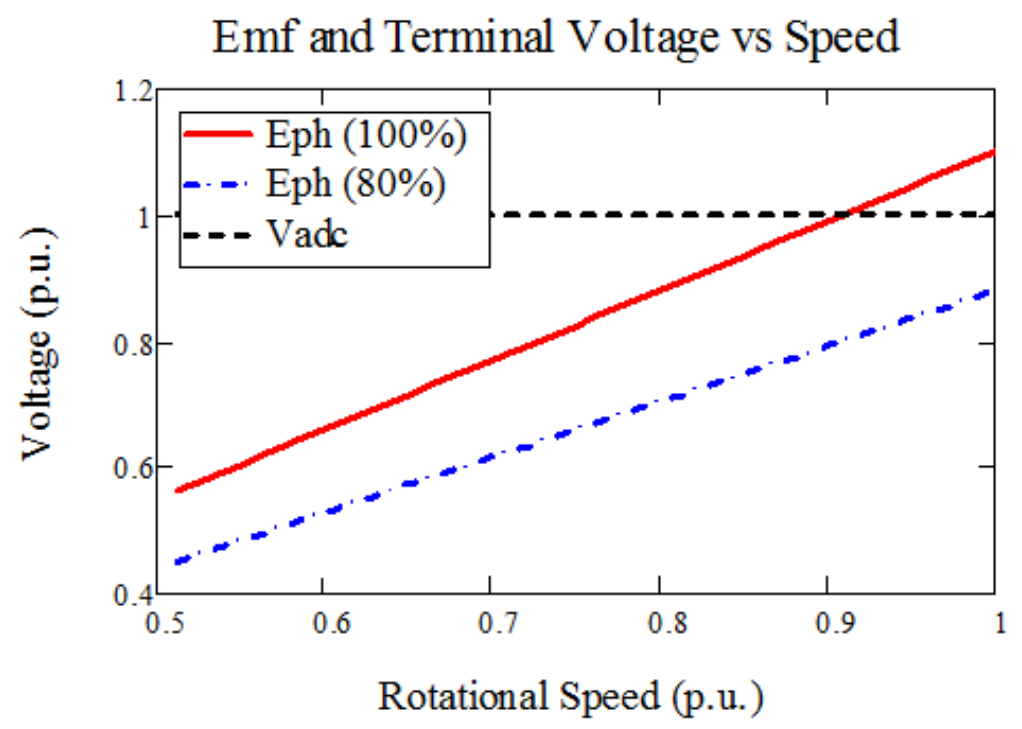

Figure 34. Per-phase internal voltage, $E_{\mathrm{ph}}$, and $\mathrm{V}_{\mathrm{Adc}}$

The corresponding output power is given in Figure 35. The rotational speed is obtained by operating the synchronous generator by varying the rotational speed (variable frequency) with a 
constant DC bus voltage. As shown here, the output power cannot be shaped; it is based on the parameters of the PMSG and the DC bus voltage to which it is connected.

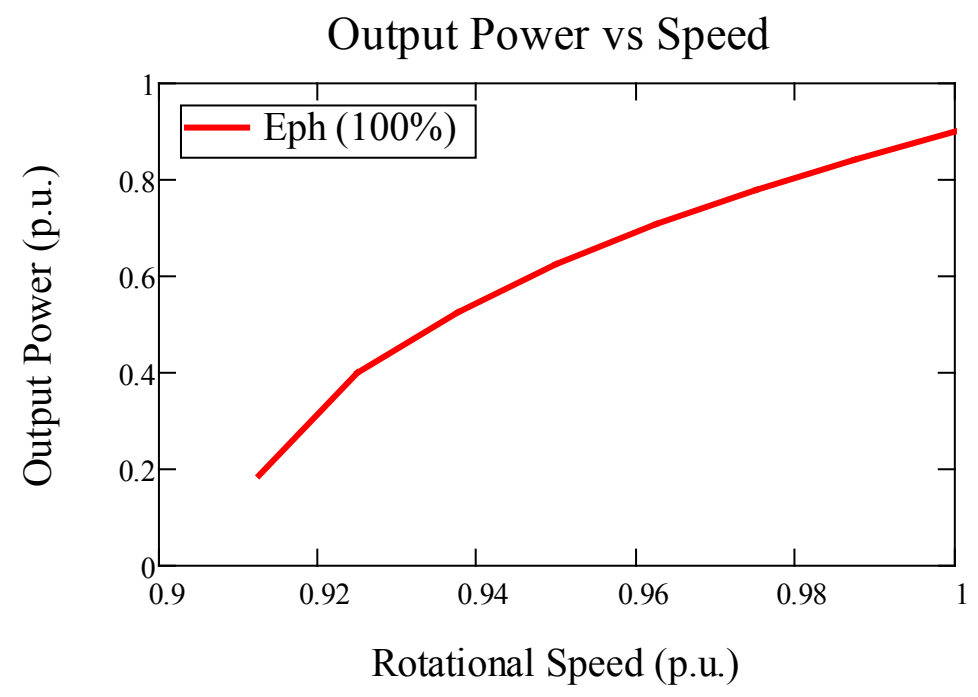

Figure 35. Output power as a function of rotational speed

\subsubsection{Operation in Variable DC Bus Voltage}

As shown in Figure 36, operating at constant frequency and constant DC bus voltage will give a single point of operation, and operating at variable speed will give a set of points of operation, but the output power cannot be shaped as a function of the rotational speed. One more variable that can be used to shape the power-speed characteristic is to control the effective DC bus connected to the output of the rectifier as the rotational speed varies.

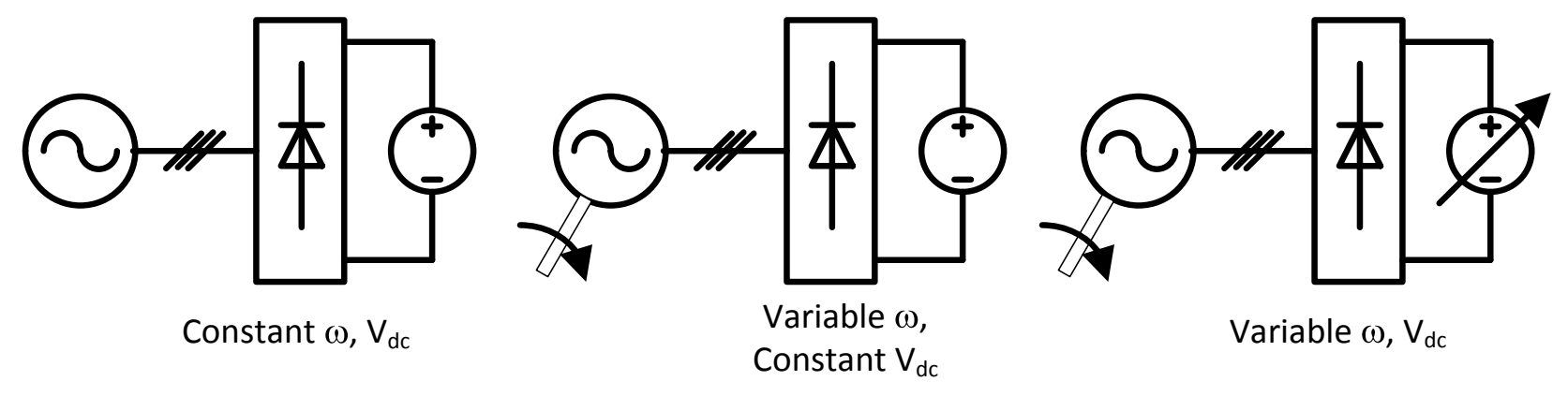

Figure 36. Three modes of operation

The operation at variable speed and variable DC bus voltage is illustrated in Figure 37. It is shown that the power-speed characteristic of the PMSG connected to a rectifier can be shaped by controlling the terminal voltage $\mathrm{V}_{\mathrm{aDC}}$ indirectly by adjusting the $\mathrm{DC}$ bus at the output of the rectifier as the rotational speed changes. Thus, in this case, the DC bus voltage is controlled to follow the cube function of the rotational speed (the dotted line). To operate along the dotted line, the DC bus voltage can be controlled accordingly. For example, to operate at Point A, the DC bus voltage is at $60 \%$ of its original value. As the rotational speed increases, the operating 
point moves to Point $\mathrm{B}$, and the DC bus voltage is at $80 \%$. At Point $\mathrm{C}$, the $\mathrm{DC}$ bus voltage is at $100 \%$.

\section{Output Power vs Rotational Speed}

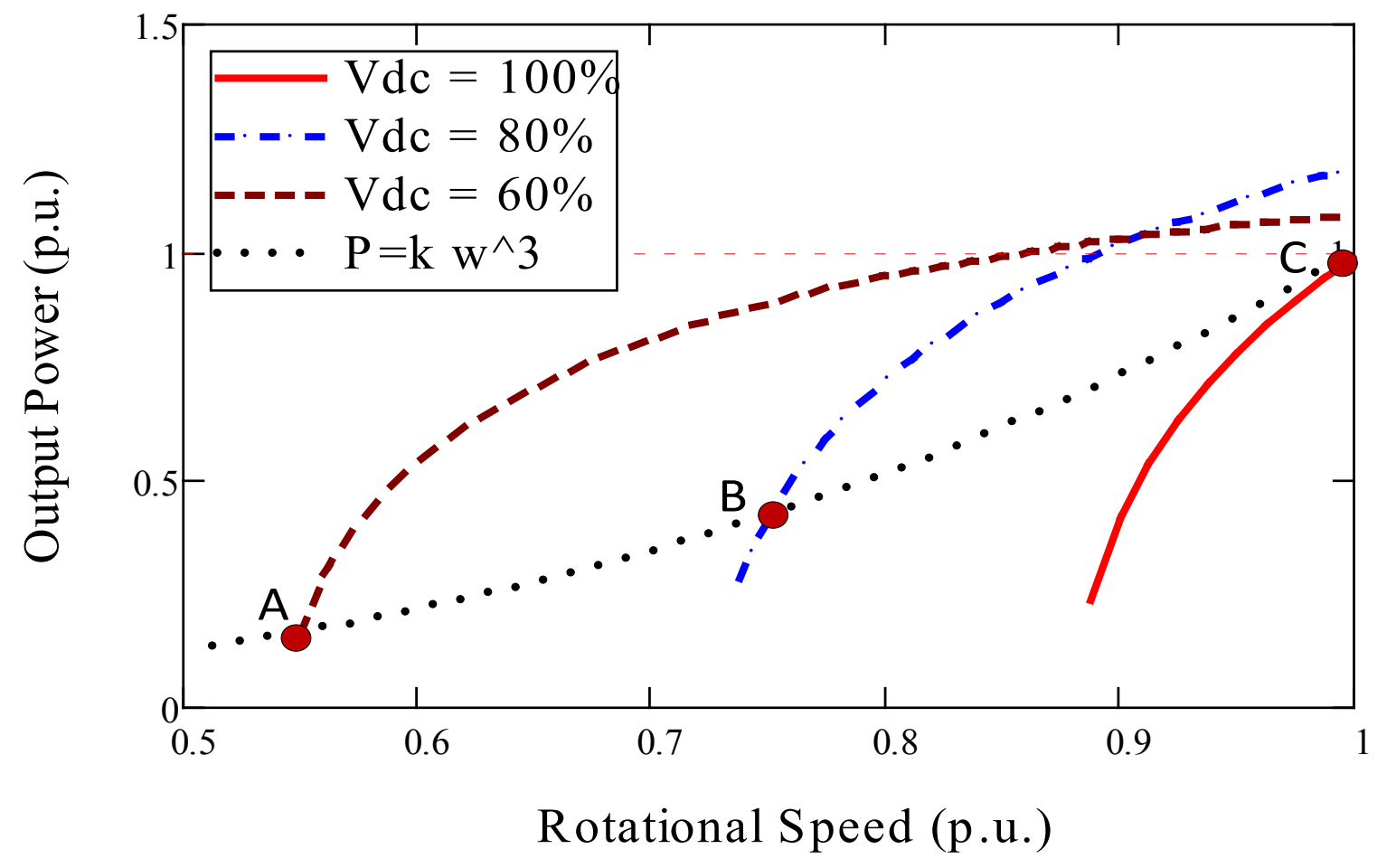

Figure 37. Operation at variable speed and variable voltage, $\mathbf{V}_{\mathrm{dc}}$

\subsection{Power Converters}

The output of the PMSG driven by a water turbine generates variable frequency proportional to the rotational speed of the turbine, and the process of converting the output power of the PMSG requires a set of power converters to transmit the power into the power grid.

\subsubsection{AC-DC Rectifier}

The first set of power converters is the DC-AC rectifier, which can be an active power inverter or a passive diode bridge. Because the PMSG is connected to the water turbine, the operating speed varies with the water flow. The internal electromagnetic field voltage, $\mathrm{E}_{\mathrm{ph}}$, and the output voltage magnitude and frequency are proportional to the operating rotational speed (see Figure 38). With an active rectifier, the output of the PMSG can be directly converted into a constant DC bus voltage. 


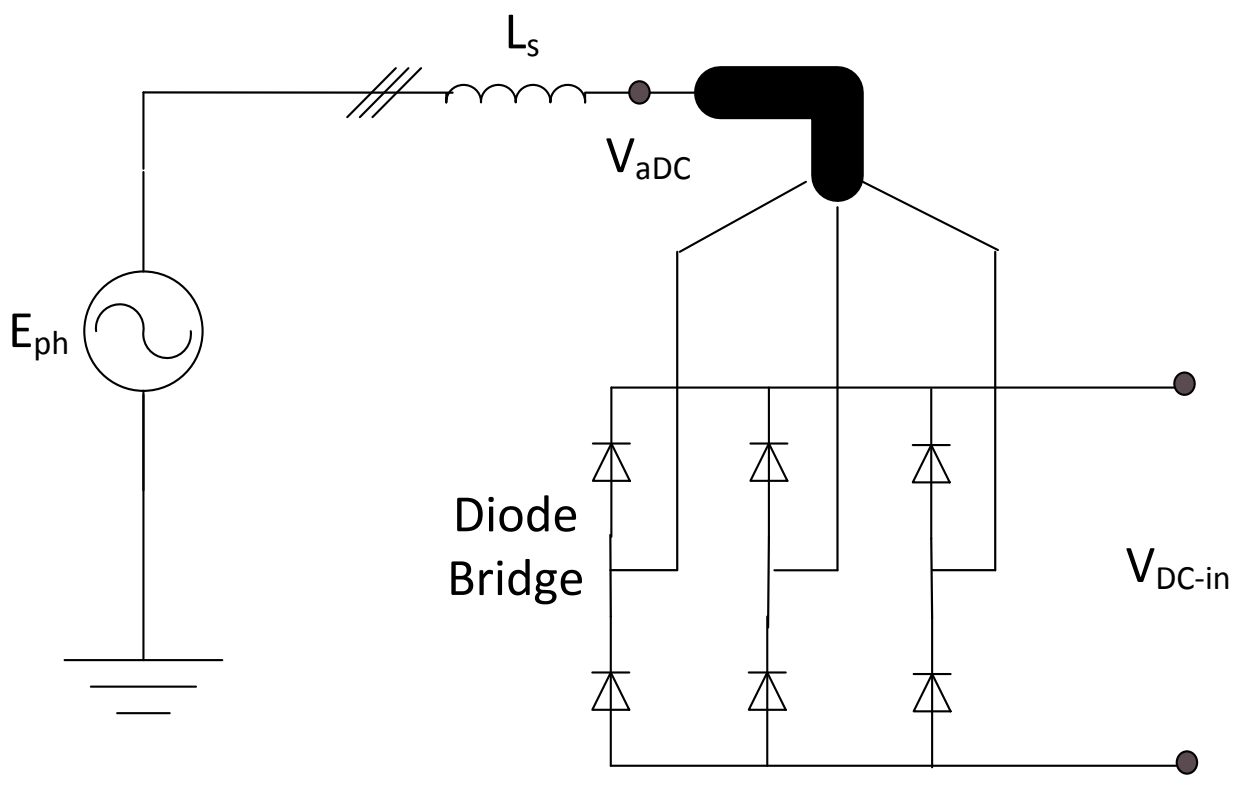

Figure 38. Equivalent circuit of a variable-speed PMSG connected to a passive diode bridge

With a passive diode bridge, as shown in Figure 38, the output DC voltage is proportional to the rotational speed. The following equations can be used to describe the relationship between the PMSG output and the output on the DC bus voltage:

$$
\begin{gathered}
V_{D C-i n}=\frac{3 \sqrt{6}}{\pi} V_{a D C} \\
V_{a D C}=k_{\Phi} \omega-j \omega L_{s} I_{S}
\end{gathered}
$$

\subsubsection{DC-DC Converter}

The output of the diode rectifier is a variable DC bus voltage; thus, before it is connected to a DC-AC inverter, the DC bus voltage needs to be matched to the required DC bus voltage of the inverter. A DC-DC converter is used to match the DC bus requirement. To match the variable voltage output of the generator and to shape the power-speed characteristic, a DC-DC boost converter is used; see Figure 39 (a). The corresponding controller is shown in Figure 39 (b). The boost converter is controlled to adjust the voltage output of the diode bridge to a constant DC bus voltage as the rotational speed of the PMSG varies. Figure 39 (c) shows the pulse-width modulation used to control the power electronic switch. Note that the pulse-width modulation

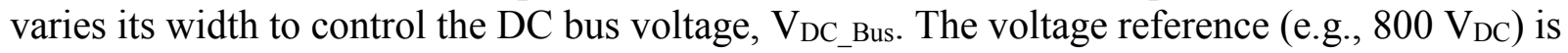
based on the voltage ratings of the power switches (insulated-gate bipolar transistor, or IGBT; and diodes) chosen. The duty ratio (also known as the duty cycle) is compared to the triangular wave (at the switching frequency; e.g., $1 \mathrm{kHz}-50 \mathrm{kHz}$ ), and the output is the pulse-width modulation signal. The operation of the boost converter is governed by the power electronics switch, SW boost. 


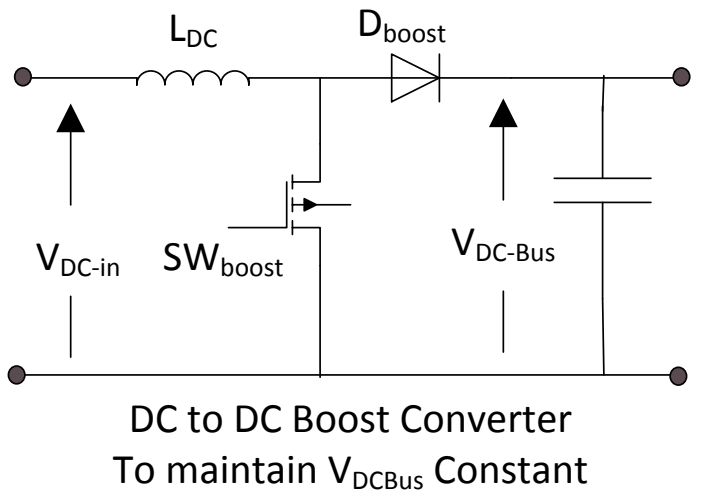

(a)

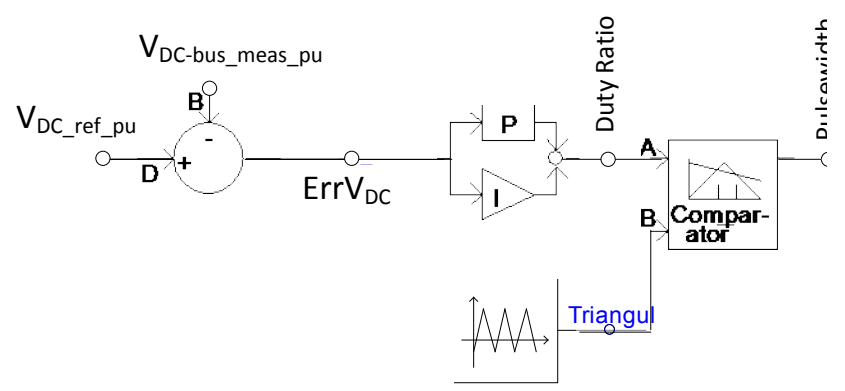

(b)

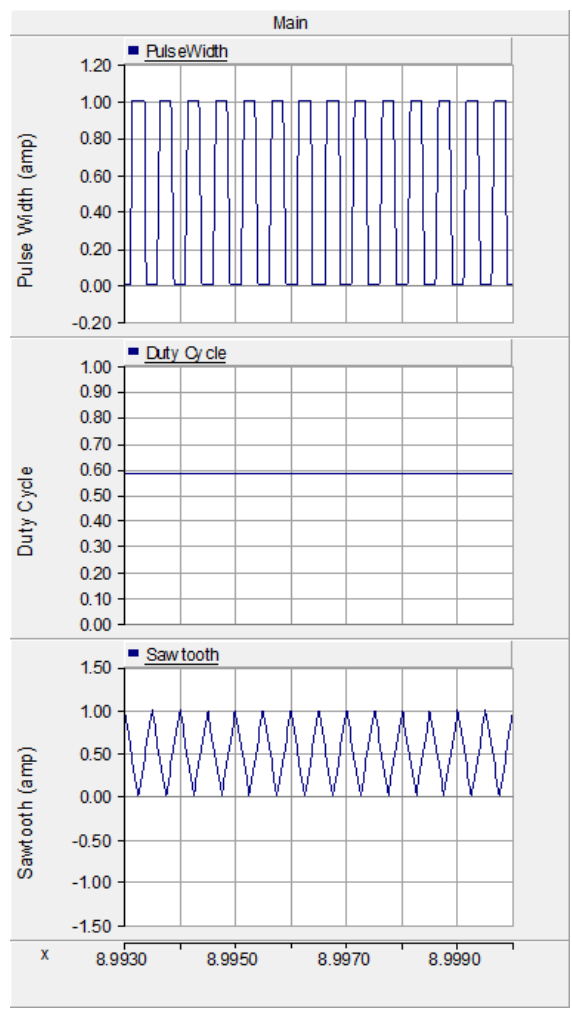

(c)

Figure 39. $\mathrm{DC}$-DC boost converter used to match the variable $\mathrm{V}_{\mathrm{DC} \text {-in }}$ to the constant $\mathrm{V}_{\mathrm{DC} \text {-Bus }}$ and the input voltage of the DC-AC inverter

(a) Circuit diagram, (b) control diagram, and (c) waveforms of the signals used to generate the pulse width modulation controlling the power switch ( $\left.S W_{\text {boost }}\right)$ for the DC-DC boost converter 

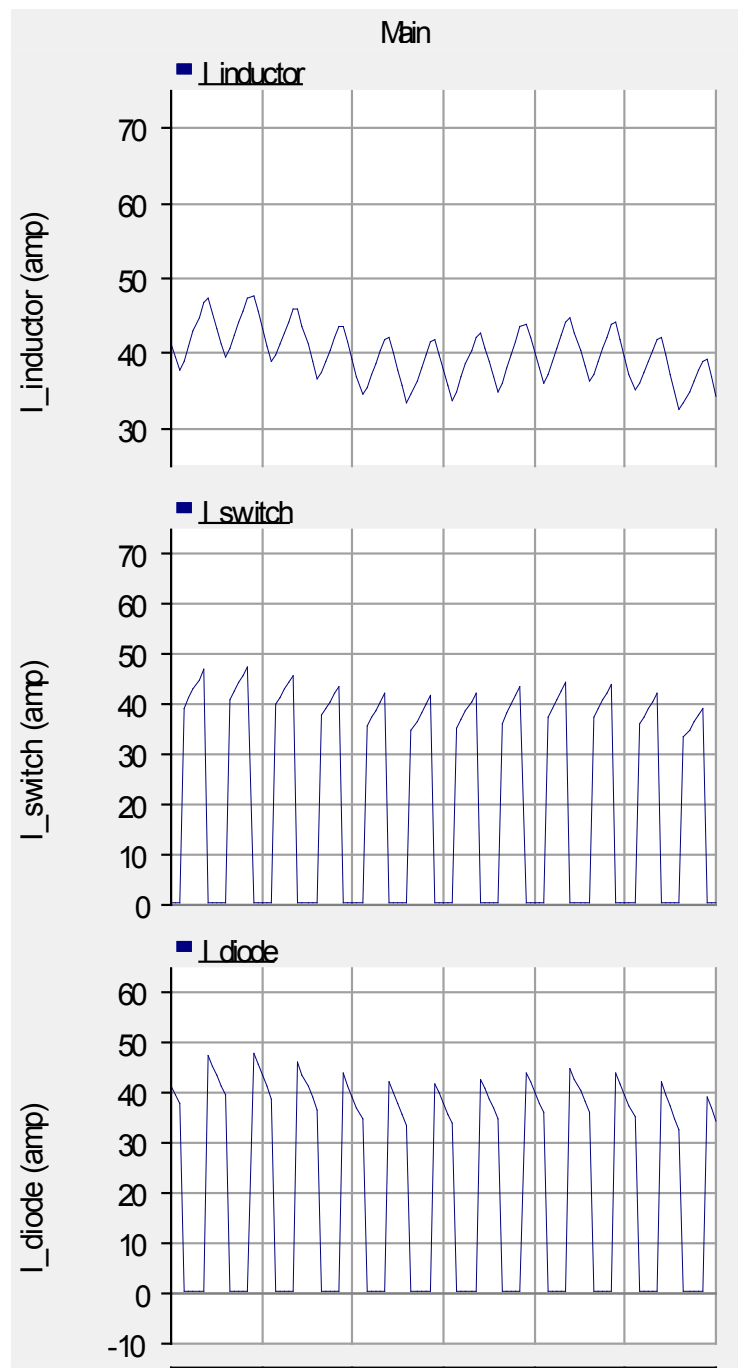

x $\quad 9.99409 .99509 .99609 .99709 .99809 .999010 .0000$
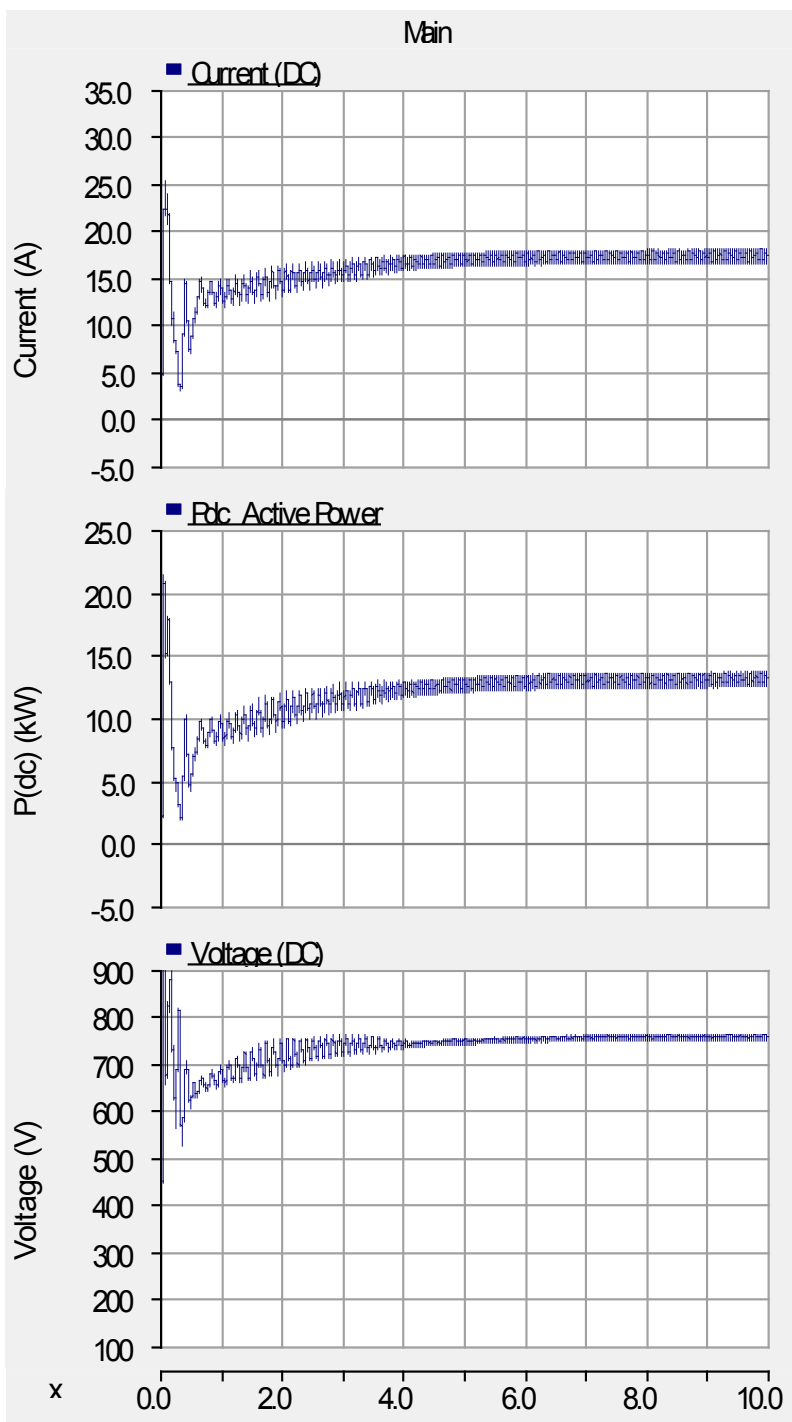

Figure 40. Currents, power, and voltage within a DC-DC boost converter

Figure 40 shows various currents, the output power, and the DC bus voltage output of the DCDC converter maintained at $\mathrm{V}_{\mathrm{DC} \text {-Bus }}=750 \mathrm{~V}$ regardless of the variability of the input DC bus

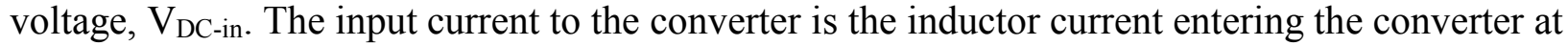
the lower voltage. The inductor current is split into two: the current that is recirculated to the input (ISWITCH) or the current through the power switch IGBT. The current that is passed to the output voltage of $\mathrm{V}_{\text {DC-Bus }}=750 \mathrm{~V}$ is the diode current $\left(\mathrm{I}_{\text {diode }}\right)$.

The ratio of the voltage output to the voltage input can be computed as

$$
\frac{V_{D C-B u s}}{V_{D C-i n}}=\frac{1}{1-D}
$$


where $\mathrm{D}$ is the duty ratio, or duty cycle, or the ratio of the "on" time of the switch during the total switching period. In an ideal boost converter, the boost capability is infinite; however, in reality, the losses and the magnetic nonlinear characteristic will limit the boosting capability of this converter. Note that the output DC bus voltage $\mathrm{V}_{\mathrm{DC}-\mathrm{Bus}}=750 \mathrm{~V}$ is controlled by the boost converter duty ratio, and the output power $\mathrm{P}_{\mathrm{DC}}$ is controlled by the $\mathrm{DC}-\mathrm{AC}$ inverter (to be discussed in the next subsection).

The equation describing the relationship between the input current (inductor current) and the output current or diode current can be derived from the power balance in this idealized situation (no losses are assumed, and input power is equal to the output power).

$$
V_{D C-\text { in }} I_{\text {inductor }}=V_{D C-B u s} I_{\text {diode }}
$$

Or

$$
\frac{I_{\text {diode }}}{I_{\text {inductor }}}=\frac{V_{D C-\text { in }}}{V_{D C-B u s}}=1-D
$$

Thus, the ratio of the average value of the diode current to the average value of the inductor current is proportional to $1-\mathrm{D}$.

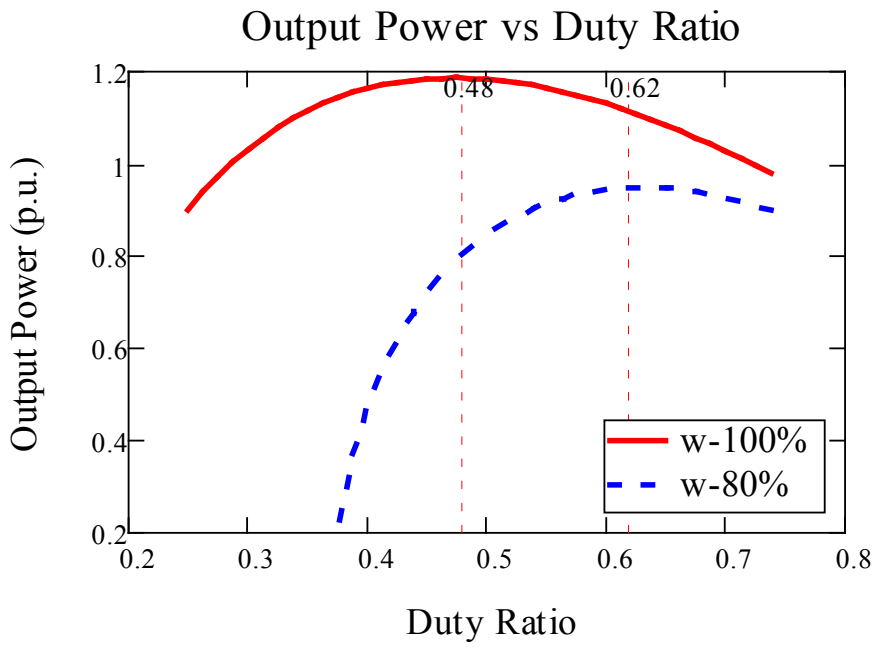

Figure 41. Output power of the DC-DC boost converter as a function of the duty ratio

Figure 41 shows the output power of the boost converter as a function of the duty ratio for two different rotational speeds of the PMSG. As shown here, we can actually shape the output power at any rotational speed by controlling the duty ratio, D, of the converter. This capability allows us to control the PMSG to maximize the output power, damp unwanted rotor oscillations, or stall the turbine. Note that the rotational speed determines the available output voltage of the PMSG; thus, as shown in Figure 41, for the same level of output power, at the duty ratio is smaller at high rotational speeds than the operation at low rotational speeds. 


\subsubsection{DC-AC Inverter}

The dynamic modeling of a DC-AC inverter from the grid perspective is similar to the grid-side inverter found in a Type 4 wind turbine generator, also known as a full-converter wind turbine or a photovoltaic (PV) inverter. It effectively decouples the generator from the grid, improving fault response in both.

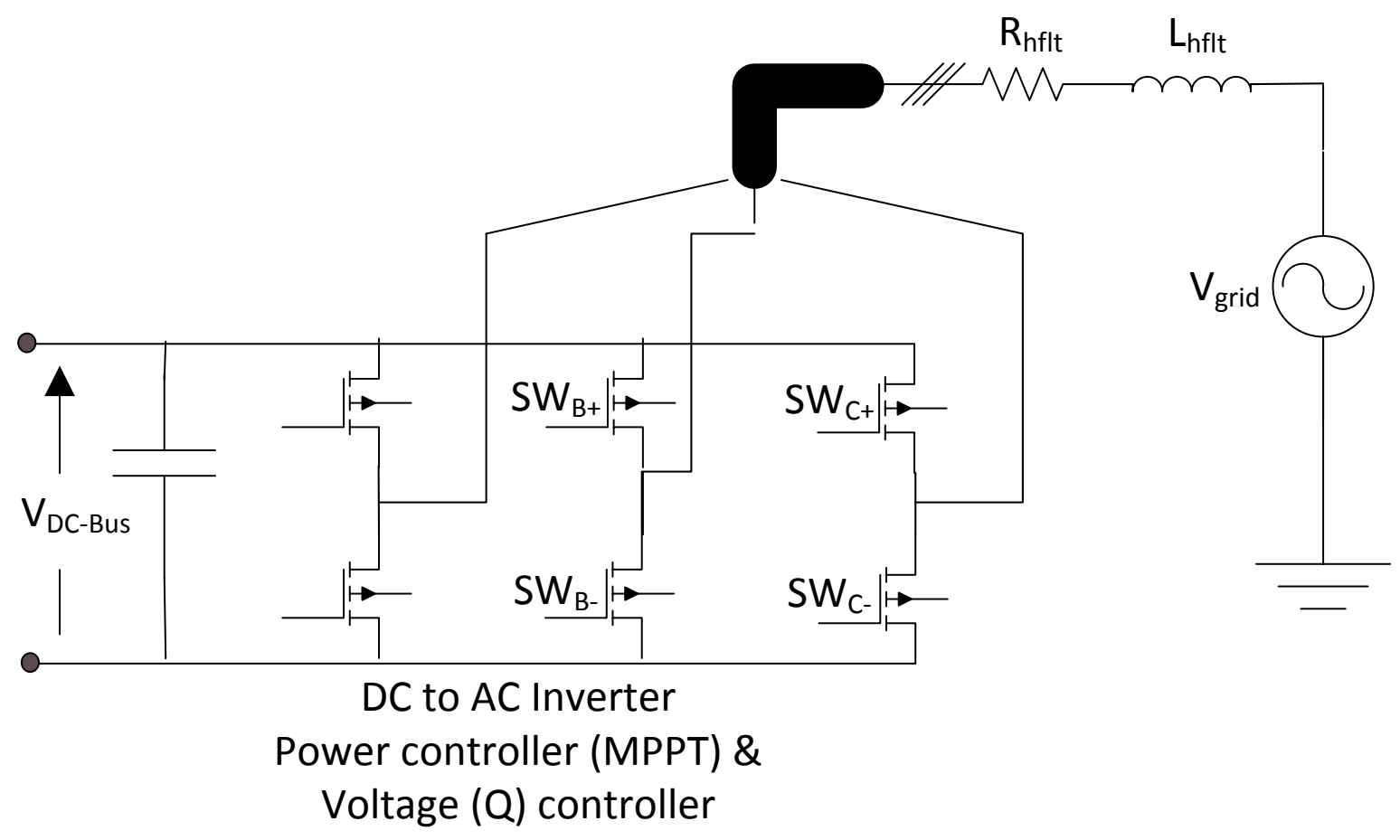

Figure 42. DC-AC inverter controlled to maximize the output power of the turbine and to interface the PMSG with the grid

\subsubsection{Current-Regulated Current Source Inverter}

The DC-AC inverter shown in Figure 42 can be controlled as a voltage source and a current source. One option commonly used to operate a commercial DC-AC inverter is the currentregulated current source inverter. Most renewable generators are controlled in this method to allow for the direct control of real and reactive power, which makes it easier to implement grid integration and adhere to grid code requirements. The block diagram shown in Figure 43 describes the operation of the current-regulated current source inverter. The inverter uses the voltage $\mathrm{V}_{\text {grid }}$ to synchronize the power converter to the grid by using the phase-locked loop to track the phase angle of the grid voltage; thus, any changes in the phase angle or frequency will be followed because the power converter is locked to the grid voltage. 


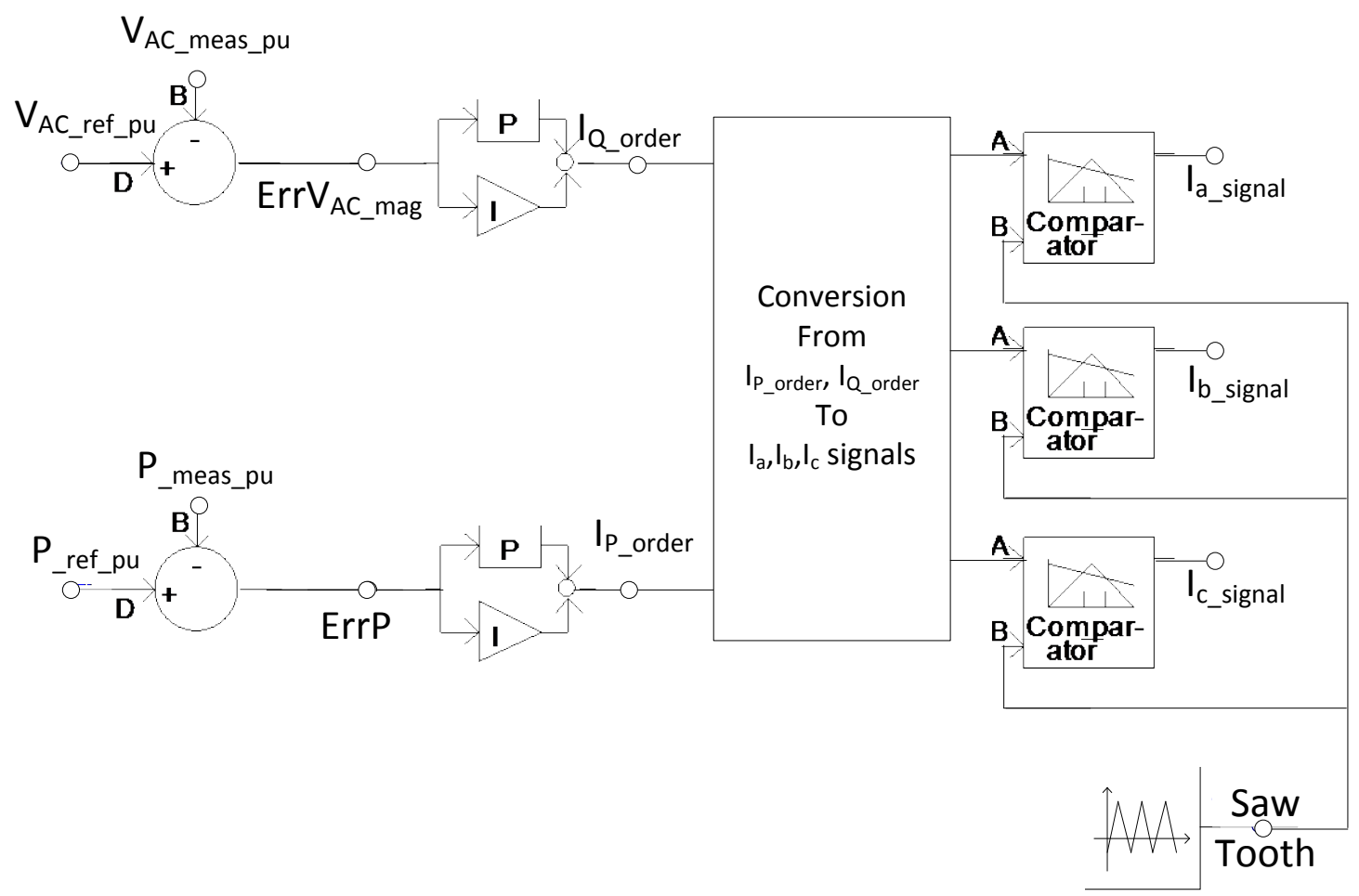

Figure 43. Real and reactive power errors drive the q-axis and d-axis current controllers, respectively

To limit the currents passing through the power semiconductor switches (e.g., IGBTs), a current limiter is used. One example is given in Figure 44. When a fault (or severe undervoltage) is detected, the relay protection will signal the controller to switch to emergency mode. In this case, we want to produce the real power if possible but also generate reactive power with the remaining current-carrying capability of the IGBTs $\left(<\mathrm{I}_{\max }\right)$ to support the voltage dip on the grid. There are many different strategies to control the terminal voltage by controlling the reactive power. One commonly adopted algorithm is to output current to supply only reactive current during the fault to boost the grid voltage. The controller will return to normal mode after the fault is removed from the grid, and if the fault is not removed from the grid after several seconds, the inverter is removed from the grid (i.e., disabled).

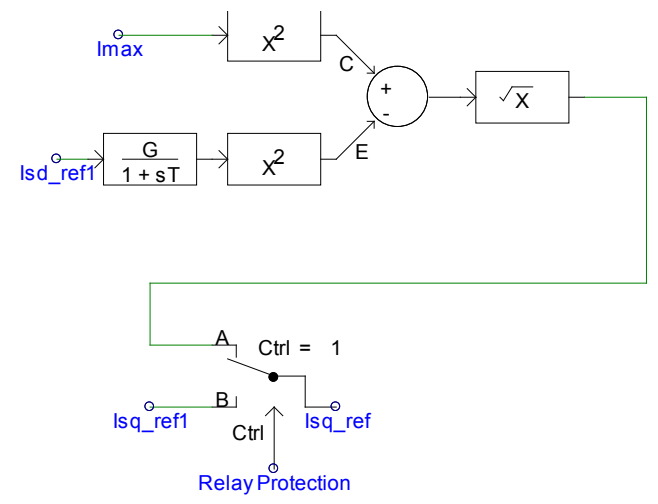

Figure 44. Current limiter to limit the current that can be passed through the power switches 


\subsubsection{Overall System Perspective}

The dynamic modeling of the entire system is presented in this section. The system consists of a PMSG, three-phase diode rectifier, DC-DC boost converter, and DC-AC inverter, and each component performs its own function.

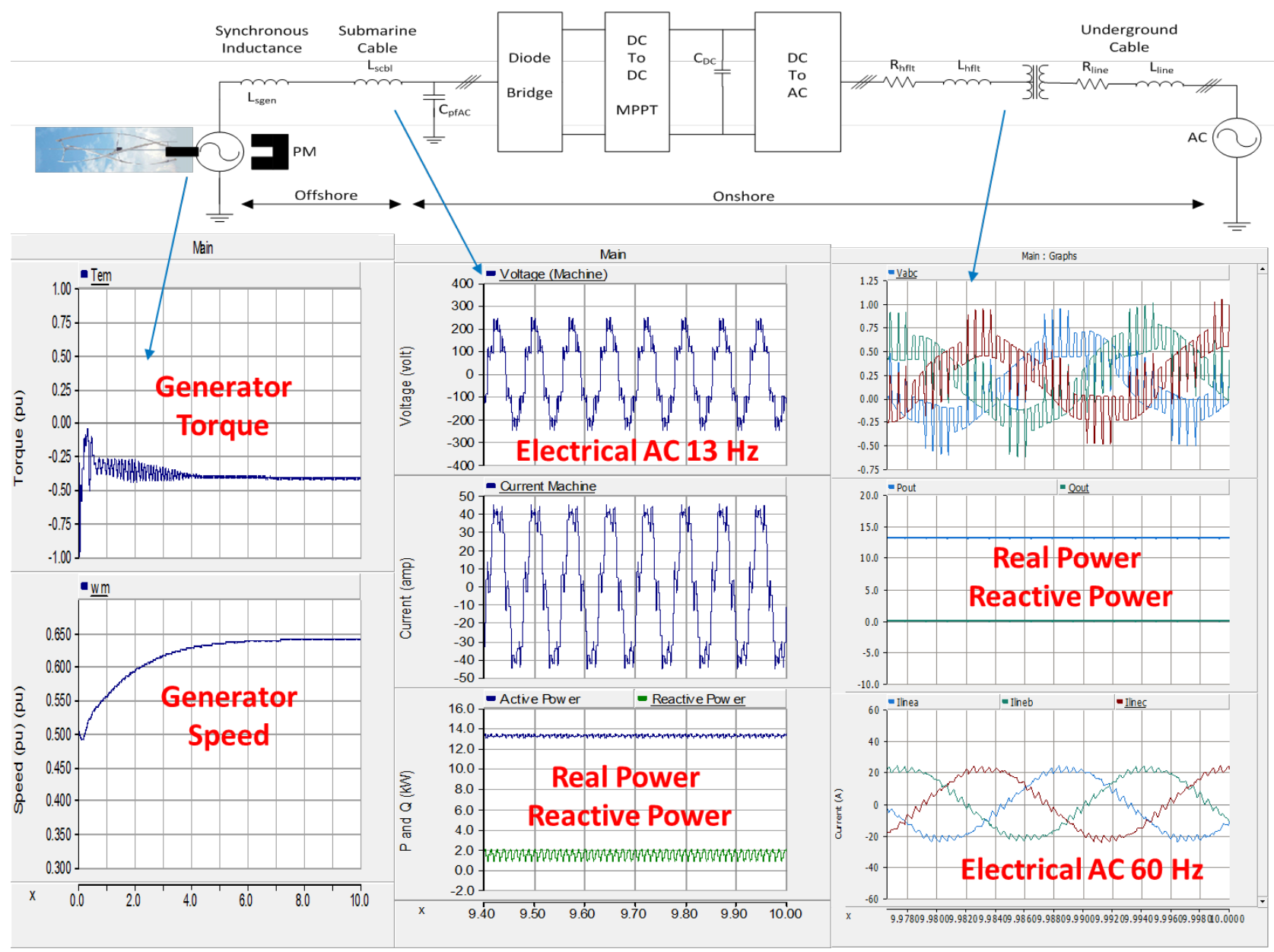

Figure 45. Entire system and corresponding outputs in three frequencies: variable AC, DC, and 60 $\mathrm{Hz}$ AC)

As shown in Figure 45, the PMSG generates a variable frequency and variable output voltage, and the internal electromagnetic field varies at a constant volt/Hz. The PMSG is under water, and it is connected via a submarine cable carrying variable $\mathrm{AC}$ from the generator (at $13 \mathrm{~Hz}$, with a line-to-line voltage of $\mathrm{V}_{\mathrm{LL}}=270 \mathrm{~V}_{\mathrm{rms}}$ ). The output of the variable $\mathrm{AC}$ is a three-phase $\mathrm{AC}$, and it is rectified by the passive three-phase diode bridge. The three-phase diode bridge will have an output of variable DC voltage. At the input of the diode bridge, a three-phase AC capacitor compensation of the size of 900 VAR is used. This capacitor compensation helps to boost the voltage at the input terminal of the diode bridge. Both the $\mathrm{AC}$ capacitor compensation and the three-phase diode bridge are located onshore, and they are connected to the submarine cable to rectify the variable $\mathrm{AC}$ from the river generator. The diode bridge output is $365 \mathrm{~V}_{\mathrm{DC}}$. A DC-DC boost converter is used to interface between the Ocean Renewable Power Company generator 
diode and the DC-AC inverter. Without the DC-DC boost converter, the output DC voltage of the diode bridge is lower than the DC bus voltage required for the DC-AC inverter (maintained at $750 \mathrm{~V}_{\mathrm{DC}}$ ), especially in the lower rotational speed of the PMSG. The DC-DC boost converter with $\mathrm{L}=10 \mathrm{mH}$ and the $\mathrm{DC}$ capacitor $\mathrm{C}=1,500 \mathrm{uF}$ at a switching frequency of $2 \mathrm{kHz}$ is used to maintain the DC bus voltage at $800 \mathrm{~V}_{\mathrm{DC}}$ (at $13 \mathrm{~Hz}$, converting the $365 \mathrm{~V}_{\mathrm{DC}}$ diode bridge output into $800 \mathrm{~V}_{\mathrm{DC}}$ input to the DC-AC inverter). The DC-AC inverter at a switching frequency of 1.9 $\mathrm{kHz}$ is controlled as described in Section 2 of this report. The output terminal voltage of the three-phase inverter is $480 \mathrm{~V} \mathrm{AC}$ at $60 \mathrm{~Hz}$ into the grid.

The diagram and the corresponding output plots are presented in Figure 45, which shows the corresponding plots in three operating frequencies. At the generator side, the operating frequency is in variable frequency operation (as shown, it is currently operated at $13 \mathrm{~Hz} \mathrm{AC}$ ). At the power converter side, it is in DC quantities; and at the grid side, it is operated in three-phase AC at 60 $\mathrm{Hz}$. 


\section{Grid Integration}

Historically, converter-based generation was developed for variable generation (renewable energy such as wind, PV, and tidal). For a long time, power converters were very expensive, and renewable energy deployment was limited to isolated generation with battery storage. In early applications, the DC output was used to operate a radio, a light, or small tools. The inverters were usually single- or three-phase AC inverters at $60 \mathrm{~Hz}$ with output power less than $10 \mathrm{~kW}$. Like any electrical appliance, small inverters are typically certified for safe application by the Underwriters Laboratory (UL 1741). The certification emphasizes the safe use of this equipment.

The adaptation of converter-based generation has gained momentum. Wind power is gaining popularity, and the price of power electronics switches has dropped significantly during recent years, in large part because their price is driven by commercial success. Community wind turbines are connected to the distribution network; however, large wind power plants (100 MW and above) are connected to the transmission network. Similarly, small PV residential rooftop systems are connected to the distribution system; however, recent PV plants exceeding $500 \mathrm{MW}$ in size have been connected to transmission lines. It is expected that tidal and river generators will follow the same trend: smaller sizes will be connected to the distribution network, and large tidal or river power plants will be connected to the transmission network.

The size of renewable energy generators and inverters has increased while costs continue to decrease. In many cases, output power has reached more than $1 \mathrm{MW}$. In 2003, the Institute of Electrical and Electronics Engineers (IEEE) issued Standard 1547 to standardize the rules for connecting distributed generation (including wind and PV inverters) to the distribution network.

IEEE 1547 is intended to ensure that renewable energy generation does not violate the basic rules of the distribution system. Conventional power flows from the generator to a residential load. With the increase of distributed generation such as PV and wind generation, power flow may reverse direction when there is excess generation from, for example, a rooftop PV generating unit. Another concern is the safety of utility service engineers performing repairs in the distribution network because of islanding (when the PV generation keeps feeding local load after the circuit breaker disconnects the load from the main distribution network). Small river and tidal generators $(<20 \mathrm{MW})$ will be covered by the IEEE 1547 standard; however, larger installations will follow the same processes, rules, and regulations as installing large wind power plants.

Figure 46 is the representation of voltage compared to maximum clearing time as described in IEEE 1547. This requirement is to ensure that the inverter continues to feed the grid as long as the operating point is located in the area between the upper limit voltage and the lower limit voltage. This requirement is needed because if the inverter system protection is set arbitrarily with low tolerance, the inverter will be disconnected from the grid with a low level disturbance; thus, there is not enough generation to support the grid during the disturbance, which can lead to a so-called "cascading event," where one by one the inverters connected to the grid are disconnected, and eventually the system experiences a blackout.

Figure 47 is the representation of frequency compared to maximum clearing time as described in IEEE 1547, where the inverter connected to the grid must stay connected during the disturbance 
as long as the operating point is in between the upper limit of the frequency and the lower limit of the frequency. This requirement also ensures the inverter will stay connected to support the loads during short or light disturbances.

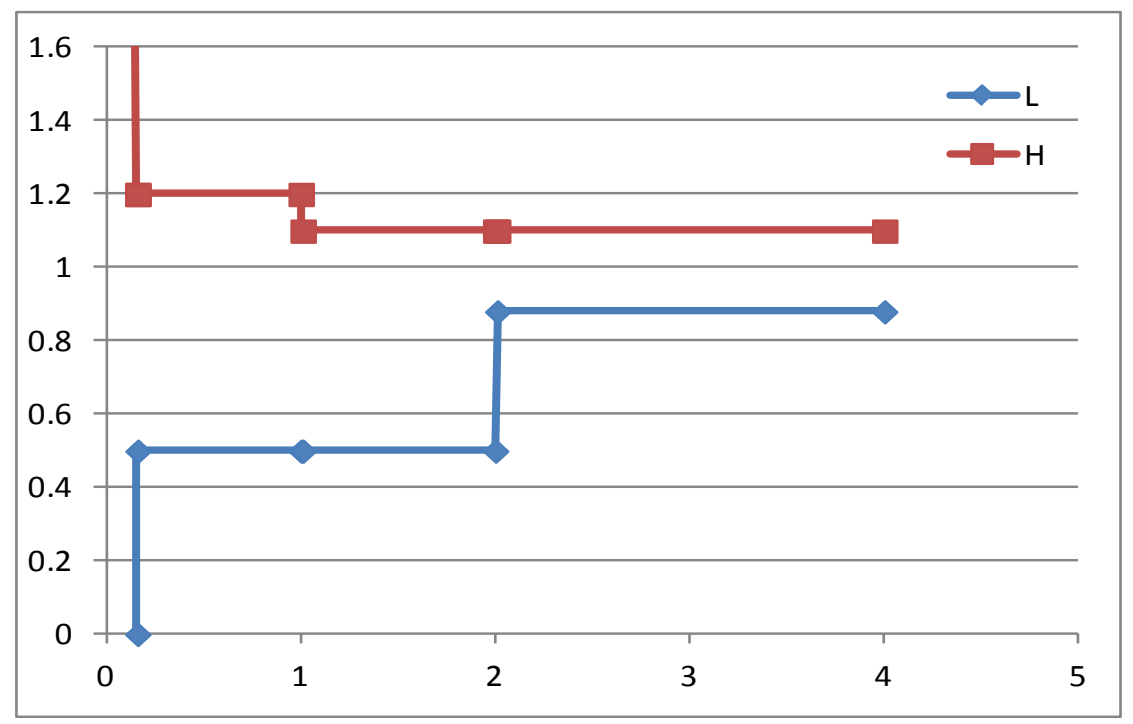

Figure 46. Representation of voltage compared to maximum clearing time as described in IEEE 1547 (L- low voltage limit, $\mathrm{H}$ - high voltage limit)

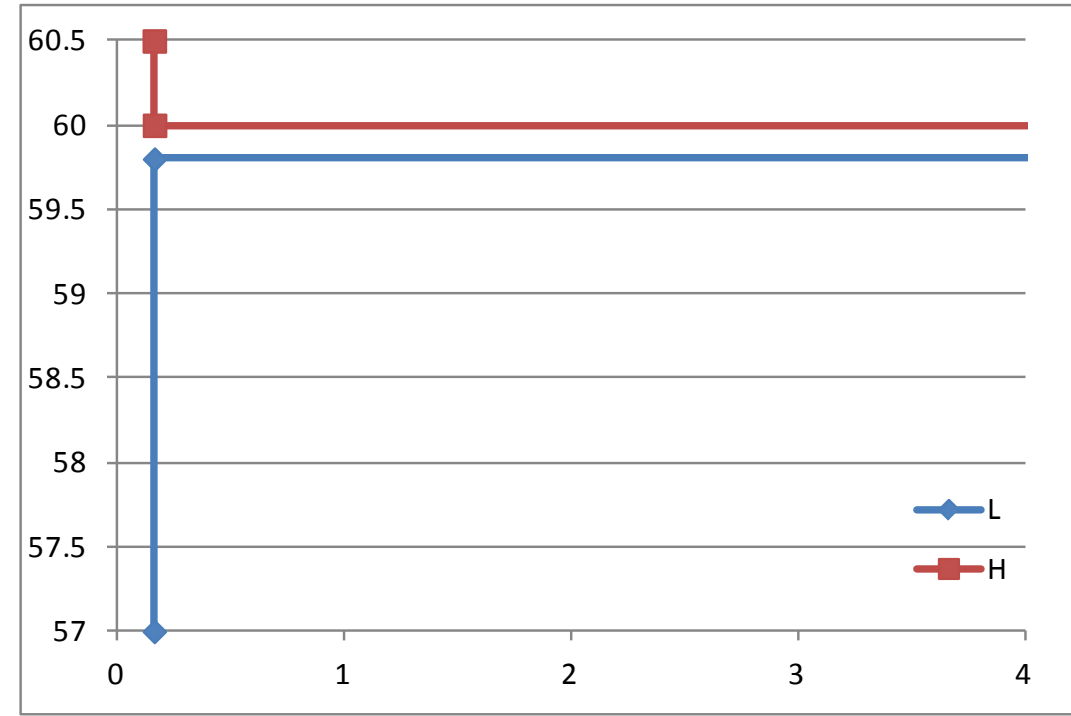

Figure 47. Representation of frequency compared to maximum clearing time as described in IEEE 1547 (L-low frequency limit, $\mathrm{H}$-high frequency limit)

In addition, disconnection requirements dictate that distributed generation must:

- Cease to energize for faults on the area electric power system circuit

- Cease to energize prior to circuit reclosure 
- Detect island conditions and cease to energize within 2 seconds of the formation of an island (i.e., anti-islanding).

Inverter manufacturers strive to comply with IEEE 1547, implement anti-islanding protection, and ensure that inverters stay connected within the allowable voltage-time and frequency-time operating region, as shown in Table 2 and Table 3. Table 2 lists the operating voltage and the maximum clearing time for distributed generation, and Table 3 lists the operating frequency and the maximum clearing time for distributed generation, both as specified in IEEE 1547.

Table 1. Voltage Range and Maximum Clearing Time

\begin{tabular}{|c|c|}
\hline $\begin{array}{c}\text { Voltage Range } \\
\text { (\% Nominal) }\end{array}$ & $\begin{array}{c}\text { * Max. Clearing } \\
\text { Time (seconds) }\end{array}$ \\
\hline \hline $\mathrm{V}<50 \%$ & 0.16 \\
\hline $50 \%<\mathrm{V}<88 \%$ & 2 \\
\hline $\mathrm{V}>120 \%$ & 0.16 \\
\hline $110 \%<\mathrm{V}<120 \%$ & 1 \\
\hline
\end{tabular}

* Maximum clearing times for distributed generation $\leq 30 \mathrm{~kW}$; default clearing times for distributed generation $>30 \mathrm{~kW}$
Table 2. Frequency Range and Maximum Clearing Time

\begin{tabular}{|c|c|}
\hline Frequency Range & Max. Clearing \\
\hline$(\mathrm{Hz})$ & Time (seconds) \\
\hline$f>60.5$ & 0.16 \\
\hline$f<57.0$ & 0.16 \\
\hline$* * 57.0<f<59.8$ & $0.16-300$ \\
\hline
\end{tabular}

* $59.3 \mathrm{~Hz}$ if distributed generation $\leq 30 \mathrm{~kW}$

** For distributed generation $>30 \mathrm{~kW}$

As the level of renewable penetration continues to increase, fault ride-through capability (currently implemented for wind turbine generation) may be required for other forms of renewable generation. This requirement ensures that a renewable power plant is not disconnected from the grid at any fault unless the voltage at the point of common coupling lies beyond the voltage-time characteristic specified; thus, balance between generation and load can be maintained, and cascading phenomena can be avoided.

As described previously, the inverter is generally placed between the renewable generator and the grid; thus, the inverter must process the entire generated power to the grid. There are two types of protection in inverters: fast disconnection (i.e., in less than one cycle) and continued operation for up to 10 cycles. The fast disconnection may be suitable for small installations connected to the grid or for isolated operations.

A renewable inverter's current contribution during a fault is not zero, and it varies by design. It was observed that for most fault conditions, several renewable inverters continued supplying current to the feeder subsequent to a fault for a period ranging from four to 10 cycles. The length of time the inverter supplies the fault current may be adjustable to comply with a regional reliability requirement. With reduced voltage, the output currents that can be supplied to the grid are limited by the current-carrying capability of the power electronics switches (i.e., IGBTs); thus, the output power is less than the rated power. If low-voltage ride-through is available, during the voltage dip the maximum power point tracking may be disabled to ensure that the inverter follows the fault ride-through requirement rather than maximizes energy yield. Similar procedures may apply to small generation (river and tidal generations).

If the inverter is required to supply reactive power during the voltage dip, the inverter models may have to supply maximum reactive power available based on the current capability of the 
IGBT. The theoretical maximum reactive power contribution is when the voltage is leading or lagging 90 degrees. The inverter may be designed to carry short-term high current during the faults; many of them are designed to reach up to $120 \%$ or more of the rated current, depending on the customer request.

In some inverter models, the inverter current during faults was maintained at the pre-fault inverter current with this current setting, and the transition back to normal operation does not affect the operation drastically. Another mode of operation found in some inverter models is that the inverter current was dropped to 0 , and the inverter was disconnected in less than 0.5 cycle for a fault when the terminal voltage reached less than $50 \%$ on any phase.

Eventually, larger renewable power plants (wind, PV, tidal, or river) must comply with Federal Energy Regulatory Commission (FERC) Order 661 and Order 661A, issued in June 2005 and in December 2005, respectively. These two documents address concerns on the ability of wind generators to stay online during disturbances, thereby ensuring that the grid will be able to maintain its reliability and stability. Order No. 661 requires public utilities that own, control, or operate facilities for transmitting electric energy in interstate commerce to append standard procedures and technical requirements for the interconnection of large wind generation to their standard large generator interconnection procedures and large generator interconnection agreements in their open access transmission tariffs. The provisions include ride-through capability, supervisory control and data acquisition (SCADA), and a specified range of adjustable reactive power capability. Also, plants must comply with the grid code based on the regional reliability organization where the plant is installed and operated, which may vary from one region or country to another. 


\section{Summary and Conclusion}

This work presented the basic operation of river and tidal generation. The similarities of these generation systems to wind turbine systems make it possible to start the analysis from the basic equations used to describe wind power generation. The data analysis and calculations are given in per unit when possible to make the analysis as generic as possible and to accomplish two major goals: to transport the control system to different power ratings and to make the analysis agnostic to different manufacturers; thus, no proprietary information is revealed.

The turbine characteristic chosen is a typical water turbine for tidal or river generation. The system is assumed to be self-regulated with no pitch control as in a wind turbine system. The $\mathrm{C}_{\mathrm{p}^{-}}$ TSR characteristic lends itself to very practical and easy to implement control algorithms designed to optimize the turbine in the productive range of water flow while also designing the rotational speed control to prevent a runaway situation.

Two major control algorithms are proposed in this paper to maximize the output power while limiting the rotational speed: one utilizes the rotational speed as the input to the controller, and the other utilizes both the rotational speed and the water flow. Both work very well, but the one with both rotational speed and water flow input controls the turbine more accurately and predictably.

In Section 2 of this report, we exercise extreme ramp rate of the water flow to study the stability of the generating system and the impact of various control alternatives. Based on field measurement and experience, the generating system tested was stable while operating at $\mathrm{C}_{\mathrm{pmax}}$, indicating that the actual ramp rate of the water flow is slower than the step function used in Section 2 and that the control algorithm chosen is able to stabilize the system without sacrificing the hydrodynamic efficiency of the turbine system.

Additional investigations are presented in Section 2.5 to observe the impact of the size of the inertia, the ramp rate of the water flow, and the shape of the $\mathrm{C}_{\mathrm{p}}$-TSR characteristics on the turbine operation.

On the electrical generation side, a detailed representation of the generating system was simulated. This detailed model represents the complexity of the power converter controls and exercises various modes of operation to analyze and investigate the sizing of the converter components and the level of power quality and to simulate numerous failures of power electronics components and protection systems. Simplified models can be used to study the bigger picture of the tidal/river generation and to shorten the simulation time. The model can be used to study the tidal power plant and power system dynamics, the interaction among turbines within a plant, the interactions among plants, or the interactions between a tidal plant and a power system.

The model of the tidal/river generation consists of a PMSG, three-phase diode rectifier, DC-DC boost converter, and DC-AC inverter with the following functionalities:

- The DC-DC boost converter is used to interface between the Ocean Renewable Power Company generator diode and the DC-AC inverter. Without the DC-DC boost converter, the output DC voltage of the diode bridge is lower than the DC bus voltage required for 
the DC-AC inverter (maintained at $750 \mathrm{VDC}$ ), especially in the lower rotational speed of the PMSG.

- The PMSG under water is connected via a submarine cable carrying variable AC from the generator (at $13 \mathrm{~Hz}$, with the line-to-line voltage of VLL $=270 \mathrm{Vrms}$ ).

- The diode bridge (AC capacitor compensation $900 \mathrm{kVAR}$ ) is located onshore and connected to the submarine cable to rectify the variable $\mathrm{AC}$ from the river generator. The diode bridge output is $365 \mathrm{~V}_{\mathrm{DC}}$.

- The DC-DC boost converter with $\mathrm{L}=10 \mathrm{mH}$ and $\mathrm{DC}$ capacitor $\mathrm{C}=1,500 \mathrm{uF}$ at a switching frequency of $2 \mathrm{kHz}$ are used to keep the DC bus voltage at $800 \mathrm{~V}_{\mathrm{DC}}$ (at $13 \mathrm{~Hz}$, converting the $365 \mathrm{~V}_{\mathrm{DC}}$ diode bridge output into $800 \mathrm{~V}_{\mathrm{DC}}$ input to the DC-AC inverter).

- The DC-AC inverter at a switching frequency of $1.9 \mathrm{kHz}$ is controlled as described in Section 2 of this report. The output terminal voltage of the three-phase inverter is $480 \mathrm{VA}$ at $60 \mathrm{~Hz}$ into the grid. 


\section{References}

1. A. Gorlov, Development of the Helical Reaction Hydraulic Turbine (Technical Report DEFGO1-96EE 15669) (Washington, D.C.: U.S. Department of Energy, August 1998) http://www.osti.gov/scitech/servlets/purl/666280/.

2. P.O. Okorie and A. Owen, "Turbulence: Characteristics and its Implications in Tidal Current Energy Device Testing" (paper presented at OCEANS 2008, Quebec City, Canada, September 15-18, 2008).

3. D. Li, Y. Yao, Q. Chen, and Z. Ye, "Numerical Simulation of Tidal Current Energy in Yangtze Estuary-Hangzhou Bay, China" (paper presented at OCEAN 2005, Genoa, Italy, May 18-21, 2015).

4. M. Liu, W. Li, R. Billinton, C. Wang, and J. Yu, "Probabilistic Modeling of Tidal Power Generation" (paper presented at 2015 IEEE Power \& Energy Society General Meeting, Denver, Colorado, July 26-30, 2015).

5. E. Muljadi and Y. Yu, "Review of Marine Hydrokinetic Power Generation and Power Plant," Journal of Electric Power Components and Systems 43:12 (2015): Special Issue: Renewable Energy Devices and Systems-State-of-the-Art and Future Trends.

6. Y. Jiang, M.F. Rong, and L.Y. Hua, "Variable Speed Constant Frequency Tidal Current Energy Generation and Control Strategy for Maximum Power Point Tracking and Grid Connection" (paper presented at the International Conference on Sustainable Power Generation and Supply, SUPERGEN, Nanjing, China, April 6-7, 2009).

7. K.S. Lee and L.Y. Seng, "Preliminary Investigation of the Potential of Harnessing Tidal Energy for Electricity Generation in Malaysia" (paper presented at the IEEE Transmission and Distribution Conference and Exposition, Chicago, Illinois, April 21-24, 2008).

8. A.S. Bahaj, W.M.J. Batten, and G. McCann, "Experimental Verifications of Numerical Predictions for the Hydrodynamic Performance of Horizontal Axis Marine Current Turbines," Journal of Renewable Energy 32 (2007): 2,479-2,490.

9. A.S. Bahaj, A.F. Molland, J.R. Chaplin, and W.M.J. Batten, "Power and Thrust Measurements of Marine Current Turbines under Various Hydrodynamic Flow Conditions in a Cavitation Tunnel and a Towing Tank," Journal of Renewable Energy 32 (2007): 407-426.

10. Y. Li, B.J..Lence, and S.M.Calisal, "Modeling Tidal Turbine Farm with Vertical Axis Tidal Current Turbines" (paper presented at the IEEE International Conference on Systems, Man and Cybernetics, Montreal, Quebec, Canada, October 7-10, 2007.

11. M.L. Rahman, S. Oka, and Y. Shirai, "Hybrid Power Generation System Using OffshoreWind Turbine and Tidal Turbine for Power Fluctuation Compensation," IEEE Transactions on Sustainable Energy 1:2 (July 2010). 
12. Y. Kyozuka and K. Ogawa, "Tidal Current Power Generation Making Use of a Bridge Pier" (paper presented at OCEANS 2006, Singapore, May 16-19, 2007.

13. N. Kumar, S. Majumdar, and G.M. Babu, "Automatic Control of Tidal Power Plant" (paper presented at the 2012 International Conference on Emerging Trends in Electrical Engineering and Energy Management, Chennai, India, December 13-15, 2012.

14. S. Davoust, A. Jehu, M. Bouillet, M. Bardon, B. Vercherin, A. Scholbrock, P. Fleming, and A. Wright, "Assessment and Optimization of Lidar Measurement Availability for Wind Turbine Control" (paper presented at the European Wind Energy Association Conference, Barcelona, Spain, March 10-13, 2014); NREL/CP-5000-61332.

15. A. Scholbrock, P. Fleming, A. Wright, C. Slinger, J. Medley, and M. Harris, "Field Test Results from Lidar Measured Yaw Control for Improved Yaw Alignment with the NREL Controls Advanced Research Turbine" (paper presented at the American Institute of Aeronautics and Astronautics Science and Technology Forum and Exposition, Kissimmee, Florida, January 5-9, 2015); NREL/CP-5000-63202. 